\title{
Abstracts of the 5th International Academic Medical Congress of Maranhão (V COIMAMA) 2018
}

01.

COVERAGE OF BASIC HEALTH CARE AND INCIDENCE OF UTERINE COLUMN CANCER IN A BRAZILIAN NORTHEAST CAPITAL

Adriana Leite Martins; Dina Stefany de Oliveira Moreira; Filipe Tamburini Brito; Livia Anniele Sousa Lisboa

Universidade Federal do Maranhão (UFMA)

BACKGROUND: Cervical cancer is considered one of the main types of cancer to reach the female population, especially in less developed regions. Comprehensive coverage of basic care is vital for the implementation of prevention actions such as vaccination campaigns and conducting preventive screenings for early detection and disease control. This study aims to analyze the coverage of basic care and the incidence of cervical cancer in Northeastern capitals, verifying a possible relationship between these data. METHODS: Descriptive study with a quantitative approach, based on secondary data collected from the Department of Primary Care (DAB) and the National Cancer Institute (INCA). We analyzed the coverage of basic care in capital cities in the northeastern region of Brazil in 2016 and the estimates of gross rates of incidence of cervical cancer per 100,000 inhabitants in the same year. RESULTS: From the data analyzed, it can be noted that, in 2016, the coverage of basic care (AB) in Aracaju - SE is 79.5\% and the incidence rate of cervical cancer is $16.67 \%$. In João Pessoa - PB, AB coverage is $93.44 \%$ and the disease incidence rate is $19.39 \%$. Regarding Recife - PE, it presents a coverage of $A B$ of $61.56 \%$ and a incidence of cervical cancer of $17.74 \%$. In Fortaleza - CE, AB coverage is $62.68 \%$ and the incidence of the disease is $21.47 \%$. In São Luís - MA, AB coverage is $43.16 \%$, while the incidence of cervical cancer is $42.58 \%$. CONCLUSION: It is not possible to establish a direct relationship between the coverage of primary care and the incidence of cervical cancer in the capitals studied only with the type of analysis performed in the study, but it is observed from the data obtained that these variables communicate between each other in a decisive way. More scientific research should be developed on the subject, ratifying the role of primary care in the promotion of preventive health.

Keywords: basic health care, coverage, cervical cancer, prevention

ACTIVITY OF HEALTH PROMOTION ON SEXUAL EDUCATION IN A PUBLIC SCHOOL OF SÃO LUÍS-MA

Dina Stefany de Oliveira Moreira; Filipe Tamburini Brito; Adriana Leite Martins; Livia Anniele Sousa Lisboa

Universidade Federal do Maranhão (UFMA)

BACKGROUND: According to the 2013 document of the Ministry of Health (MS) "Basic guidelines of comprehensive health care for adolescents in primary health care schools" educational actions in schools can be carried out by partners in the community. In this perspective, as an intervention proposal of the students of the first period of the Medical School of the Federal University of Maranhão (UFMA), in the discipline integrating Axis, an action was taken at the Basic School Unit Professor Rosália Freire, which aimed to guide students about sex education and contraception. As a basis for the activity was used the adolescent health booklet, made available by the Ministry of Education in partnership with the MS. CASE DESCRIPTION: The action consisted of classes separated by sex to students of both sexes and age group between 11 and 15 years of age. The guidance provided to adolescents was about the rights and duties of the public health care user sexually transmitted infections (STs), teenage pregnancy, use of contraceptives and how to obtain them. The importance of basic care was emphasized, indicating the names of the health units closest to the school as well as information on how to schedule consultations and update vaccination portfolios, focusing on the human papillomavirus vaccine. Finally, the speakers drew doubts from some students, who were very receptive throughout the action. Many of them thanked the visit and asked for it to occur more often. CONCLUSION: In the action, there was a great informational discrepancy among the students, since they demonstrated knowledge related to the initiation of sexual life and, however, they do not know about contraceptive methods and the risk of pregnancy. In this perspective, it is important to take actions of this nature with greater frequency in order to reduce the occurrence of STls, unplanned pregnancies and poor coverage in the vaccination network among adolescents.

Keywords: Health Education, Sexual Education, Contraception

03. PROFILE OF PATIENTS WITH GYNECOLOGICAL CANCER REGISTERED IN THE HOSPITAL ALDENORA BELIO

Leticia Costa Sousa Nina; Juliana Lima Araújo; Juliana Lins da Paz Portela; Natalia Cristina Silva Oliveira; Nathália Lustosa Souza Domiciano; Andrey Pinto da Silva; Rodrigo Lopes da Silva

Centro Universitário do Maranhão (CEUMA), Hospital Aldenora Bello

BACKGROUND: In Brazil the estimates for the biennium 2018-2019, is the occurrence of 600 thousand new cases of cancer, for each year. Of these new cases, 16,370 are of cancer of the cervix, 6,600 are new cases of cancer of the body of the uterus and 6,150 are cases of ovarian cancer. Thus, it is evidenced that the collection of statistical data about cancer is of fundamental importance in order to outline the best strategy to combat the disease and the best conduct for each case. OBJECTIVE: to analyze the characteristics of the cases treated in HOSPITAL DE CANCER ALDENORA BELLO in 2014, highlighting the age range of risk, clinical staging and treatments performed. METHODS: The medical records collected correspond to the year 2014. The data cataloged were analyzed in the SISRHC program (Hospital Registry of Cancer), version 3.2, made available by the National Cance Institute. RESULTS: cases: 3561; deaths: 606; age 20-29 years: 137; 30-39 years: $523 ; 40-49$ years: $828 ; 50-59$ years: $884 ; 60-69$ years: $659 ; 70-79$ years 373: 80-89 years: 115 . Staging $0: 428 ; 1: 15$ cases; $1 \mathrm{~A}: 195 ; 1 \mathrm{~B}: 341 ; 1 \mathrm{C}: 18$ 2:14; 2A: 169; 2B: 739; 2C: 3; 3:16; 3A: 73; 3B: 956; 3C: 44; 4:61; 4A: 156; 4B 164. First treatment none: 233; surgery: 1126; radiotherapy: 1650; chemotherapy: 533; hormone therapy: 3; other: 16 . CONCLUSION: The data analyzed showed a higher incidence of gynecological cancer between 40 and 59 years. The number of deaths is mainly due to the number of new cases arriving at an advanced clinical stage. Effective actions to detect pathology in early clinical stages should be adopted urgently in our state.

Keywords: Gynecological Cancer, Epidemiology, Cérvix

04. NURSING PROCESS: IMPLEMENTATION OF A PATIENT CARRIER OF ANOREXIA

Erica Fernanda Silva Lima; Thayrine Larissa Melonio Almeida; Maycon Jhones Batista Mota

Centro Universitário do Maranhão (CEUMA) 
BACKGROUND: Anorexia is characterized by severe weight loss caused by an extremely rigid diet, long periods of fasting, where there is a constant search for thinness, morbid fear of fattening and distortion of body image and negation of the pathological condition itself. Anorexia is a disorder of eating behavior and considered as a psychiatric condition. Clinical case study developed during the practical activities of the discipline (SAE) Systematization of nursing care, Nursing Undergraduate course, held in the first semester of 2018, in a mixed unit of São Luís - MA, supervising the teacher and counselor Anielly Silva, aimed to implement the Nursing Process in the care of a patient with anorexia. The data were obtained through physical examination and report of the patient A.K.P.F, after evaluation and clinical judgment to elaborate NANDA-I diagnoses, NIC intervention and evaluation of NOC results. RESULTS: The results showed that the nursing interventions performed positively contributed to improve the patient's condition, helping her to better understand her condition as an anorexia patient, which led to her involvement in self-care. CONCLUSION: It was concluded that a systematized and individualized assistance allowed a better organization of the work and care provided, providing, during the implementation of the actions, better evaluation of the results and, whenever necessary, modification or completion of some interventions. It is important to emphasize the importance of the process as a focus of the nursing professionals' work in hospitals, with a view to favoring the return of patients to their family context, as well as reinforcing the credibility of nursing work.

Keywords: Anorexia, Nursing care, Nursing process, diagnose, implement

EPIDEMIOLOGICAL PROFILE OF EXOTIC INTOXICATIONS IN BRAZIL IN THE PERIOD 2007 TO 2017

Rayla Bezerra Rocha; Wesley Costa Barros; Ana Clara Sampaio Lima Vasconcelos; João Víctor Pacheco Florentino; Marcos Fernando Camara Maranhão; Kevin Waquim Pessoa Carvalho; Monique Santos do Carmo

Centro Universitário do Maranhão (CEUMA), Universidade Federal do Maranhão (UFMA)

BACKGROUND: Intoxication is the manifestation, through signs and symptoms, of the harmful effects produced in a living organism as a result of its interaction with some chemical substance, venomous animals, plants, pesticides or medicines. Intoxications can be accidental or intentional causes and result in a significant portion of health expenditures, in addition to promoting numerous clinical complications to patients. Therefore, the objective of this study was to conduct a retrospective analysis of a quantitative approach to the incidence profile and evolution of exogenous intoxications in the Brazilian population from 2007 to 2017. METHOD: The methodology used involved the evaluation of the data obtained in the (SINAN) of the Ministry of Health. RESULTS: During the 10 years, 804,797 cases were reported, the most prevalent being the Southeastern region equivalent to $47.6 \%$. Most of these cases (23.29\%) resulted from accidenta ingestion of medications by children aged $1-4$, followed by adults aged 20 29 years $(13.06 \%)$, being more prevalent in females $(55,8 \%)$ and in the white race $(37.6 \%)$. The data collection identified flaws regarding the filling of the notification fields, which made it impossible to know the totality of the cases. The underreporting was responsible for the alleged decrease in poisoning and poisoning in the country, a fact evidenced by the reduction of the participation of the Information and Assistance Centers (CIATs) in these surveys. CONCLUSION: The high prevalence of exogenous intoxications combined with social and economic impacts in Brazil reveals the importance of this study, since there is a shortage of current research in the literature. Therefore, it was possible to verify that exogenous poisonings still represen a serious problem for the country, reflecting high public health costs and significant morbidity / mortality rates.

Keywords: Poisoning, Epidemiological profile, SINAN

\section{APPROACH ON ELDERLY'S LIFESTYLE IN A HEALTH CENTER}

Maria Da Conceicão Pereira De Carvalho; Letícia Teixeira Torres; Kirlian Karolene Araújo Pereira; Jéssica Raiany Costa e Costa; João Vitor Lobo Nascimento; José Gonçalves Da Rocha Neto; Waldeney Costa Araújo Wadie

Universidade Federal do Maranhão (UFMA)

BACKGROUND: The choices of elderly's lifestyle are modulated by the socioeconomic context in which they are inserted, and it may contribute to

or impair the quality of life. Thus, it is understood that health promotion and disease prevention are related not only to medical measures but also to proactive behaviors in relation to health promotion. This is an experience report of a work promoted during the obligatory curricular nursing traineeship of Elderly Health in a Center for Integral Health Care of the Elderly in São Luís, MA, during July of 2018. The strategy used was the active methodology "dialogue circle." The topics discussed were about the lifestyle of elderly people who frequent the place, and it was performed while they were waiting for the consults and physical activities. RESULTS: The following items were discussed: 1. Eating healthy 2. Exercise, 3. Solar exposure, 4 Excessive use of medication, 5. Overweight, 6. Hydration and 7. Stress and fatigue. Elderly self-rated on a scale of 0 to 10 . The lower the score for items $1,2,3$ and 6 the more compromised was the lifestyle, and the smaller the score for the items 4, 5 and 7 less compromised. It was observed that the majority of the elderly tried to maintain a healthy diet; frequently participated in the physical activities offered by the health center; denied use of sun block; used more than 3 medicines for chronic diseases, but affirmed not to self-medicate; were overweight; consumed more than 2 liters of water per day; and did not feel very stressed and / or tired. CONCLUSION: This learning approach contributes not only to the elderly, but also to professionals, in the search for new and better ways to promote knowledge and care for this age group. It is also noticed that the use of active methods that include the elderly in the care process values the elderly, because it allows the expression of opinions and the adaptation of the lifestyle according to the possibilities of each one.

Keywords: Life Style, Health, Aged.

\section{EPIDEMIOLOGICAL PROFILE OF LEPTOSPIROSE CARRIERS IN MARANHÃO} IN THE YEARS FROM 2007 TO 2017

Alana Jessica Pinheiro Oliveira; Aline Barros Silva; Alianna Christine Assunção Pinto; Samyra Marjoyreanne Álvares da Silva

Universidade Federal do Maranhão (UFMA)

BACKGROUND: Leptospirosis is a zoonosis transmitted through water or urine with Leptospira. In Brazil, there are about 13,000 reported cases per year, with a lethality of $10.8 \%$, on average. In the urban area, the main reservoir is rodents. This pathology is of a compulsory nature, aiming the implementation of interventions to the population and especially to groups at risk. In view of the above, we intend to describe the data of leptospirosis in Maranhão, from 2007 to 2017. METHODS: Retrospective Iongitudinal descriptive study. The data were obtained from the Notification of Injury Information System (SINAN). The collection took place in July 2018, with analysis of data from 2007 to 2017 of reports of confirmed cases of leptospirosis in children less than 1 year to 80 years or more of age. Descriptive exploratory analyzes of the data were performed, based on the calculation of absolute and percentage frequencies for the categorica variables. RESULTS: A total of 319 cases were recorded, of which 262 (82.1\%) progressed to cure and $59(18.5 \%)$ died, $254(79.6 \%)$ were male, and 67 $(21.0 \%)$ were female. The majority of the subjects were aged 20-39 years, with $149(46.7 \%)$, brown race $241(75.5 \%)$, followed by black race with 39 $(12.2 \%)$ and schooling from 1 st to 4 th grade $6520.3 \%)$ and the minority, incomplete higher education registering $1(0.3 \%)$. The urban area registers $219(68.6 \%)$ and rural $75(23.5 \%)$. CONCLUSION: The results suggest that the majority of cases occur among brown males, in urban areas and with low schooling, and may be related to the fact that they are more exposed to environments with inadequate infrastructure conditions, in urban agglomerations, associated to infestations of rodents and floods that spread the pathogenic leptospires. It is important that there are more studies collaborating in the creation and implementation of public health policies that encourage their prevention and adequate conditions of infrastructure and basic sanitation to the population.

Keywords: Leptospirosis, Public Health, Prevention.

08.

\section{CASE REPORT: POLYARTICULAR CHRONIC TOPHACEOUS GOUT IN A} YOUNG PATENT

Mirla Kalina Silva dos Santos; Thais Costa Alves; Nayanna Láyza Oliveira de Sousa; Nícya Maria Paiva Batista Santana; Elaine Pereira de Andrade; Nathalia Farias Pereira; Francisco Airton Veras de Araújo

Centro Universitário do Maranhão (CEUMA), Hospital Dr. Clementino Moura 
BACKGROUND: Gout is an inflammatory arthritis that affects mainly middleaged men. The crises are characterized by excruciating pain, edema and inflammation. It may present as acute arthritis, usually monoarticular, intercritical period and chronic tophaceous gout associated with hyperuricemia and the presence of crystals of sodium monourate. After several seizures, synovitis and chronic polyarthropathy may develop. CASE DESCRIPTION: I.F.G, 29 years old, male, black, natural and resident of São Luis- MA, sought care due to left knee and elbow pain for 5 weeks. He reported edema and severe pain in the joints mentioned with periods of remission and activity that made it difficult to walk for 2 years without medical follow-up. Physical examination: REG, lucid, eupneic, hydrated, tachycardic, febrile and normotensive. In the locomotive he presented muscular hypotrophy, arthritis and multiple joint deformity, especially in bilateral knees, elbows, ankles and podagra, besides hot, hard edema with positive locker and intense pain (EVA: 09) in left knee and ankle, preventing his locomotion. No change in other systems. Negative morning stiffness, alcoholism and family history of arthropathies. Laboratory tests revealed $\mathrm{Hb}: 8.71 \mathrm{~g} / \mathrm{dl}$; Leuc: 7,790; B.C. uric acid: $8.6 \mathrm{mg} / \mathrm{dl} ; \mathrm{Cr}: 1.4 \mathrm{mg} / \mathrm{dl}$ and Ur: $54 \mathrm{mg} / \mathrm{dl}$. Analysis of synovial fluid: glucose: $30 \mathrm{mg} / \mathrm{dl}$; global and specific cytology: numerous amounts of uric acid crystals; proteins: $6 \mathrm{mg} / \mathrm{dl}$; albumin: $1.8 \mathrm{~g} / \mathrm{dl}$. CT revealed polyarticular deforming arthropathy in the knees, ankles and joints of the feet, with bone erosions, reduction and incongruence of joint crevices, synovial thickening, joint effusion and gross periarticular calcifications, characteristic of deposit arthropathy. CONCLUSION: The diagnosis and late treatment of gout corroborate a disabling and irreversible condition. Therefore, adequate and early treatment prevents comorbidities and contributes to a better prognosis.

Keywords: Gout, Hyperuricemia, Treatment, Gouty arthritis

CHARACTERIZATION OF HOSPITAL INSTRUMENTS BY ASTHMA IN BRAZIL Werbene Caroline de Queiroz Gomes; Kaiza Vilarinho da Luz; Gideon Batista Viana Júnior; Fernando Cleydson Lima Paiva Filho; Raynnara Carvalho Silva; José de Ribamar Rodrigues dos Santos Júnior; Orientadora: Jessica Sâmia Silva Tôrres Ribeiro

Universidade Estadual do Maranhão (UEMA); Universidade Estadual do Piauí (UESPI).

BACKGROUND: According to the World Health Organization (WHO), 235 million people suffer from asthma in the world, constituting the most common chronic illness of childhood. Asthma is a common chronic disease characterized by recurrent episodes of shortness of breath and wheezing that cause limitation to day-to-day activities and may require urgent care, including hospitalization and risk of death. The objective of this study was to demonstrate the Brazilian epidemiological survey of asthma cases from 2010 to 2017. METHODS: This is an exploratory-descriptive study with a quantitative approach. The data collection was done through the Hospital Information System of SUS (SIH / SUS), made available by the Department of Informatics of the Unified Health System (DATASUS). RESULTS: From January 2010 to December 2017, 1072021 cases of hospitalizations for Asthma in Brazil were reported. In the period under study, 2010 was the year that presented the most cases, with 193,197 (18.02\%). With regard to the geographical regions of the Country, the Northeast Region leads with $473857(44.20 \%)$ cases. It was observed that 543962 (49.26\%) cases are female patients. Regarding the age group, there was a predominance of the under 10 age group, with $574089(53.55 \%)$ cases. Regarding the character of the service, there were 1030545 emergency calls, pointing out $96.13 \%$ of the total number of calls. In $5276(0.5 \%)$ cases, the final outcome was death. CONCLUSION: In the country, asthma was predominant in the Northeast, in children less than 10 years of age. In this perspective, it is worth emphasizing that the disease has high morbidity, when not adequately managed, leading to the development of complications that reduce the quality of life in children and adolescents. Therefore, the control of environmental triggering factors is necessary, as well as the correct adherence to drug treatment in the prevention of future risks.

Keywords: Asthma, Chronic Disease, Hospital Instruments.

EPIDEMIOLOGICAL PROFILE OF MENINGITIS IN THE STATE OF MARANHÃO Rodrigo Mitoura Rocha; Isabella Lima Chagas Reis Batista; Heitor Queiroz Torres; Lise Gabrielle Alves Rodrigues dos Santos; Luiz Felipe Bezerra de Sousa; Luecya Alves de Carvalho Silva Universidade Federal do Maranhão (UFMA)
BACKGROUND: Meningitis is a disease whose pathophysiology consists of inflammation of the meninges, caused mainly by bacterial or viral infection. This research aims to trace the epidemiological profile of patients affected in the State of Maranhão, as well as to analyze the evolution of the disease and its most recurrent subtypes. METHODS: Descriptive observational study, based on information contained in the Notification of Injury Information System. All cases reported and diagnosed with meningitis were included. RESULTS: In the period from 2013 to 2017, 750 cases of meningitis were diagnosed in the study region, which is equivalent to a detection coefficient of 10, 71 per 100 thousand inhabitants. Among these, $61.7 \%$ of the cases occurred in males. The ethnicity most affected was brown with $78.5 \%$. In relation to the age group, the highest prevalence occurs between 20 and 39 years $(23.6 \%)$, followed by children under 1 year $(16.5 \%)$. Among the subtypes, 357 cases are of "unspecified" meningitis (lethality $=29.4 \%$ ), 51 of other etiologies (lethality $=41.1 \%$ ), 152 viral (lethality $=7.5 \%$ ) and 190 are meningitis (lethality $=30.9 \%$ ). The lethality rate for all meningitis was $26.5 \%$, corresponding to 197 deaths. Among the cities with the highest prevalence, São Luís stands out with 425 cases diagnosed, followed by Imperatriz with 34. CONCLUSION: The results of the study indicate a lethality that exceeds the common disease rates in relation to the national territory. The high proportion of unspecified etiology may indicate both the deficiency of diagnostic methods and infrastructure, and the inability of health professionals to classify the disease. The actions of epidemiological surveillance to control the evolution of meningitis in Maranhão can be improved to reduce these indices.

Keywords: Meningitis, Epidemiological surveillance, Public health

\section{TREATMENT OF SENSITIVE-MOTOR DIABETIC NEUROPATHY IN A PAIN} CENTER IN SÃO LUÍS - MA

Beatriz Morais Costa; Erika Barros Lima Pinheiro; Abner de Oliveira Freire; João Batista Santos Garcia; Luiz Nycollas Carneiro de Oliveira; Rayanne Luiza Tajra Mualem Araújo; Thiago Alves Rodrigues Universidade Federal do Maranhão (UFMA)

BACKGROUND: Peripheral neuropathy is a common neurological disorder in diabetic patients. This study aims to describe how a pain reference center in São Luís, Maranhão, conducts the treatment of diabetic neuropathy and the response of patients to the prescribed intervention. METHODS: The sample consisted of 20 patients with diabetes mellitus and symptomatology of diabetic sensory-motor neuropathy, accompanied at the Chronic Pain Service of the University Hospital of the Federal University of Maranhão (UFMA), whose last consultation took place between January 2013 and May of 2017. Data were collected from charts and the variables evaluated were: location and intensity of pain, associated symptoms, previous pharmacological and non-pharmacological treatment, prescribed treatment, response to medication and adherence to therapy instituted. RESULTS: Lower limbs were the most affected (80\%), with intense pain being $45 \%$ and moderate pain in $50 \%$ of cases. The most associated symptoms were alterations in sensitivity $(75 \%)$, burning (55\%) and pinning (50\%), as well as reports of sleep disturbances (70\%) and limb edema (50\%). The medications most used as the first treatment option were gabapentin $(40 \%)$ and pregabalin (30\%), with response rates being $71.4 \%$ and $87.5 \%$, respectively. Amitriptyline was associated with $30 \%$ of the treatments, and tramadol $25 \%$. Three-quarters of the patients showed some improvement. The rate of adherence to pharmacological treatment was $55 \%$, while nonpharmacological treatment was $64 \%$. The main causes for nonadherence to pharmacological treatment were adverse effects $(42.8 \%)$ and economic condition (28.5\%). CONCLUSION: Anticonvulsants are the predominant medications in the initial treatment, associated or not with a tricyclic antidepressant. The majority of patients reported improvement. However, better adherence rates to pharmacological treatment and rehabilitation therapies could reflect better pain control.

Keywords: peripheral neuropathy, diabetes, pain, treatment

PERCEPTION OF HUMANIZATION IN A NEFROLOGY CENTER OF A HOSPITAL IN SÃO LUÍS, MA

Adriana Leite Martins; Dina Stefany de Oliveira Moreira; Filipe Tamburini Brito; Igor Matheus Lima Cruz Fortaleza; Livia Anniele Sousa Lisboa

Universidade Federal do Maranhão (UFMA) 
BACKGROUND: Chronic kidney disease is one of the main public health problems in the country and has hemodialysis as one of the most used treatments for renal function replacement. The provision of a humanized care is necessary so that the therapy is adhered in a continuous way and so that the harmful biopsychosocial consequences that the process can cause are mitigated. As a proposal for the activity of the Integrative Axis discipline of the Federal University of Maranhão, a visit was made to the hemodialysis program of the University Hospital Presidente Dutra (HUUFMA) and observed the humanization provided at the site. RESULTS: It was observed that the patient has three shifts for hemodialysis, with the support of a trained multiprofessional team, which is available for continuous monitoring and individualized care. As a long-term treatment, which can be exhaustive and expensive, it is offered the Out-of-Home Treatment, in order to help it to adapt to the conditions of hemodialysis therapy and to guarantee its adherence according to its specificities. In addition, the $A B C$ Nefro project is organized in order to promote patient literacy and help in the understanding of treatment information and related materials, making them aware and autonomous in the therapeutic process. Thus, from the visit it was possible to observe that the conditions of the offered service are favorable to the patient and capable of integrating him to his healing process. CONCLUSION: The provision of a humanized care to patients allows them to deal with difficulties related to dialysis, such as physical and emotional exhaustion. In addition, it encourages greater adherence to the procedure, due to the adaptation to some conditions of care according to the patient's needs, and allows the organization of proposals that guarantee their socio-cultural enrichment and social reintegration.

Keywords: Hemodialysis, Chronic Kidney Disease, Humanization

13. MAIN AMPUTATIONS OF LOWER LIMBS AT CEMESP IN SÃO LUÍS-MA Wesley Costa Barros; Rayla Bezerra Rocha; João Víctor Pacheco Florentino; Ana Clara Sampaio Lima Vasconcelos; Eva Rayane Ramos: Tatiana Cristina Fonseca Soares de Santana Centro Universitário do Maranhão (CEUMA)

BACKGROUND: Diabetes mellitus (DM) is a set of metabolic diseases that have high glycemia in common, being a product of distortion in the production of insulin, in action or in both. DM is responsible for half of the non-traumatic amputations in the world. (MATHEUS and PINHO, 2006). One of the most serious and costly vascular complications of DM is partial or total amputation of the lower limbs (WL) or the formation of wounds that are difficult to heal. The present study has the objective of identifying the most frequent levels of AMI by DM in patients attended at a specialized center in the city of São Luís, Maranhão. METHODS: A retrospective descriptive study was carried out with quantitative data analysis through medical records analysis of the years 2015 and 2016. The final sample consisted of 30 medical records of both genders over 50 years of age at the Medical Center Specialized CEMESP São Luís - MA, with amputations of MMI due to vascular complications caused by DM. RESULTS: There was a highe prevalence of males (73\%) and the majority of the sample had diabetic diagnoses between 11 and 20 years old (54\%). Concerning comorbidities the medical records included only the presence or absence of systemic arterial hypertension, being present in $67 \%$ of the analyzed cases. The highest prevalence of MMII amputations was of the Hallux, with $30 \%$, followed by metatarsus (20\%) and the 5 th toe (17\%). It is observed that $97 \%$ of the total sample underwent standing amputation. CONCLUSION: This study shows that the most frequent levels of amputations were distal amputations. It is relevant because it may help health professionals to perceive the situation in the region when talking about amputees due to vascular causes due to DM, since it is a public health problem, in addition to adding to the scientific environment, since there are few publications on the subject at the national level, mainly in the state of Maranhão.

Keywords: Diabetes mellitus; amputations; diabetic foot

\section{FOURNIER'S SYNDROME DUE TO POSTECTOMY: A CASE REPORT}

Vitória Gonçalves Alves de Oliveira; Maria Augusta Ribeiro Gaspar; Laís da Hora Lucena Silva; Gabriel Mendes Costa; Waslei Lima Santos; Pedro Henrique Silva Barros; Thiago Sousa Dourado Universidade Federal do Maranhão (UFMA)

BACKGROUND: Fournier syndrome is a condition associated with factors such as alcoholism, diabetes, patients undergoing urologic surgery, colorectal disease, advanced age, among others. It is characterized by tissue necrosis of the perineal region, originating in the penis and testis in men, and vulva and groin in women, and was formerly described as having idiopathic cause. However, it is now known that such a condition can be triggered by bacteria infections. CASE DESCRIPTION: LBR, 75 years old, male, diabetic, natural and resident of a small city, after elective postectomy at a medical center in his city of origin, evolved with surgical site infection, developing Fournier's Syndrome and urethral stenosis. He was admitted, 39 days ago, to the regional hospital of the city of Pinheiro, with perineal necrosis associated with acute urinary retention, and an opinion was requested for the surgical clinic. At the time of admission, the patient was in a regular genera condition, with blood pressure of $140 \times 90 \mathrm{mmHg}$ and Glasgow: 15. As a procedure, debridement of necrotic tissue and cystostomy were performed. After the procedures were carried out, the testicles were protected with wet dressings, which were changed twice a day, while the patient was transferred to a reference medical center for the purpose of performing the surgical reconstruction, by means of a graft, of the injured area. CONCLUSION: The patient in the case in question had some conditions that are associated with the development of the Fournier Syndrome, such as the urological procedure, diabetes and old age. These factors are not pathognomonic of perianal necrosis, but are characteristics that need attention in the management of patients with such clinical presentations, especially those affected by surgical site infection.

Keywords: Fournier's syndrome, infection, urethral stenosis, cystostomy.

\section{150 TEIRASSOMY IN A CHILD OF PARENTS WITH MULTTPLE ABORTIONS} IN SÃO LUIS-MA

Luiz Gonzaga Marques Dos Reis Júnior; Isabela Castelo Guimarães; Paula Silvine Costa Alves; Decarthon Vitor Dantas Targino; Maria Juliana Rodovalho Doriqui

Hospital Infantil Juvêncio Mattos (HIJM)

BACKGROUND: The term repeat abortion (RA) is defined as two or more consecutive gestational losses before the 20th week of pregnancy. Although it is a heterogeneous condition, most of the time, RA is caused by genetic abnormalities in the embryo. Its overall incidence is approximately $3 \%$. CASE DESCRIPTION: A 2-year, 7-month-old female, natural and resident in São Luís. Daughter of non-consanguineous parents. Advanced maternal and paternal age ( 35 and 40 years, respectively). Mother G5P2A3, all abortions were first trimester. It denies smoking and alcoholism. The child was born of elective cesarean delivery, term, weight suitable for gestational age and without malformations at physical examination. He was discharged after 2 days. It evolved with delay in neuropsychomotor development, initiating cephalic sustenance at 6 months and crawling only at 15 months; at 2 years and 7 months, mumbles words, accompanies objects with his eyes and stands with support. Diagnosed at 7 months with bilateral hip subluxation. It presents discrete dysmorphia, such as low nasal root and short neck. Thorax, spine, abdomen, limbs, genitalia without significant changes. Magnetic resonance imaging of the skull showed hypersignal in $\mathrm{T} 2$ in the bilateral periventricular white matter, and may correspond to terminal myelination. Karyotype: $47, X X$, sea [20]. Karyotype with $G$ band of parents within normal range. Array (SNP) revealed 15q11.1q13.3 X 3-4: compatible with tetrassomia (4copies) in most segment-arr [GRCh37] 15q11.1q13.2, with a smaller region containing 3cop-arr [GRCh37] 15q13. 2q13.3. Other tests, normal. CONCLUSION: The chromosomal changes encompass rare conditions, such as tetrasomy $15 \mathrm{q}$ of the case in question. Early identification and management of the child with delayed acquisitions of neuropsychomotor development is fundamental. If this is of a genetic / chromosomal cause, it is essential to guide the risk of recurrence, and the options against risk.

Keywords: repetitive abortion, delayed neuropsychomotor development, tetrasomy $15 q$, genetic counseling

PERIPHERAL POLYUROPATHY ASSOCIATED WITH HIV AND CHRONIC OSTEOMYELTTS: CASE REPORT

João Batista Santos Garcia; Thiago Alves Rodrigues; Ana Karolina Torres Mendes; Alexandre Lima Machado; Renata Coelho Chaves Gaspar; Renato Albuquerque Heluy; Luis Nycolas Carneiro de Oliveira

Universidade Federal do Maranhão (UFMA)

BACKGROUND: Osteomyelitis is a bone infection caused by colonies of microorganisms involved in biofilm, increasing its protection against the immune system and antibiotics. Thus, when it affects immunocompromised 
patients, there is a predisposition for its chronification, configuring a difficult to control picture. CASE DESCRIPTION: EDM, male, age 38, bricklayer, was referred to the specialized pain department of the Presidente Dutra University Hospital by the infectology team reporting pains of strong intensity, continuous character, on burning, that worsened with cold or movement and improved with medications or rest. The pains extended through the thoracic and lumbosacral regions, left upper limb and lower limbs. He presented limitation of the movements, hypoesthesia to the touch in upper and lower left limbs and diminished muscle strength (grade 4). Diagnosed with HIV since 2010, he reported onset of pain in 2014, being diagnosed with osteomyelitis. Bone scintigraphy revealed the presence of osteoblastic lesions on the left humerus. Bone densitometry showed a high risk of lumbar spine fracture and ENM indicated sensitive peripheral polyneuropathy of the upper and lower limbs. Treatment with Gabapentin $400 \mathrm{mg}$ (three times daily), Amitriptyline $25 \mathrm{mg}$ (one tablet in the evening) and Tramadol $100 \mathrm{mg}$ (twice daily) have been proposed. Upon his return, he reported partial improvement of the pain (EN $=7$ ), complaining of pain in the left hemibody. Methadone $2.5 \mathrm{mg}$ every 12 hours was added and Tramadol and Amitriptyline withdrawn. In more recent consultation, the patient continued to report pain in the left upper and lower limbs. We chose to maintain methadone and increase the dose of gabapentin to two tablets three times a day. CONCLUSION: The case shows the difficulty in controlling the pain of an immunocompromised patient with peripheral neuropathy and chronic osteomyelitis, implying the use of several medications for pain management.

Keywords: Chronic osteomyelitis; Polyneuropathy; Pain.

\section{SURGICAL PROCEDURES FOR BREAST CANCER TREATMENT IN BRAZIL}

Felipe Moraes da Silva; Paula Cristina Alves da Silva; Anália Rabelo Oliveira; Tayse de Oliveira Freitas; Ana Cláudia Lisboa Serrão Universidade Federal do Maranhão (UFMA)

BACKGROUND: Breast cancer is the second most frequent type of cancer in the world and the most common among women, accounting for $25 \%$ new cases a year. Currently, there are several means of treatment to combat breast cancer, varying according to tumor characteristics and staging, in addition to the physical conditions of the patient. Thus, the objective of this research is to identify the surgical procedures used to treat breast cancer in Brazil. METHODS: This was a quantitative descriptive study based on secondary data collected from DATASUS / Hospital Production, with a cut from January 2008 to June 2018. Six categories of procedures were evaluated: radical mastectomy with lymphadenectomy, simple mastectomy, reconstructive mammary reconstruction, sectorectomy-quadrantectomy, glanglionar emptying and radical mastectomy with axillary lymphadenectomy, and used in the data layout the 02 procedures with the most significant numbers: sectorectomy-quadrantectomy and radical mastectomy with lymphadenectomy. RESULTS: A total of 217,213 surgical procedures were performed to treat breast cancer in Brazil. Of these, 20.85\% ( $n=45.307$ ) refer to data from the Northeast region, presenting the second highest percentage among the regions. In Maranhão, 3,852 surgeries were performed. Thus, the breast-lumpectomy-in-oncology sector was performed in 2,031 of the cases, presenting the highest frequency (52.72\%). Radical mastectomy with lymphadenectomy, in turn, was performed in 893 women $(23.18 \%)$. It is noteworthy that, although the number of procedures is high only 28 of these are related to reconstructive mammary plastic post mastectomy. CONCLUSION: The data show that surgeries performed in the country still do not meet the real demand of the population, leading to queues in the Unified Health System and consequent aggravation in the patients.

Keywords: Breast Cancer, Breast Surgery, Cancer Treatment

EPIDEMIOLOGICAL ANALYSIS OF PATENTS WITH ACUTE MYOCARDIAL INFARCTION IN MARANHÃO

Lucas Albuquerque de Sousa Martins; Maria Carolina Albuquerque de Sousa Martins

Universidade Federal do Maranhão (UFMA) Universidade Estadual do Maranhão (UEMA)

BACKGROUND: Acute Myocardial Infarction (AMI) is an acute coronary syndrome, characterized by ischemia of the cardiac muscle tissues, due to obstruction and interruption of blood flow in the coronary arteries. This pathology causes serious dysfunctions in the affected organ and its prognosis may even result in death, especially among the more advanced ages. This study aimed to analyze the epidemiological profile of patients with AMI in Maranhão between 2012 and 2017. METHODS: A quantitative descriptive study was carried out, using a cross-sectional study, based on data obtained from the Hospital Information System of SUS (SIH / SUS), referring to the state of Maranhão between the years of 2012 and 2017. RESULTS: During the period evaluated, 5,625 AMl cases were identified in the State of Maranhão, among which there is a predominance of males $(61 \%)$, . Despite this, the mortality rate was higher among women, with a rate of $16.84 \%$, as opposed to $15 \%$ among men. The most frequent age group was 60 to 79 years, with about $50 \%$ of the cases. However, it is after 80 years that the disease is more devastating, since it has the highest mortality rate (27\%). In addition, according to the period studied, 2014 and 2017 had the highest number of cases (1,081 and 1,054, respectively). CONCLUSION: According to the present study, although the prevalence of infarction was higher among elderly men, the mortality rate was higher in females.

Keywords: Epidemiology, Infarction, Maranhão, Mortality, Public Health.

\section{EPIDEMIOLOGICAL PROFILE OF HANSENÍASE IN THE CITY OF CAXIAS-MA} BETWEEN THE YEARS OF 2014 TO 2017

Thiago Paiva de Sousa; Brenda Cavalcanti de Oliveira Melo; Ana Valéria Melo e Silva; Mathews Resplandes Batista Batista; Marcos Santos Luz Leal; Lucano André Assunção Barros Universidade Estadual do Maranhão (UEMA)

BACKGROUND: Leprosy is an infectious disease caused by Mycobacterium leprae that affects skin and peripheral nerves. It is a public health problem in Brazil, with Maranhão leading the ranking of prevalence among states. The objective of this study was to evaluate the cases reported by leprosy in the municipality of Caxias (MA), from 2014 to 2017. METHODS: This is a retrospective cross-sectional study based on the cases reported in the Notification of Injury Information System (SINAN) for the years 2014 to 2017, according to the variables: gender, age group, diagnostic operational classification, mode of entry, clinical form and type of output. RESULTS: In the analyzed period, 426 cases were reported. In 2014, the highest prevalence was obtained (37.08\%) and the year 2017 was the lowest $(11.73 \%)$. As for sex, 230 cases (53.99\%) were male and $196(46.01 \%)$ were female. The most affected age group was 50 to 69 years (18.77\%), followed by 40 to 49 years $(15.96 \%)$. Regarding the operational diagnostic classification, there is mainly multibacillary $(60.79 \%)$. Regarding the mode of entry, there are $385(90.37 \%)$ new cases and 15 (3.52\%) recurrences. On the clinical form, the most common was the dimorphous $(40,37 \%)$, followed by the indeterminate $(20,89 \%)$. Regarding the type of output, it is noteworthy that $34.97 \%$ of the patients were cured, but $57.74 \%$ of the outcomes were left blank. CONCLUSION: It was observed that in the evaluated period the year of 2014 had the highest prevalence, affecting more males and the age group from 50 to 69 years. The cases of leprosy are mainly presented as multibacillary and dimorphic. Regarding the type of output, more than half of this criterion was not filled, which may represent a failure to follow up these patients. The analysis of clinical and epidemiological data is essential for choosing the best course of action in order to maximize cure rates and prevent possible complications.

Keywords: Leprosy, epidemiological profile, Caxias

\section{PREVALENCE OF HIATAL HERNIA BY SLIDING ASSOCIATED WITH} ESOPHAGITE IN ADULTS AND ELDERLY

Amanda Angelo Pinheiro; Letícia Muniz de Abreu Murad; Maria Tereza Pereira Gonçalves; Geyza Cristine Oliveira Mendes; Arthur Silva Soares

Centro Universitário do Maranhão (CEUMA)

BACKGROUND: Hiatal sliding hernia (HHD) is an anatomical condition characterized by the displacement of the cardiac portion of the stomach into the thoracic cavity through the esophageal hiatus. Its pathophysiology is due to the loosening of the brainstem-esophageal ligaments, which is responsible for the maintenance of the anti-reflux mechanism. Currently, $\mathrm{HHD}$ is considered an aggravating factor in the pathogenesis of reflux esophagitis. The main risk factors involved in the onset of HHD are: age over 60 years, obesity, pregnancy, smoking, chronic cough and multiparity. To resolve such cases, High Digestive Endoscopy (EDA) is used as a diagnostic method. Considering the increasing number of HHD cases in the adult population, the interest in conducting a study with the objective of 
identifying the prevalence of this anatomical dysfunction in adults and the elderly was aroused. METHODS: A cross - sectional, descriptive and quantitative study was carried out through the analysis of medical records in the database of the private network endoscopy service in São Luís, Maranhão. RESULTS: A total of $91 \mathrm{HHD}$ cases were analyzed in patients aged 19 to 100 years, from July 21,2017 to July 21,2018 . Of these 91 cases, $35.17 \%$ were male and $64.83 \%$ to female. Regarding the age group, $3.29 \%$ of the cases are in patients between 19 to 29 years of age, $6.59 \%$ between 30 and 39 years, $14.28 \%$ between 40 and 49 years, $14.28 \%$ between 50 and 59 years, $24.17 \%$ between 60 and 69 years, $19.80 \%$ between 70 and 79 years, $11 \%$ between 80 and 89 years and $6.59 \%$ between 90 and 100 years. 83 patients, ie, $91.2 \%$ of the cases present associated esophagitis and only $8.8 \%$ do not CONCLUSION: Data analysis revealed that the highest prevalence of HHD is in the age group from 60 to 69 years and more frequently in females, being this a risk factor and severity of esophagitis. EDA is indicated as the best diagnostic method.

Keywords: Hiatal Hernia, Esophagite, High Digestive Endoscopy.

\section{ABDOMINAL TRAUMA CLOSED BY "BULL HORN"}

Rayla Bezerra Rocha; Sádina Mayara dos Santos Oliveira; Larissa Vidigal Hortegal de Oliveira; Jéssica Islane Amorim de Sá; Luana Bogéa Ribeiro; Carlos Brandão Feitosa Nina; Manoel Francisco da Silva Santos

Centro Universitário do Maranhão (CEUMA)

BACKGROUND: Trauma represent a serious public health problem and are among the first causes of mortality, causing a high economic and social cost. Abdominal trauma is one of the most prevalent in the context of trauma, and liver injury is very common in closed trauma. CASE DESCRIPTION: C.R.P., 31 years old, male, brown, natural and resident in Santa Inês - MA. From a regional hospital with a history of abdominal trauma, closed by "bull horn", undergoing exploratory laparotomy (LAPE) where hepatic laceration of zone III and IV was identified, with active arterial bleeding, suggesting left hepatic artery injury, being performed hepatorraphy and Damage Control. It evolved with 4 episodes of bleeding per abdominal drain, being carried out a new approach. He was admitted after 1 month in a hospital of High Complexity in São Luís, to confirm left hepatic lesion and, during hospitalization, he evolved again with live bleeding, abdominal pain and significant fall in hemantimetry. At the reexamination, a frozen abdomen was visualized, with clots and purulent secretion; performing only raffia of the skin for a new approach after an angiotomography report (ANGIOTC). ANGIOTC showed moderate / severe narrowing of the left hepatic artery. After hepatic arteriography, a massive pseudoaneurysm was visualized in the left left / accessory hepatic gastric artery. Superstructive catheterization of the aforementioned branch was performed. Embolized pseudoaneurysm with glue +Lipiodol. After 24 hours, the abdominal wall was closed and the patient evolved stable, being discharged. CONCLUSION: The management of closed abdominal trauma is challenging, since intra-abdominal injuries and LAPE indications are not as clear as in penetrating trauma. Therefore, Damage Control is of paramount importance and is essential to increase patient survival and promote a favorable prognosis.

Keywords: Abdominal trauma, hepatic artery injury, hepatic laceration, damage control.

\section{PAIN AFTER GASTROPLASTY}

Lais Maria Gaspar Coelho; Gustavo Mesquita Bruno; Caio Marcio Barros de Oliveira; Plinio da Cunha Leal; Ed Carlos Rey Moura Hospital São Domingos (HSD), Universidade Federal do Maranhão (UFMA)

BACKGROUND: Pain is an unpleasant sensory and emotional experience associated with tissue injury. Lidocaine, through its anti-inflammatory properties, has been shown to promote important relief of postoperative pain. OBJECTVE: To evaluate pain intensity after laparoscopic gastroplasty with intraoperative intravenous lidocaine. METHODS: Prospective, comparative, randomized, double-blind study. Inclusion criteria were patients undergoing gastroplasty, between 18 and 60 years, with ASA 1 or 2. These were randomized and divided into two groups. Patients in group 1 $(\mathrm{n}=28$ ) received IV lidocaine $1.5 \mathrm{ml} / \mathrm{kg}$ administered for $5 \mathrm{~min}$ before anesthetic induction and group $2(n=24)$ received saline solution $0.9 \%$ in equal volume. Then, lidocaine infusion $(2 \mathrm{mg} / \mathrm{kg} / \mathrm{h}$ ) or $0.9 \%$ saline solution was started throughout the surgery. Postoperative analgesia was performed with patient-controlled pump morphine. Patient demographic, clinical and surgical characteristics, pain intensity (through the verbal scale) 30min, $1 \mathrm{~h}$ $2 \mathrm{~h}, 4 \mathrm{~h}, 6 \mathrm{~h}, 12 \mathrm{~h}$ and $24 \mathrm{~h}$ after surgery, duration of analgesia, use of complementary morphine, volume of sevoflurane, time to wake up and side effects were evalueted. RESULTS: Patients in group 1 presented a reduction $(p \quad 0.05)$ in pain intensity soon after anesthesia was awakened compared to group 2. Mean sevoflurane consumption was lower $(p \infty .05)$ in group 1 $(39 \pm 6)$ than in group $2(62 \pm 12)$. In group 1 , a smaller amount $(p \& .05)$ of people presented side effects than in group 2 . Regarding pain in the other postoperative times and the time to wake up, there was no difference between the groups $(p>0,05)$. CONCLUSION: The use of IV intraoperative lidocaine has been shown to reduce pain after laparoscopic gastroplasty, to increase the duration of analgesia, to reduce the consumption of morphine, to decrease the volume of sevoflurane used and to reduce the occurrence of side effects.

Keywords: Postoperative Pain, Lidocaine, Gastroplasty.

\section{EPIDEMIOLOGICAL STUDY OF TUBERCULOSIS CASES IN THE CAXIAS} MUNICIPALITY, FROM 2013 TO 2017

Indira Odete Amorim de Matos Menezes; Renata Costa Cavalcante Universidade Estadual do Maranhão (UEMA)

BACKGROUND: Tuberculosis is caused by Mycobacterium tuberculosis of Koch's Bacillus, which mainly affects the lungs and may affect other organs and systems. The bacillus is transmitted person to person by inhalation. Its common symptoms are dry or productive cough for more than three weeks, the diagnosis is usually made by sputum analysis and the main prophylaxis is the BCG vaccine. In Brazil, tuberculosis is still evident, making the disease a public health problem. Thus, reporting and outlining the epidemiological profile of tuberculosis cases in the municipality of Caxias-MA contributes to the planning and development of preventive actions. METHODS: Quantitative research was carried out through the retrospective epidemiological study from 2013 to 2017, using the Information System of Notification Diseases (SINAN) as a source of information. The following criteria were analyzed: sex, age, presence of Human Immunodeficiency Virus (HIV) and disease outcome. The data for the Numbers software for study were exported. RESULTS: During the study period, 303 new cases of tuberculosis were reported, of which 197 patients $(65.01 \%)$ were male. The prevalent age range was 20-39 years, with 104 cases (34.32\%). Of the patients, 15 (4.95\%) were HIV positive. Regarding the outcome, 14 patients $(4.62 \%)$ abandoned treatment, 211 cases (69.63\%) progressed to cure and $13(4.29 \%)$ died of tuberculosis. CONCLUSION: Therefore, it is evident that the most affected are adult males. In addition, the low dropout rate and the high cure rate show the efficacy of care for patients with tuberculosis in Caxias. It is seen that the low number of seropositive patients with tuberculosis indicate the good performance of antiretroviral drugs. However, the total number of cases reiterates the relevance of the elaboration of educational measures focused on the prevention of tuberculosis, aiming at reducing the incidence of the disease

Keywords: Tuberculosis, Epidemiology, Public health, Maranhão

\section{CRANIOENCEPHALIC TRAUMA BY COLD WEAPON WITH EXPOSURE OF ENCEPHALIC MASS}

Thaíse Maria de Morais Carvalho; Emanuel Henrique Cardoso Muniz; Isabella Caldas Bastos; Jéssica Mendes Costa; Mateus Guimarães Benvindo; Luan Pinheiro Domingues Moreira; Acacia Pinto Morais Centro Universitário do Maranhão (CEUMA)

BACKGROUND: currently, trauma is the main cause of death in individuals between 5 and 44 years of age, being responsible for $10 \%$ of the total deaths throughout the world, with a higher prevalence between 19 to 30 years. Within this group, cranioencephalic traumatism (tce) is the main determinant of morbimortality and disability. In brazil, in $2006,74.4 \%$ of the homicides had as an instrument of firearms and $16.1 \%$ of the white gun. The whole weapon (fab) breakdown traumas depends only when compared with fire gun failures, are not less important. The damages caused by these injuries are restricted to the penetration area of the objects, since these, different of the firearms, do not accompany the shock waves produced by the penetration of the projects at high speed. In this context, the objective of the present work is to report a case of trauma perfurocortant encephalic 
skull by white arm with exposure of encephalic mass with positive blamping in a public hospital of são luís, maranhão. CASE DESCRIPTION: patient 37 years, male sex, deu entrance in the municipal hospital djalma marques (hmdm) branched by samu with a wheel drilling frame in frontal region of skull. For physical examination: airplanes periods with cervical immobilization in rigged plane, presenting single perfurocortant injury in frontal region of skull with exposure of encephalic mass, without other changes to physical examination. Attended by the neurocirurgy that performed surgical distraction and durorrhage immediately. On the 7th postoperative day, the patient evolves with operating wound of good aspect, without neurological deficits, obtaining high hospital with indication of ambulatorial accompanying. CONCLUSION: in this way, it is of still important in clinical practice, which present high morbimortality with a great potentia of reversibility when treated early.

Keywords: White Arm, Perfocortant Trauma, Neurosurgery.

\section{CORRIDORS}

Diogo Matheus Barros Da Silva; Raimunda Silva e Silva; Ester da Silva Caldas; Bruno Luiz Galvão de Miranda; Ezequias Rodrigues Pestana; Marlon Lemos de Araújo

Centro Universitário Leonardo Da Vinci (Uniasselvi), Universidade Federal do Maranhão (UFMA), Centro Universitário do Maranhão (CEUMA)

BACKGROUND: The rustic race is a sporting modality of athletics, where it requires the participation of aerobic metabolism predominantly and anaerobic in short moments, and the training intensity parameters used are: Vo2max is a cardiorespiratory component that determines the amount of oxygen consumed during exercise and the anaerobic lactic power that matches the maximum energy generated by the glycolytic system. Currently, much is discussed in the scientific community regarding sleep in the quality of life population. Sleep is seen as a component of paramount importance in high performance sports, derived from its restorative and physiological ability. In view of this perspective, this study aims to correlate sleep quality with Vo2max and anaerobic potency. METHODS: Twelve male suit runners with a mean age of $29.17 \pm 5.64$ were analyzed. The assessment of sleep habits was measured by the Pittsburgh Sleep Quality Index (PSQIBR). The Vo2max was evaluated by means of the $3200 \mathrm{~m}$ test. Anaerobic power was measured by the Running Anaerobic Sprint Test. BioStat 5.0 software was used for the statistical treatment, performing a descriptive analysis followed by the Kolmogorov-Smirnov test and Pearson's correlation. RESULTS: Runners have poor sleep quality with a sleep duration lower than that recommended for adults. They have an excellent Vo2max and a high lactic acid resistance. A significant negative significant correlation was observed between sleep quality and Vo2max, sleep quality and fatigue index per $\mathrm{m} / \mathrm{s}$ showed a significant strong positive correlation, sleep quality and significant negative power peak (watts). CONCLUSION: It was concluded that the corridors present a poor sleep quality having a correlation with Vo2max and anaerobic power. Checking this situation requires a sleep repair in terms of quantity and quality for a good sporting performance.

Keywords: Sleep, Vo2max, Anaerobic power, Running

THE STUDENT OF MEDICINE: AN ASSESSMENT OF QUALITY OF LIFE AND ASPECTS OF MENTAL HEALTH

Isadora Yashara Torres Rego; Ana Carine Guedes Pinheiro; Karla Kalene Fernandes Melo; Ricardo Nunes da Silva; Simone da Nóbrega Tomaz Moreira

Universidade Federal do Maranhão (UFMA), Universidade Federal do Rio Grande do Norte (UFRN), Universidade Potiguar (UNP)

BACKGROUND: The student, when entering the Medicine course, experiences joys and achievements, however, during the course of the course, he is faced with stressful situations that can compromise his quality of life. With this, the objective was to know and compare the perception about quality of life and mental health aspects of 190 medical students in public and private institutions of Rio Grande do Norte. METHODS: This was a descriptive, cross - sectional, quantitative study. A self-reported and anonymous electronic questionnaire was used through the Google Forms platform. Participants were informed about the terms of the research and signed the Free and Informed Consent Term. RESULTS: Of the interviewees, $86.4 \%$ were
16 to 24 years old and $62.1 \%$ were women. Most are in the initial periods and are from public institutions. Regarding course satisfaction, more than $80 \%$ rated higher than 8 on a scale of 0 to 10 . Faced with evaluative activities, $52 \%$ judged with 8 or more anxiety and $38.9 \%$ said they felt panic or fear of some teacher. On a scale of 0 to $10,73.2 \%$ reported at least 5 degrees of competitiveness among colleagues. Almost $90 \%$ feel some kind of pressure from family or society. Only $52.6 \%$ are excited about the future. Of the participants, $44.8 \%$ had had at least one suicidal thought and $72.6 \%$ reported having little time to take care of themselves. Only $21.6 \%$ have 7 to 8 hours of sleep, the rest sleep less. Among those interviewed $10 \%$ feel depressed and $32.1 \%$ think they can. Regarding psychological or psychiatric care, $44.2 \%$ already sought some kind of help, of these $22.7 \%$ started after entering the course. CONCLUSION: The study revealed that students have several stressors, such as level of competitiveness, lack of sleep, fear of teachers, anxiety and pressure, and may lead to a psychological situation that requires attention, and an amparo by institutions and community is required

Keywords: Mental health, Medical student, Quality of Life.

\section{ARTERIAL HYPERTENSION AND RENAL ARTERY STENOSIS IN TAKAYASU ARTERITS: CASE REPORT}

Eldan Junior de Araujo Silva; Andressa Sousa Aguiar; Jorge Patrick Oliveira Feliciano

Centro Universitário Tocantinense Presidente Antônio Carlos (UNITPAC)

BACKGROUND: Takayasu arteritis (TA) is a progressive, idiopathic systemic vasculitis that affects the aorta and its main branches. The inflammatory process causes narrowing of the artery wall. Its initial symptomatology is nonspecific, and it evolves with manifestations according to the location and degree of the lesions. CASE DESCRIPTION: Q.T.S.D., female, 25 years old sought ophthalmologist with severe headache complaint, associated with nausea, vomiting, dizziness. At examination, blood pressure (BP): $170 \times 100 \mathrm{mmHg}$. Referred to the cardiologist, where there was no palpable pulses in the left lower limb. An electrocardiogram was requested, which had no abnormalities and abdominal and thoracic aortic angioresonance, which detected mural thickening of the abdominal aorta transition, with signs of wall edema and marked focal stenosis, suggestive of TA. She was submitted to angioplasty, with stent insertion in the proximal abdominal aorta. After the procedure, the patient remained asymptomatic for 6 months using only methotrexate. After this time, the patient returned to the initial symptoms. Angiotomography of the abdominal aorta was performed, which did not observe flow in the right renal artery, right kidney with reduced dimensions. Referred to nephrology, who requested a renal scintigraphy, confirming functionally excluded right kidney. Patient started lower limb edema and uncontrolled BP, prescribed antihypertensive drugs and requested angiotomography, which showed left renal artery with significant reduction of the caliber, indicating disease activity. She initiated therapy with methylprednisolone and methotrexate. CONCLUSION: We can conclude that for the diagnosis of this entity with such a variable clinic it has been of particular importance the creation and evolution of diagnostic criteria towards a diagnosis and earlier therapy.

Keywords: Takayasu arteritis; Vasculitis; Diagnostic imaging

\section{ANALYSIS OF THE ORGAN DONATION AND TRANSPLANTATION IN} MARANHÃO BETWEEN 2015 AND 2017.

Renata Costa Cavalcante; Indira Odete Amorim de Matos Menezes Universidade Estadual do Maranhão (UEMA)

BACKGROUND: In Brazil, the National System of Transplants (SNT) is responsible for the transplants' administration. It is unfolded in States through the Centrals of Notifications, Reception and Donation of Organs (CNCDO). According the Law 10.211/2001, the donation is authorized by the family starting from the diagnosis of brain death without clinical contraindications. In Maranhão, the organs and woven's donation and transplant service (kidney and cornea) is structured by the Academical Hospital of the Federal University of Maranhão (HUUFMA) with the support of the Hospital Santa Mônica (Imperatriz) and of the Hospital Carlos Macieira (São Luís), headquarters of CNCDO in the State. Then, the study's target is analyze the conjuncture of those services in Maranhão between the years of 2015 and 2017. METHODS: A quantitative study was delineated using the RBT (Brazilian Registration of Transplants) as source of data, which were 
exported for the software Microsoft Excel and later analyzed according to the potential / effective number of donors and of active patients in wait list, the family refusal and the amount of absolute transplants. RESULTS: Of the 419 notified potentials donors, only 48 (11,45\% - 18 in 2015, 16 in 2016 and 14 in 2017) were executed in State. Besides, there were 115 cases of family negative (27,44\% - 55 in 2015, 32 in 2016 and 28 in 2017). Considering the active patients in wait list, in 2015 there were 847; in 2016, 925; in 2017, 672. Besides, in the marked period, there were 568 and 141 cornea and kidney transplants, respectively. CONCLUSION: The main obstacles to effect those services in Maranhão are: the subnotification of potentials organs and woven's donors; the reduced number of donors; the human resources' deficiency; the insufficient support of the civil society, of the media, and of the public organs. Then, the difficulty is observed in the donation culture related to issues of affection, of religion and of explanation lack.

Keywords: Organ donation, Transplant, Maranhão, Efectiveness.

\author{
IN POST CARE DEATH: ETHICS AND \\ PROFESSIONALISM \\ Erica Fernanda Silva Lima \\ Centro Universitário do Maranhão (CEUMA)
}

BACKGROUND: According to the resolution COFEN n ${ }^{\circ} 311 / 2007$ that regulates professional practice based on the preservation of human rights to a dignified care, it brings in its article ${ }^{\circ} 19$ that care should be provided to the patient with respect and preservation of privacy of the human being in all circumstances of life, including the preparation of the body after death. Death can be defined as the end of the vital activities of an organism ceasing to live the definitive cessation of life, between the time when the disease becomes irreversible to that in which the individual stops responding to any therapeutic measure, progressing to the death. Methodologically, this is a study based on a case report of a nursing student from the 5th graduation period of a university in Maranhão, the author used a death scene that occurred during an internship in an intensive care unit) in a large public general hospital. In view of this scenario of human finitude demanded of the professional C.N.R humanized practice and scientific technical preparation to perform palliative care of the body after death RESULT: It was observed that although death is a natural process of the life cycle, being still seen as the finitude of the relationships, the professional presented reactions and feelings of fear, anguish, sadness but behaved with ethics and professionalism, making respect and knowledge important, as well as the preservation of patient and family dignity in the execution of procedures by nursing professionals. CONCLUSION: The nursing professional needs to be aware of the ethical and legal principles that govern his profession, using them as the main part in caring for the patient whether in life or after death.

Keywords: Nursing care, Palliative care, Humanized practice, Professional ethics.

\section{ASSOCIATION OF SPYGLASS WITH LASER LTHOTRIPSY AS A THERAPEUTIC} ALTERNATIVE FOR MIRIZZI'S SYNDROME

Poliana Lima Campos; Daniela Lima Campos; Vanessa Moreira Lima; Murilo Lima Campos; Sérgio Ryschannk Dias Belfort; Wilson José de Sena Pedro

Centro Universitário Tocantinense Presidente Antônio Carlos (UNITPAC). Universidade Federal do Maranhão (UFMA). Centro Universitário do Maranhão (CEUMA).

BACKGROUND: Mirizzi syndrome (MS) consists of a rare condition, characterized by mechanical obstruction of the main biliary tract (VB) secondary to calculus impaction in the infundibulum of the gallbladder. The importance of its diagnosis comes from the high risk of bile duct damage during surgical procedures. The objective of this study is to report the use of the new spyglass endoscopic technology associated with laser lithotripsy (LML) as a less invasive and safer therapy alternative for type IV MS. CASE DESCRIPTION: W.C.C., female, 43 years old, complaining of intense abdominal pain in the epigastrium and right hypochondrium, irradiated to the back, 4 days ago, worsening after fatty eating, associated with jaundice. At the physical examination, the patient had poor general condition and abdominal pain with diffuse deep palpation. Cholangioressonance showed signs of choledocholithiasis and cholelithiasis with dilatation of BV. Laparoscopic cholecystectomy was then chosen. During the intraoperative period it was evidenced the presence of MS type IV, with a $1 \mathrm{~cm}$ impacted in the main bile duct of diameter disproportionate to the distal bile duct. As a result of the risks of surgical exploration, endoscopic retrograde cholangiopancreatography (ERCP) + Spyglass associated papillotomy was performed, which enabled LML. Patient progresses clinically well, without complications. CONCLUSION: In advanced cases of this syndrome, as reported, open surgery is considered the ideal. However, due to the extensive inflammatory process that can de-structure the anatomy and the high risk of iatrogenic in both conventional and laparoscopic surgery, a less aggressive form of treatment was chosen through the use of spyglass via ERCP followed by LML of the calculation, a procedure rarely described in the literature, being even rarer for type IV, which until then has the treatment by open surgery as the only option.

Keywords: Endoscopy, Mirizzi's syndrome, Spyglass.

31.

ALGIC MANIFESTATIONS OF A PATIENT WITH FALCIFORM ANEMIA IN AN AMBULATORY OF PAIN IN THE SEA

João Batista Santos Garcia; Thiago Alves Rodrigues; Melina Machado de Oliveira; Alexandre Lima Machado; Francisco Silva; José Rodolfo Teixeira da cunha; Rodrigo Lima Carvalho Santos

Universidade Federal do Maranhão (UFMA)

Sickle cell disease encompasses a group of hereditary hemolytic anemias that have in common the presence of hemoglobin $\mathrm{S}$ comprising the red blood cell. It is the most prevalent hereditary disease in the world. Chronic refractory pain in this situation arises from the microcirculatory obstruction caused by red blood cells, commonly reaching the bones and may be accompanied by fever, edema, neuropathy, necrosis and local heat. The subjectivity of pain is a challenge to treatment, given the need to stick to the already proven correlation between pain persistence, life-style impairment and risk of sudden death. In this way, it is justified the diffusion and detailed description of this case.

Keywords: Anemia, Pain, Therapy, Osteonecrozantes

32. DESCRIPTION OF THE SOCIODEMOGRAPHIC PROFILE OF ACTIVE AND ELDERLY ELDERLY PEOPLE IN SÃO LUÍS - MA

João Florêncio Monteiro Neto; Regislene Bomfim de Almeida Brandão; Ivana Mota Soares; Ingrid Mendonça Lourenço; Luciene Cipriano de Andrade; Jessica Kerly Garcês Campos; Lídia Maria Lopes da Silva

Centro Universitário Do Maranhão (Ceuma)

BACKGROUND: An individual aged 60 or over for developing countries or 65 years for developed nations is defined as an elderly person. Demographic projections of international base indicate an accelerated growth of the Brazilian population over 60 years for the coming decades. But as chronological age increases, people become less active, which facilitates the onset of chronic and degenerative diseases. And, to try to minimize or even delay this process, physical activity has been indicated as a fundamental part of the global health promotion programs. METHODS: This cross-sectional descriptive study was carried out in São Luís, MA, Brazil, with a sample of 40 elderly women divided into two groups. The objective of this study was to analyze the sociodemographic profile of elderly women practicing physical activity and sedentary elderly in São Luís. distinct: 20 physical exercise practitioners and 20 sedentary. Data collection was done through a sociodemographic questionnaire for geriatric evaluation, which was applied to the active elderly women attending the PAl (Integrated Action Program for the retiree) and the sedentary elderly women in the Vila Nova Mothers Association. RESULTS: The group of sedentary elderly women $40 \%$ had a 53-63 age group, 40\% were single, $45 \%$ retired, 55\% had complete primary education, $55 \%$ had income between 1 and 3 minimum wages and $95 \%$ did not live alone, while $50 \%$ of the active elderly women are aged 64 $74,40 \%$ are widowed, $70 \%$ are retired, $65 \%$ have completed elementary education, $60 \%$ have income with more than 3 minimum wages, and $85 \%$ do not live alone. CONCLUSION: In view of the results, it can be concluded that active elderly women have higher income, age and grade and independence when compared to sedentary women, showing that physical activity is linked to an improvement in quality of life.

Keywords: Elderly, Physical activity, Sedentary lifestyle 
33. KNOWLEDGE REGARDING YELLOW FEVER BETWEEN PHYSICIANS IN THE STATE OF MARANHÃO

Larissa Rolim de Oliveira Sales; Ricardo Tadeu Villa; Yanca Lacerda Albuquerque; Gilberto dos Passos Júnior; Vitor de Oliveira Dominici, Marcos Vinicius Araújo Brito; Thiago de Sousa Santos Universidade Federal do Maranhão (UFMA)

BACKGROUND: Yellow fever is a non-contagious infectious disease caused by an arbovirus maintained in wild cycles in which monkeys act as hosts and mosquitoes are the vectors. Despite advances in prevention, the disease once again scared Brazilians in 2017, with the proliferation of cases of wild yellow fever. OBJECTIVES: To assess the knowledge of Maranhão physicians about yellow fever and to suggest if there is a relationship between the very low incidence of yellow fever in Maranhão and the lack of technical knowledge about the disease. METHODS: Observational, analytical and crosssectional study. A questionnaire was prepared by the authors containing 5 objective questions on epidemiology, vaccination, symptomatology, transmission and notification of yellow fever. The questionnaires were administered individually, with physicians working in public and / or private institutions in Maranhão, in May 2018. RESULTS: 34 physicians were interviewed, the average age group being $45-60$ years and the majority with more than 10 years of formation. None of the questions was answered by $100 \%$ of respondents. The first question on epidemiology was answered by $18(52 \%)$ doctors. The second question on the current vaccination scheme was correct in $16(47 \%)$ responses and the third, on symptomatology, were $14(41 \%)$ correct. The fourth question had a higher percentage of correct answers: 28 professionals (82\%) pointed out the correct answer regarding the form of transmission of the disease. The fifth issue, on yellow fever notification, was answered by 23 doctors $(68 \%)$. CONCLUSION: It was observed that the physicians interviewed presented low level of knowledge about yellow fever. This questionnaire raises the suspicion that the low level of knowledge of the disease may lead to an underreporting in the state and even an increase in recurrence of the disease did not show an increase in the level of knowledge on the part of the professionals interviewed.

Keywords: Yellow fever, Knowledge, Medical, Medical education

ACUTE PRIAPISM IN PEDIATRIC PATIENT CARRIER OF SICKLE CELL ANEMIA

João Vitor de Oliveira Fernandes Santos: Lukas Pedrosa Duarte; Paulo Afonso de Oliveira Falcão Neto

Universidade Federal do Maranhão (UFMA), Centro Universitário do Maranhão (CEUMA)

BACKGROUND: Priapism is defined by prolonged and painful penile erection not accompanied by sexual desire or stimulation. This condition can be considered a urologic emergency and erectile dysfunction is a common sequel to inadequate treatment. The typical form of priapism in patients with sickle cell disease is that of low flow, which may occur acutely or recurrently. Acute priapism is characterized by episodes of painful and / or persistent erection for more than 4 to 6 hours. In sickle cell anemia, priaprism is associated with low hemoglobin levels and changes in markers of hemolysis. PURPOSE: This study aims to report a case of acute priapism in a pediatric patient with sickle cell anemia in a public hospital in. CASE DESCRIPTION: F.K.D.S.M., 10 years old, male, was attended at the Municipal Hospital of Buriti presenting painful and persistent erection upon waking in the morning. He remained in the unit for 6 hours and was medicated with diazepam and was referred to the Djalma Marques Hospital for specialized treatment of Pediatric Surgery. At admission, the patient had worsening of the pain and penile cyanosis for 12 hours. The companion reported that the patient had sickle cell anemia and was not being seen at a hemocenter. At physical examination, the penis was erect, painful, cyanosis $(2+/ 4+)$, with no signs of necrosis. The treatment was performed with Dipirone, Tramal Simple Ringer's hydration and red blood cell transfusion. CONCLUSION: In acute priapism in sickle cell patients, prevention is better than cure and limitation of duration of recurrent episodes are important. The evidence is conflicting between conservative and surgical therapeutic efficacy in the case of acute priapism. Surgery is reserved for severe and prolonged cases, and it is possible that subsequent erectile dysfunction is related more to duration of the condition than to surgical intervention

Keywords: Priapism, Sickle cell anemina, Surgery

\section{5. \\ THE CHALLENGE OF DIAGNOSING ACUTE MYOCARDIAL INFARCTION IN} WOMEN

Igor Roberto Guilhon Costa; Ester Ercília Borges; Vitor Paixão Cruz; Luis Cleiton Callegario; Solano Kaluangila Andrelino; Daniella Pereira da Silva; Danilo José Brito de Arruda

UNIVERSIDADE FEDERAL DO MARANHÃO

BACKGROUND: The challenge of the diagnosis of acute myocardial infarction in women is pertinent in view of the different clinical manifestations of acute myocardial infarction in women and men. In their majority women feel atypical symptoms and the symptoms men call typical (classic). This study aims to clarify this difference of symptoms and, consequently, to contribute to the improvement of the recognition and diagnosis of such pathology by health professionals. CASE DESCRIPTION: During the observation of reality, several topics were proposed, where it was decided to speak of acute myocardial infarction in women. It has been observed that many women are rescued in emergency rooms, hospitals or emergencies with atypical pains of an acute infarction, which are often attributed to fatigue, stress, stomach pain, among other causes. In the theorization of the work, key points were decided: epidemiology, pathophysiology, differences in the clinical manifestation of signs and symptoms of acute myocardial infarction in women and men, factors that lead to late diagnosis, consequences of late diagnosis and treatment. During the stage of the intervention of reality, an Educational Search was proposed in the Environmental Park of the Itapiracó reserve. The action aimed at approaching people (mainly women) and delivering an educational pamphlet. In addition, it was explained about the content of the pamphlet, which contains epidemiological data, risk factors, symptoms, and where to seek help when suspected acute myocardial infarction. CONCLUSION: In view of this problem, it was observed that the intervention proposal was pertinent due to the lack of knowledge of atypical symptoms by the population, besides instructing on the risk factors, for the reduction in the number of cases and mortality.

Keywords: Acute Myocardial Infarction in women, Atypical symptoms, Late diagnosis.

\section{SYSTEMATZZTION OF NURSING ASSISTANCE TO THE ANCHILOSANT SPONDILITE CARRIER}

Samyra Marjoyreanne Alvares da Silva; Clara Costa Fontes; Alana Jessica Pinheiro Oliveira; Aline Barros Silva; Alianna Christine Assunção Pinto; Rosilda Silva Dias

Universidade Federal do Maranhão (UFMA)

BACKGROUND: Ankylosing Spondylitis (AS) affects the cartilaginous joints of the spine and adjacent tissues, lumbar pain is the main symptom. It is most prevalent in men, it is usually diagnosed in the second or third decade of life. The progression of the disease can affect the ankylosis of the entire spine, leading to respiratory compromise. The aim of this study was to report the experience in the application of Systematization of Nursing Care (SAE) to a patient with AD based on Wanda de Aguiar Horta's Basic Human Needs Theory of Nursing Process in 1979. CASE DESCRIPTION: Adult male, 21 years old, brown, natural and resident of Paco do Lumiar-MA. He sought care presenting persistent fever for 15 days, headache, chest pain, polyarthralgia and weight loss. After laboratory and imaging exams, he had a diagnosis of $A D$ presenting complication, diagnosed with pneumonia. From the problems, Nursing Diagnoses with the affected NHBs were raised: psychobiological (immunological, thermal and neurological regulation, oxygenation, nutrition, sleep, hygiene, therapeutics, exercise / physical activity and environment), psychosocial (health education). Among the conducts: check vital signs, weight, administer prescribed medication, evaluate respiratory pattern, perfusion, pain management, make thermal change, help and guide correct decubitus and stretching, guide breathing exercises, walking, diet and water intake, capillary stimulation and on the disease, refer to the nutritionist, dentist and physiotherapy. CONCLUSION: The application of the Nursing Process was of paramount importance in the complete assistance to the patient, provided us with a rich experience, in which the implantation of all stages of the process contributed to the improvement and clarification of the patient, with satisfactory response, resulting in a good prognosis.

Keywords: Nursing, Ankylosing Spondylitis, Nursing Process, Adult Health. 


\section{EMBOLIZATION OF PSEUDO-ANEURISM OF HEPATC ARTERY - CASE \\ REPORT}

João Victor Pimentel de Oliveira; Ciro Bezerra Vieira; Carlos Eduardo Coimbra Melonio; Vanisse Portela Ramos; Lidmar Costa Lima Júnior; Naiara Fonseca Ferreira

Universidade Federal do Maranhão (UFMA) Hospital Universitário da Universidade Federal do Maranhão (HUUFMA)

BACKGROUND: Aneurysms are defined as a localized increase in more than $50 \%$ of normal arterial diameter and occur, among other factors, due to weakening of the muscular layer of the vessel. Visceral aneurysms are rare entities and correspond to $5 \%$ of intra-abdominal aneurysms. Intrahepatic pseudoaneurysms, in this context, are difficult to diagnose and generally result from penetrating abdominal trauma (TAP). The present report seeks to explain one of these rare cases, diagnosed after trauma with firearm perforation (FAP). CASE DESCRIPTION: CJCF, male, 24 years old, a TAP victim with a firearm for 3 months, was treated in a hospital in the city of Humberto de Campos, MA, and was referred to the Barreirinhas hospital. bleeding. After that, as the bleeding was not contained, he was transferred to the Djalma Marques Municipal Hospital, where he underwent computed tomography (CT) of the upper abdomen with contrast, showing liver damage with hepatic artery pseudoaneurysm (HA), remaining hospitalized for 20 days. During hospitalization, the patient was maintained with a high head, venous access saline and bladder catheter delay. He was referred to the University Hospital of the Federal University of Maranhão (HUUFMA) to perform AH embolization. Procedure occurred without intercurrences. On the 1st postoperative day, the patient did not present complaints, accepting the diet. Wound clean and dry wounds without phlogistic signs. Patient was transferred to another hospital, returning to HUUFMA for contrast control CT after 14 days. CONCLUSION: Treatment for splanchnic pseudoaneurysms should be individualized according to the severity, location of the lesion and available methods. Embolization has lower morbidity and mortality compared to surgery and has proved to be an efficient method for the treatment of this patient.

Keywords: Development of pseudoaneurysm, Penetrating hepatic trauma and therapeutic embolization.

THE PREVALENCE OF LEPROSY IN CHILDREN UNDER 15 YEARS IN A HYPERENDEMIC REGION OF MARANHÃO

Isabella Lima Chagas Reis Batista; Heitor Queiroz Torres; Lise Gabrielle Alves Rodrigues dos Santos; Luiz Felipe Bezerra de Sousa; Rodrigo Mitoura Rocha; Iraciane Rodrigues Nascimento Oliveira Universidade Federal do Maranhão (UFMA)

BACKGROUND: Leprosy is a chronic infectious contagious disease. Detection in children younger than 15 years indicates an active and recent transmission of the infection, especially in endemic areas, such as in the Region Tocantina of Maranhão. The objective of this research was to verify the prevalence rate of the disease in the age group and region mentioned above, as well as to determine the results of the current operational classification and clinical forms. METHODS: Observational descriptive study, based on information contained in the Notification of Injury Information System. We included all the cases reported and diagnosed with leprosy residing in the municipalities that make up the 4th Health Regional of mperatriz-MA. The survey was carried out with the help of the population estimate of the Brazilian Institute of Geography and Statistics of 2017. Data were analyzed through SPSS software (version 22). RESULTS: Between 2016 and June 2018, 71 cases of leprosy were diagnosed in children under 15 years of age in the study area, which corresponds to a detection coefficient of 14.23 per 100,000 inhabitants (hyperendemia). Among these, $57.7 \%$ of the cases occurred in males. Regarding the current operational classification, $38 \%$ comprise paucibacillary forms, indeterminate $(19.7 \%$ and tuberculoid (18.3\%), opposed to $61.9 \%$ of the multibacillary forms, with a predominantly dimorphic form (54.9\%), followed by Virchowian (5.6\%) and unclassified (1.4\%). Regarding the age groups, the current operational classification of children under 15 years of age is $9.5 \%$, while in those ove 15 years this percentage is $90.5 \%$, thus there was a significant statistical association $(p=0.005$ ). CONCLUSION: The results confirm the high incidence of leprosy in the region, with a predominance of multibacillary forms, indicating late diagnoses and revealing the lack of control actions of this disorder, requiring a greater active search and expansion of the early diagnosis of the cases.

\section{USE OF THE THERAPEUTIC TOY IN HOSPITALIZED CHILD HEALTH CARE:} CASE REPORT

Mayllane Lays Barbosa

Universidade Federal do Maranhão (UFMA):

BACKGROUND: In the area of pediatrics, the use of therapeutic toy is one of the main strategies used to create a more humanized hospital environment, since it contributes to the reduction of fear and anxiety of the child in relation to the situation experienced, involving it in therapeutics and facilitating their understanding regarding the procedures to be performed by the health professional. This is a qualitative study, with the purpose of reporting the experience of the use of the therapeutic toy during the nursing care to a hospitalized child. CASE DESCRIPTION: The therapeutic toy inserted in the nursing care stimulates the interaction of the child with the environment and favors a greater bond between the child, the family and the team, besides representing an efficient resource for teaching about the practices of care. Through the use of therapeutic toys in the pediatric sector, a number of benefits have been identified, including encouragement for fun and entertainment, age-appropriate educational development through playfulness, and prior demonstration of invasive and / or painful procedures to which the child would be subjected, causing a decrease in stress and anxiety. Given this, not only the evolution in the treatment itself, but an improvement in the care provided by the nursing, bringing together the physical and emotional care of the child. CONCLUSION: The therapeutic toy has been shown to be fundamental in minimizing the impact of hospitalization. It is of great importance the incentive to use the therapeutic toy, since this practice makes possible the provision of a more humanized and welcoming care, being important in the treatment and recovery of the pediatric patients.

\section{Keywords: Pediatrics; Child hospitalized; Nursing care.}

40.

EFFECT OF PERIOPERATVE LIDOCAINE ON POSTOPERATVE ILEUS AND HOSPITAL DISCHARGE

Gustavo Mesquita Bruno; Laís Maria Gaspar Coelho; Caio Márcio Barros de Oliveira; Plínio da Cunha Leal; Ed Carlos Rey Moura; Roclides Castro de Lima

Universidade Federal do Maranhão (UFMA); Hospital São Domingos (HSD)

BACKGROUND: Obesity is a chronic disease and a primary cause of death that can be prevented, which has led to bariatric surgery gaining much space. Postoperative ileus (PI), characterized by nausea, vomiting and abdominal distension, is a common complication of surgery and causes increased hospital admission. Opioids used in the postoperative period are among the causes. Intravenous lidocaine may promote decreased opioid consumption, faster return of bowel function and early discharge. OBJECTIVE: The objective of this study was to evaluate the IP time after laparoscopic gastric bypass with perioperative intravenous lidocaine. METHODS: Prospective, randomized, comparative, double-blind study. Patients were allocated into two groups by lot, and the researche responsible was not aware of the distribution. The sample was defined in 60 patients. The time of elimination of the first flatus and of hospitalization were evaluated. The level of significance was set at $₫ .05$. RESULTS: Twentyone patients were collected and analyzed, 11 females and 10 males, with a mean age of $34.4 \pm 10.8$ years, and predominance of obesity grade 3 and ASA 2. Most patients had comorbidities (hypertension, diabetes) and the mean hospital stay was 48 hours. The group that did not receive lidocaine (9) had mean time of elimination of the first flatus (TF) of $-26 \mathrm{~h}$ and 31 minutes, and $66 \%$ of patients with early discharge criteria (up to $18 \mathrm{~h}$ ). The group receiving lidocaine (12) had TF of $26 \mathrm{~h}$ and 29 minutes and $50 \%$ of patients with early discharge criteria. There was no significant difference between the groups between the groups $(p>0.05)$, as well as the analysis of the criteria for discharge and collateral effects. CONCLUSION: It is not possible to draw definitive conclusions from the study, since only 21 patients were analyzed, but there was no significant difference when comparing the main variables between the two groups of patients ( $p$ ه.05).

Keywords: bariatric, lidocaine, complications

Keywords: Leprosy, Endemic Diseases, Child, Teenager 
41. CORRELATION OF THE COGNITIVE LEVEL BETWEEN ELDERLY AND ELDERLY SEDENTARY PEOPLE IN SÃO LUÍS, MA

Regislene Bomfim de Almeida Brandão; João Florencio Monteiro Neto; Lorenna Batista Braga de Sousa; Mariana de Arruda Frazão; Maria Zali Borges Sousa San Lucas; Lídia Maria Lopes da Silva; Jessica Kerly Garcês Campos

Programa de Ação Integrada para o aposentado (PAl), Associação de mães da Vila Nova, Centro Universitário do Maranhão (CEUMA)

BACKGROUND: The aging process is characterized by impairment in the functioning of all systems, with the CNS being one of the most affected. An important factor that may contribute to the worsening of this cognitive loss is sedentarismo. Estudos suggest that practitioners of physical activity have lower risk of presenting mental disorders than sedentary ones, with a better cognitive processing. The objective of this study was to correlate the cognitive level among elderly women practicing physical activity and sedentary elderly women. METHOD: This is a cross-sectional analytical study. The population was composed of 49 elderly women aged. 60 years old healthy and divided into two groups, the first one composed by active elderly women and the second by sedentary elderly women. The data collection instrument was a pre-structured sociodemographic questionnaire the IPAQ questionnaire for classification of the level of physical activity and the MMSE to evaluate the cognitive level. In the statistical analysis SPSS 18.0 and Mann-Whitney were used in the comparison of age and cognitive level, being significant $p, 0.05$. RESULTS: Among the 49 elderly women, 21 belonged to the sedentary group and 28 to the physical activity group. The median age of the sedentary group was 66 years and the active group was 68. In the comparison of the cognitive level between both groups it was verified that the median of the sedentary group (G2) was 25 , with a minimum of 17 and a maximum of 29 , of the group practicing physical activity (G1) was 27 , with a minimum of 23 and a maximum of 30 with a pvalue of 0.000 . CONCLUSION: The results show that regular practice of physical activity is essential for the maintenance of cognitive processes once a statistically significant difference is found when compared to a sedentary state. The results corroborate with most of the findings in the literature and reinforce the importance of the implantation of physical activities in programs of attention to the elderly, providing quality of life.

Keywords: Cognition, Physical inactivity

\section{PROGRESSIVE OSSIFICANT FIBRODISPLASIA: A CASE REPORT}

Flávia da Conceição Silva Reis; Diego de Sousa Silva; Itallo Alves dos Reis; Marjorie Tarsila Lima Dantas; Willian Marciano da Silva; Fabrício Leocádio Rodrigues de Sousa; Paulo Henrique Balby Couto Universidade Federal do Maranhão (UFMA)

BACKGROUND: Progressive Ossificans Fibrodysplasia (FOP) affects one in 2 million people worldwide. It is a genetic disease of autosomal dominant inheritance that causes gradual ossification of the connective tissue. Thus it constitutes a disabling factor for the patient of the disease, since it limits or extinguishes joint movements. This work intends to show the evolution of the disease, from the first symptoms to the diagnosis and current situation. CASE DESCRIPTION: A 42-year-old female patient, with no relevant family history, had FOP. At age two, he suffered a fall that resulted in arm injury and syncope. He underwent surgery in the cervical region, which, due to procedural error, caused a compromise in the position of the neck, with permanent horizontalization. At age seven, she had falls in an attempt to get back on her feet and was encouraged to move, succeeding. However, due to the advancement of the disease and the aftermath of the surgery, he could not remain in the orthostatic position and began to feel pain. At age 13 , he suffered a fall that injured his leg and caused severe pain that stopped over a period, with the application of injectable painkillers. However, there was consequent extinction of joint movements and the patient stopped walking. During this period, edema appeared through the body, clinodactyly and swelling. At the age of 27, the diagnosis of FOP was confirmed, even in the advanced form, when the body was almost paralyzed. Currently, the treatment aims to slow the progression of the disease and is done with the drug Fopcon and Ibuprofen. Despite the joint limitation caused by FOP, the patient does not present any impairment of respiratory capacity. CONCLUSION: From this report, we can see how late the diagnosis of the disease was, greatly affecting the quality of life of the patient. Studies are needed to understand precisely the progression of the disease and to enable more effective treatments, bringing better quality of life.
Keywords: Fibrodysplasia Progressive Ossificans, Heredity, Joints

\section{WOLF-HIRSCHHORN SYNDROME: A CASE REPORT}

Rebeca Xavier Fontes Cunha; Maria do Perpétuo Socorro Balby Pires; Greta Maria Murad da Costa; Jaysla Ravenna Oliveira Andrade; Hyara Oliveira Barros; Maria Juliana Rodovalho Doriqui

Centro Universitário do Maranhão (CEUMA)

BACKGROUND: Wolf-Hirschhorn Syndrome (WHS) is a chromosomal disorde caused by the deletion in the short arm of chromosome 4, which has a facial appearance characteristic of the "Greek warrior's helmet", delayed growth and development, intellectual disability, hypotonia and seizures. Skeletal abnormalities, congenital heart defects, hearing loss, malformations of the urinary tract and / or brain abnormalities may also occur. The size of the deletion varies between people with WHS, and larger deletions tend to result in more severe characteristics. Most WHS cases are not inherited, but some cases are inherited from a parent who does not have WHS, but carries the gene. It has a rare incidence (1: 50000), in order to compromise the female sex (2: 1). CASE DESCRIPTION: Child, currently 1 year, which presents cleft palate, low weight-stature gain, hypotonia in cheeks, tongue and lips, in which these are thin and with songs facing downwards. Echocardiography revealed an oval fossa blade with wide opening, with FOP E-D flow. It manifests global development delay. It has in the MPLA deletion of the WHSCH genes (exons 5,9,25) TACC3 located in the $4 p 16$ region and, also, the presence of duplication (X3) of the NSD1 gene (exons $2,15,24$ ) located in the $5 q 35$ region, the suspected diagnosis of WHS She presented 2 hospitalizations per respiratory picture and today is accompanied by a multidisciplinary team. CONCLUSION: Due to the diverse clinical manifestations that the patient can present and its similarity with other syndromes, the WHS has a difficult diagnosis, being essential more research about the subject and, also, it is necessary to associate the clinical examination with the genetic research for diagnostic confirmation, thus promoting adequate follow-up for better patient development.

Keywords: Pediatrics, Wolf-Hirschhorn syndrome, Genetics, Chromosomeopathy, Case report.

\section{CERVICAL RADICULOPATHY: CERVICAL ARTIFICIAL DISK}

Maria Arlete da silva Rodrigues; Eustáquio Diego Fabiano Campos.; Joelminstokles Luís da silva de Macêdo Vale; Matheus Nogueira de castro; Maria Santa Ribeiro de Santana; paulo Henrique Silva Bezerra

Centro Universitário do Maranhão (CEUMA)

BACKGROUND: Cervical radiculopathy is characterized by involvement of cervical nerve roots, which are compressed by disc hernias, stenosis of the spinal canal, or trauma to vertebrae and inflammation, generating symptoms such as pain, numbness or tingling, and loss of muscular strength corresponding to the root dermatomes. This occurs because the nerves and their nerve roots are responsible for carrying information between the brain and the extremities of the body, so when they undergo injury, the functions of the areas innervated by the affected roots are compromised. Arthroplasty is one of the surgical treatments used to correct instabilities, caused by diseases that affect the spine. This method consists in implanting an artificial disc in the injured segment, which ensures the maintenance of the natural mobility of the spine and also preserves the disc height. In this case, there is no fusion of vertebrae, as in conventional arthrodesis. Although surgical access is similar, the differential is the maintenance of spinal extension and flexion movements, which is especially important for young patients. CASE DESCRIPTION: the patient was 29 years old, a female patient, a preg - nant right education student with no majo morbid antecedents, who had a left cervicobrachial - gia with involvement of the $c 6$ and $c 7$ dermatomes one year ago. A six-month clinical-conservative treatment was instituted, but there was no response. CONCLUSION: The artificial cervical disc implant was used to correct the patient's symptoms and thus maintain the spinal movements in the long term, considering their age and the need to maintain their quality of life. In addition, the technique has a lower risk of refractory symptoms, thus reducing the need for subsequent surgeries.

Keywords: Radiculopathy, Nervous Root, Arthroplasty. 
EVALUATION OF THE HORMONAL PROFILE OF PATIENTS WITH POLYCYSTIC OVARIAN SYNDROME

Emilly de Jesus Garcia Ataide; Luciane Maria Oliveira Brito; Haissa Oliveira Brito; Aline Maria de Lemos Araujo

Universidade Federal do Maranhão (UFMA)

BACKGROUND: The Polycystic Ovarian Syndrome (PCOS) is the most common endocrinopathy in women of reproductive age, affecting between 6 and $15 \%$ of these women. In Brazil, PCOS presents some regional variations, however its prevalence is estimated in $13 \%$ of the women in the menacme. Its high prevalence has attracted attention in terms of public health. Being a complex endocrinological condition due to its heterogeneity and uncertain etiology, the syndrome is still the main focus of many studies. The objective of this study was to evaluate the hormonal levels of patients with PCOS in comparison with the control group. METHODS: Cross-sectional study of analytical character, accomplished at the Gynecology Outpatient Clinic of the University Hospital Materno Infantil the period from December 2017 to May 2018. Values of Luteinizing Hormone (LH) and Follicle Stimulating Hormone (FSH) of 59 patients in test group and 41 in control group were evaluated. RESULTS: In the group of women with PCOS, LH and FSH had average values, respectively, of $17,22 \mathrm{mUI} / \mathrm{mL}$ and $5,24 \mathrm{mUI} / \mathrm{mL}$. In the group of women without the diagnostic of PCOS, the average values were of $8,16 \mathrm{mUI} / \mathrm{mL}$ and $7,72 \mathrm{mUI} / \mathrm{mL}$, respectively. In the group of PCOS, $96,6 \%$ presented values of the relation LH/FSH above 2, while only $12,2 \%$ in the control group. CONCLUSION: High levels of androgens are a key factor in the pathogenesis of PCOS. Hyperandrogenemia of PCOS is attributed to elevated levels of $\mathrm{LH}$, which positively regulates the production of androgens by theca internal cell of ovarian. This situation is contrasted with a reduction of FSH levels, which results in less estrogen synthesis in the follicle granulosa cell. Therefore, understanding and better characterizing the changes and mechanisms of PCOS becomes a public health issue, because of the prevalence and severity of the implications that may result from the syndrome.

Keywords: Hormonal profile, Polycystic ovarian syndrome, Hyperandrogenemia

\section{TUMORATION OF CECAL APPENDIX: A CASE REPORT}

Laís da Hora Lucena Silva; Maria Augusta Ribeiro Gaspar; Raphae Oliveira Lima Silva; Gabriel Mendes Costa; Waslei Lima Santos; Vitória Gonçalves Alves de Oliveira

Universidade Federal do Maranhão (UFMA)

BACKGROUND: Tumors of the appendix are less frequent, accounting for $0.5 \%$ of intestinal tumors, possibly due to the small size of the organ. Embryologically, the vermiform appendix and the large intestine have the same origin, thus, cases favorable to the appearance of colon tumors may also be associated with those of the appendix. CASE DESCRIPTION: L.R.P.C 51 years old, female, admitted to a regional hospital with a history of abdominal pain in the lower abdomen located in the right iliac fossa. At physical examination, the patient had a inespecific volume in the lower abdomen, was oriented, eupneic, normotensive, acyanotic and afebrile. The initial diagnostic suspicion was of uterine myomatosis. The surgical finding was a vermiform appendix with an exacerbated volume increase, hyperemic, adhered to the cecum and part of the ascending colon with cystic appearance forming at macroscopy. An appendectomy was performed to remove the tumor. The patient evolved well postoperatively, being discharged on the second day of post-surgical. Histopathological examination revealed that the nodule consists of proliferation of spindle cells, without atypia, and is covered by typical squamous epithelium and cecal appendix with reactional lymphoid hyperplasia. CONCLUSION: In general, appendage tumors are rare and are associated with acute appendicitis. However, there may be cases with nonspecific, diverse and even asymptomatic symptoms. Preoperative diagnosis is rare, and is usually curable with surgical treatment, especially if precocious. Whole-colony research is important for detecting synchronous tumors.

Keywords: Tumor of appendix, Appendectomy, Uterine myomatosis.

47. RAMSAY SYNDROME AND SERIOUS FACIAL PARALYSIS: CASE REPORT Leonardo Nascimento de Sousa Batista; Julio Cezar Passos Raminho; Fábio Pimenta de Melo; Guilherme Castro Alves; Rafael Leite Freitas; Fausto Rezende Fernandes: William da Silva Lopes Clínica Othos e Universidade Federal do Maranhão (UFMA)

BACKGROUND: Ramsay-Hunt syndrome is a rare condition that presents with vesicular eruptions in the outer ear, otalgia, facial paralysis and cocleovestibular symptoms due to the reactivation of the herpes zoster virus. This syndrome accounts for $7-16 \%$ of non-traumatic unilatera peripheral facial palsies (PFP). The purpose of this paper is to describe a typical case of this syndrome with sudden and severe presentation of facial paralysis. CASE DESCRIPTION: DSP, male, 24 years old, presented with an emergency with complaints of intense otalgia and pre-auricular pain associated with the appearance of vesicular lesion that evolved to ulcerated lesions in the right ear accompanied by otorrhea, vertigo and emesis 7 days after hospitalization. Associated with this, he reported alteration of the facial mimic on the right. At the examination, the patient showed significant peripheral facial dysfunction in the right hemiface according to the House Brackmann scale (Grade 5), with facial asymmetry at rest, absence of right frontal movement, incomplete closure of the ipsilateral eye and discreet movement of the oral rhyme. Patient denies fever and other comorbidities. In the audiometric examination, deep sensorial hearing loss was observed. At admission, high-dose venous corticosteroid therapy, ceftriaxone antibiotic therapy and then ceftazidine, plus topical acyclovir and ora valaciclovir for 6 weeks were initiated. After improvement of PFP (grade 3) and other symptoms, the patient was discharged and oral corticosteroid and oral valaciclovir were prescribed for 2 weeks. Patient is followed up with speech therapist for facial mimic rehabilitation. CONCLUSION: It is essential to emphasize the importance of early diagnosis of this condition, as well as the monitoring of its evolution, since it is a syndrome that presents multiple manifestations and can lead to significant neuropathic complications, such as facial paralysis, which is a major challenge in practice.

Keywords: Ramsay Hunt Syndrome, Peripheral Facial Paralysis, Herpes Zoster.

\section{CITATON OF RECURRED UPRACUS: A CASE REPORT}

Fredderyco Rodrigues Leao; Jessika Freitas de Souza; Patrícia Alves mangueira

Centro Universitário Tocantinense Presidente Antônio Carlos

BACKGROUND: The persistence of the urachus is an infrequent finding and has clinical importance in the presence of infections, neoplasias or cystic dilatation, the latter complication corresponding to $36 \%$ of the nonobliteration situations of the canal. The urachus cyst is a pathology difficult to diagnose, and usually diagnosed incidentally. Embryologically, the urachus channel extends from the apex of the bladder to the umbilicus, and its closure occurs around the 4th and 5th month of gestation, with the bladder descending into the pelvis during embryonic development, becoming a structure obliterated fibrotic tubular. The objective of this study is to report a case of a patient with recurrent urethral cyst, diagnosed by symptomatology and submitted to surgical management. CASE DESCRIPTION: Patient, male, 22 years old, admitted with severe abdominal pain in the hypogastrium, irradiated to periumbilical region with inflammatory signs, associated with fever and without other systemic alterations. With previous history of urachal cyst surgery 2 years ago. After preoperative exams were requested, the case was performed with surgical reassessment. Excision of all fistulous pathways was performed on the eighth day of hospital stay, with immediate postoperative without intercurrences, with resolution of the symptom, being discharged on the second postoperative day. CONCLUSION: The definitive diagnosis of uracal abnormalities can be made through a good physical examination associated with an appropriate imaging study. Among them, ultrasonography has been presented as the main diagnostic method in this type of disease. The patient's knowledge of the patient's progression by the attending surgeon assisted in the diagnosis of recurrence of urachus cyst, and the cyst itself was difficult to diagnose and, therefore, referred to surgical treatment

Keywords: Cyst of urachus, Relapse, Surgery.

49 HUUFMA

Larissa Rolim de Oliveira Sales; André Melo e Silva de Figueiredo Gustavo Mesquita Bruno; Manuella Goes dos Santos Raposo; Larissa Lopes Alves; Kenneth Anderson Magalhães; José Albuquerque de Figueiredo Neto

Hospital Universitário da Universidade Federal do Maranhão (HUUFMA) 
BACKGROUND: Heart failure (HF) is one of the main causes of hospitalization in adults in Brazil. We searched for evidences of factors already related to $\mathrm{HF}$ that had significant relevance in the clinical outcomes found in patients with IC diagnosis at university hospital of Maranhão. The present study is linked to the research project entitled "BREATHE Extension. OBJECTIVE: To evaluate the epidemiological, clinical and therapeutic profile of patients with HF admitted to HUUFMA. METHODS: Retrospective, descriptive and observational study of HF patients hospitalized at the University Hospital of the Federal University of Maranhão (HUUFMA). Eligibility criteria: diagnosis of $\mathrm{HF}$ in any functional class; both sexes, with no age limit. Data collection included: demographic aspects, medications in use at the time of admission, LVEF up to 6 months before admission, laboratory tests and clinical outcome (discharge or hospital death). RESULTS: We evaluated 169 medical records of patients whose mean age was $58 \pm 18$ years, most of them male (55.6\%); in functional class III or IV (61.5\%); and reduced LVEF (58\%). The main etiologies of HF were: ischemic (33.1\%), hypertensive $(27.2 \%)$, idiopathic or other $(22.5 \%)$ and valvular (11.8\%). Among risk factors and/or comorbidities, $58 \%$ had 3 or more of hypertension, DM, anemia, or coronary artery disease. The most prescribed drugs before admission were beta-blocker (89.5\%), ACEl or ARB (74.3\%), aldosterone antagonist (67.1\%), diuretic $(63.8 \%)$, antiplatelet $(50 \%)$ and Hypolipidemic $(46.7 \%)$. Better hospital outcome was observed with diuretic use. Elevated urea and creatinine values were associated with worse clinical outcomes; respectively, $54.2( \pm 30.7) \mathrm{mg} / \mathrm{dL}$ and $1.47( \pm 1.03) \mathrm{mg} / \mathrm{dL}$. Hyponatremia showed significant significance: $(435 \mathrm{mmol} / \mathrm{L}), 45.5 \%$ of deaths $(p=0.003)$. Intrahospital mortality was $16 \%$. CONCLUSION: The diagnosis has been shown at earlier ages and the treatment does not follow the current guidelines published in its entire

Keywords: Heart Failure/Clinical outcomes; Epidemiology; Comorbidities; Therapy; Breathe Extension Study

\section{ANALYSIS OF OBSTEIRIC FACTORS ASSOCIATED WITH LOW BIRTH WEIGHT IN MARANHÃO}

Débora Priscyla Gigante de Sousa; Larissa Holanda Assunção; Fernanda Santos Magalhaes; Luis Venicius Resplandes Gomes; Gabriel Carvalho de Souza; Leonardo José Castelo Branco Portela Universidade Federal do Maranhão (UFMA); Centro Universitário do Estado do Pará (CESUPA)

BACKGROUND: Low birth weight (LBW) represents a serious public health problem and is highly related to perinatal morbidity and mortality due to biological immaturity and psychic disorders in adult life. And several factors can be determinant for BPN such as the age of the pregnant woman gestational duration, number of prenatal consultations, socioeconomic and educational conditions as well as behavioral conditions. Thus, we highlight the analysis of some obstetric factors to understand the association with low birth weight. METHODS: A cross-sectional descriptive study was carried out through the analysis of the numbers of prenatal consultations, age and duration of gestation related to low birth weight in Maranhão collected in the database of DATASUS (SUS Department of Informatics) in the year 2016. RESULTS: Mothers without prenatal care had $8.91 \%$ of children with LBW while those attended had a frequency of $5.04 \%$. There was a greater number of LBW among the adolescents up to 19 years old with $8.89 \%$, whereas in the age group of 20 to 29 years old it was $6.45 \%$ of low birth weight infants. Regarding the gestational age of delivery, the relationship with LBW up to 36 weeks with $31.78 \%$ was notorious, whereas in the gestational period of 37 to 41 weeks it reduced dramatically to $4.03 \%$ and further reduced to $2.94 \%$ when it reaches 42 weeks or more. CONCLUSION: In this way, the role of prenatal care is highlighted, since it promotes the recognition and management of modifiable conditions, aiding in fetal health and growth. And the importance of improving primary care in Maranhão, a region of low prenatal care in the country, is highlighted, with public policies that increase access to these services, especially in places where there is no effective coverage.

Keywords: Low birth weight, Obstetric factors, Prenatal.

51. METHODOLOGY OF PROLEMATIZATION AS A LEARNING STRATEGY FOR SUICIDE PATENTS

Vitor Paixão Cruz; Maria das Graças de Oliveira Souza Aragão; Luis Cleiton Callegario; Danilo José Brito de Arruda; Ester Ercília Borges; Daniella Pereira da Silva; Solano Kaluangila Andrelino Santiago UNIVERSIDADE FEDERAL DO MARANHÃO (UFMA)
BACKGROUND: Suicide is one of the three main causes of death among people between the ages of 15 and 44, with Brazil among the ten countries with the highest absolute numbers of suicides in the world. This paper aims to report an action proposed by the Axis-integrator (EI), Federal University of Maranhão, on the problem of suicide. RESULTS: The El is based on the methodology of the problematization and has as reference the method of the Maguerez arch, made in five stages (observation of the reality and definition of the problem, key points, theorization, hypotheses of solution and application to reality). The El meetings are mediated by the teachercounselor. The subject of suicide addressed to prevention and intervention was addressed. The key points defined were: concept of suicide, associated diseases, protective and risk factors, epidemiology in Brazil and Maranhão, interventions with patients in crisis and treatment. In the Theorization stage, research was carried out to support the debate from the defined topics and possible interventions. The Reality Intervention was a panel discussion composed of a psychiatrist, an occupational therapist, the teaching staff and a medical student with the theme: "Multiprofessional interventions in potentially suicidal patients." The event was held at the Faculty of Medicine with the target audience of professionals and students in the health area and counted on 50 participants. Participants discussed: how to perceive suicidal attitudes, protective and risk factors, psychological aspects of suicide, how to intervene with the patient and referral CONCLUSION: Patients with mental disorders are at-risk populations and preventive care is essential to intervene in suicide. Therefore, empowering academics through transdisciplinary activities becomes useful in preparing them for dealing with critical patients.

Keywords: Axis-Integrator; Suicide; Prevention.

\section{WOMEN'S KNOWLEDGE ABOUT THE PAPANICOLAOU TEST IN AN} EXTENSION PROGRAM

Ana Josephy da Silva Costa Oliveira; João Victor de Sousa Garcia Saphyra Medeiros Salem; Gelson Farias Arcos Junior; Karen Lopes de Sousa Ferreira; Helaine Dias Guimarães; Graça Maria de Castro Viana

Universidade Federal do Maranhão (UFMA)

BACKGROUND: Cervical cancer (UCC) results from disordered replication of the lining epithelium of the organ. Maranhão has cervical cancer as the most prevalent in the female population, accounting for a gross incidence rate of 30.55 / 100,000 in the state and 41.78 / 100,000 in the capital of São Luís. Thus, the present study aims to evaluate the women's knowledge degree regarding the prevention of cervical cancer. METHODS: A crosssectional, analytical-descriptive, quantitative study of 97 women attended at the Nucleus of Basic and Applied Immunology of the Federal University of Maranhão. Data collection was carried out in the period from May 2016 to June 2017 through the application of a semi-structured questionnaire with information necessary for the study of the topic. It was considered appropriate knowledge: situation where the woman reported having heard about the exam and knew that it was to detect precursor lesions of cervical cancer. The data were analyzed by the statistical program Epi Info 7.2.1.0® RESULTS: Appropriate knowledge about the Papanicolaou Test was $97.4 \%$; other objectives for the examination, such as the investigation of Sexually Transmitted Infections and other pelvic diseases, were reported by them. CONCLUSION: Women's knowledge about cervical cancer prevention was considered adequate despite the myths surrounding the exam. This suggests that the high incidence of the neoplasia in question in the State is due to the search for health care only in the presence of symptoms together with the difficulty of access to services.

Keywords: Uterine Cervical Neoplasms; Knowledge; Perception; Papanicolaou Test.

HEPATO-BILIARY ASCARIASIS IN PATIENTS AT A PRIVATE CLINIC IN SÃO LUÍS: RESULTS

Thalita Martins Bezerra

Centro Universitário do Maranhão; Clínica Gastrocentro.

BACKGROUND: Ascariasis is a human parasitosis produced by the nematode Ascaris lumbricoides, from the Ascarididae family. Its cycle is composed of 2 stages: migratory, from the intestine to the lungs, and chronic in the small intestine. When the anomalous migration of the helminth to the bile ducts occurs, the condition of Hepato-biliary ascariasis (HAB) takes place. The objective of this study was to report the prevalence of HAB in patients at a 
private clinic in the city of São Luís - MA. METHODS: A cross-sectional study was carried out through the review of electronic medical records in a private clinic in the city of São Luís - MA. The data collection was done through the completion of a questionnaire prepared for this research. 18 medical records were analyzed. The most prevalent age group was 21 to 30 years (44.4\%), prevailing in the female sex (66.7\%). Most patients had a family income of ess than the minimum monthly wage $(77.8 \%)$ and lived in urban areas (100\%). RESULTS: All patients presented pain in the upper right quadrant of the abdomen and palpation sensitivity. $H A B$ was evidenced by ultrasonography in $100 \%$ of the cases. The treatment of choice was endoscopic (100\%) and in (88.9\%) the living worm was found located in the common bile duct $(100 \%)$. The use of anthelmintic was performed after Endoscopic Retrograde Cholangiopancreatography (ERCP) in (100\%) of the cases. CONCLUSION: The present study shows the need to track the prevalence of hepato-biliary ascariasis, as well as to describe the socioeconomic and demographic conditions of the patients affected, the therapeutics used and their efficacy.

Keywords: Hepato-biliary ascariasis. Prevalence. Parasitosis.

\section{AMNIOTC BAND SYNDROME: CASE REPORT}

Matheus Sousa Miranda; Priscila Isabelita Veloso da Silva; Ana Valquíria Santos e Gomes; Carolline Evellyng Barbosa Morais; Montanaro Mauricio Pacheco Araújo; Manoel Ilton Sarmento Neto; Palmerindo Antônio Tavares de Mendonça Neto Faculdade Santa Maria (FSM )

BACKGROUND: Amniotic band syndrome is a rare congenital disorder that results in poor formation and can reach any part of the body, resulting in amputation and abortion. It is believed to have etiology in the embryonic matrix, being explained by two theories. The first, extrinsic, proposed by Forpin and Faulkner, according to which the amniotic membrane that makes contact with the chorionic surface is broken causing a grip of this structure with the various body segments of the fetus, leading to the fetal body imprisonment. It is also believed that this process occurs in the firs trimester of gestation. The second, endogenous, created by Streeter is associated with intrauterine bleeding, that is, if bleeding occurs and that blood clumps in the form of a fibrin tract, a part can adhere to the baby and restrict its movement, altering the functionality and aesthetics. It is an exploratory field study of the case report type that aims to describe the framework in question. CASE DESCRIPTION: In this case, the female LMF patient, born at the end of normal delivery, on May 14, 2018, at the Dr. Deodato Cartaxo maternity hospital, in the city of Cajazeiras, PB presented acrossindactyly in both upper and lower limbs and bands of constriction in the left leg, in addition to congenital crooked foot, being thus diagnosed with amniotic flange syndrome at birth. The mother also reported that four ultrasonography, including morphology, were performed during prenatal care, in which no signs of the syndrome were detected. Radiographic examinations detected a syndactyly, caused by a vascular compression in the development of the child, in addition to an equinovular foot. The conduct will be the accomplishment of reconstructive plastic and treatment after the correction of the deformity in the fascia of the leg. CONCLUSION: The treatment of this dysplasia is most often surgical and requires follow-up by a multidisciplinary team.

Keywords: amniotic flange syndrome; newborn; congenital abnormalities

55. NUTRITIONAL STATUS AND FOOD HABITS OF ADOLESCENTS FROM MARANHÃO

Jorge Tadeu Araujo Bezerra; Ingrid Menezes Leite Pereira; Monique Fernandes de Castro: Gabriele Pereira Roch

Faculdade Pitágoras do Maranhão

BACKGROUND: Nutritional status and feeding and nutrition of adolescents are related to chronic diseases in adulthood. The present study aims to characterize the nutritional status and dietary intake of adolescents. METHODS: A cross - sectional study was carried out with 20 students of both sexes, from elementary school to public school in the municipality of Paço do Lumiar, Maranhão. Weight, height and age anthropometric data were collected for Body Mass Index (BMI) according to age (BMI / I) and Height for Age (BMI). The Food Frequency Questionnaire (FFQ) was used to evaluate food consumption and the recommendations of the Nutrition Committee of the American Academy of Pediatrics (2012) and the recommendations of daily portions of the food groups (cereals (65\% eutrophic), the majority of the adolescents presented adequate EN (65\% eutrophic), with a high percentage of animals, (35\%), although the dietary intake was not adequate for all food groups, whereas the diet was not adequate for all food groups, (90\%) consumed sugars and sweets in excess, contrasting with the low consumption of Fruits and Vegetables and legumes, respectively (70\% and $65 \%$ ). the low intake of animal proteins present in meat and eggs and milk and dairy products (both $70 \%$ of inadequacy). CONCLUSIONS: The alteration of EN combined with inadequate dietary practices evidences the urgent need for interventions that reach the internal and external environment of the school and thus contribute to prevent health problems related to food.

Keywords: Adolescence, Nutritional Status, Food Consumption, Food Standards, Food.

56. THE NURSING CARE OF THE PATIENT SUBMITTED AMPUTATION OF THE LOWER LIMB

Milka Borges da Silva; Daniela de Sousa lima; Amanda Barros de Santana

Universidade Federal Do Maranhão (UFMA)

BACKGROUND: Amputation is the term used to define the total or partia withdrawal of a limb, which is a treatment method for several diseases. The objective of this study is to implement the Systematization of Nursing Assistance (SAE) to the elderly patient submitted to amputation of the lower limb. RESULTS: The data collection was based on the history, based on the Wanda Horta theory, then nursing diagnoses were elaborated from the NANDA taxonomy, the results according to the Nursing Results Classification (NOC) ) and interventions through the Classification of Nursing Interventions (NIC) 14 diagnoses were found.These are: Fragile elderly syndrome, Unstable glycemia risk, Impaired transfer ability, Deficit in self-care for bath, Risk of ineffective renal perfusion, Risk of impaired cardiovascular function, Risk of decreased cardiac output, Risk of low chronic self-esteem, Ris with a feeling of impotence, impaired dentition, impaired tissue integrity, risk of infection, risk of pressure injury and acute pain. From the diagnoses raised, nursing results and interventions were established. At the end of the care, the client was discharged. At the time, he received guidelines on locomotion, care in the transfer of the bed to the wheelchair and adequate positioning of the stump to avoid contractures. CONCLUSION: This report confirmed the importance of SAE, favoring a care planning for a patient undergoing surgery amputation of the lower limb, seeing not only disease and other comorbidities, but the person in all its aspects, verifying their basic human needs affected and the care to rehabilitate them according to the steps of the SAE, providing better quality and safety to the client and greater autonomy for professionals.

Keywords: Nursing, amputation, care

\section{CONSUMPTION OF HEALTHY EATING MARKERS BY BRAZILIAN CHILDREN} Louhanne Yacones Lessa Moura; Ana Paula Costa Castro dos Santos; Sueli Ismael Oliveira Da Conceição; Ana Karina Teixeira Da Cunha Franca; Carolina Abreu de Carvalho; Poliana Cristina de Almeida Fonseca

Universidade Federal do Maranhão (UFMA)

BACKGROUND: Food consumption is influenced by several factors such as socioeconomic, cultural, regional, among others. This study aims to analyze the food consumption of Brazilian children, according to race, in order to identify groups in nutritional vulnerability. METHODS: Cross-sectional study with secondary data collected in Sistema de Vigilância Alimentar e Nutricional (SISVAN) [Food and Nutrition Surveillance System] on the consumption of markers of healthy eating. A total of 38,375 Brazilian children aged 5 to 9 years old were enrolled for the year 2016. Filters were selected by macroregions of the country, for all peoples and communities schooling and sex. For the race the data were obtained for blacks and browns (grouped) and white. In order to verify differences in food consumption according to race, the Chi-Square Test was used, being considered a level of significance of 5\%. RESULTS: Among the healthy eating markers, it was observed that the percentage of bean $(83.0 \%)$ and vegetable consumption $(63.0 \%)$ was higher $(p \& .001)$ among white children. The percentage of fruit consumption (97.0\%) was higher among black or brown children ( $\$$ ه.001). The most consumed healthy food among white children was beans, followed by fruits and vegetables in all regions. Among the black or brown color were the fruits, followed by the beans and vegetables. Bean consumption was higher in the Southeast among children of both breeds. 
The highest consumption of fruits by white children occurred in the South region. Among the children of black or brown color the highest consumption was in the North and Northeast regions. As for vegetables, white children consumed more in the South and Southeast, and those of black or brown in the Southeast. CONCLUSION: The food intake of the children differed according to race. The highest consumption of healthy foods was observed among white children, evidencing that black and brown children are at nutritional risk.

Keywords: Racial inequality, Food consumption, Children

58. ASSOCIATION BETWEEN THE NUTRITIONAL STATUS AND SLEEP HABITS IN STREET CORRIDORS

Diogo Matheus Barros Da Silva; Raimunda Silva e Silva; Ester da Silva Caldas; Bruno Luiz Galvão de Miranda; Ezequias Rodrigues Pestana; Marlon Lemos de Araújo

Centro Universitário Leonardo Da Vinci (Uniasselvi), Universidade Federal Do Maranhão (UFMA) Centro Universitário do Maranhão (CEUMA)

The rustic race is one of the fastest growing sport modalities in Brazil and in the world, and for the accomplishment of a good sport performance besides the training there are other factors that influence in this segment being: nutritional status is an associated health condition between consumption and utilization of nutrients already sleep has the function of recovering the physiological and psychological aspects. Verifying their respective importance, this study aims to correlate nutritional status with sleep quality in street corridors. The sample consisted of 12 male amateur players with a mean age of $29.17 \pm 5.64$ years. Nutritional status was verified by Body Mass Index (BMI) $=[$ Weight $(\mathrm{kg}) /$ Stature2 (meters) $]$. Sleep habits were assessed by the Pittsburgh Sleep Quality Index (PSQI-BR). The statistical treatment was performed by BioEstat 5.0 software, performing a descriptive analysis. The Kolmogorov-Smirnov tests and Pearson's correlation were used. Runners are classified as eutrophic, presenting poor sleep quality. There was no correlation between body mass index and sleep quality of the runners. Based on the results obtained, no correlation was found between nutritional status and sleep quality in the corridors.

Keywords: BMI. Quality of sleep. Running

59. BOTHOPICAL OFFICIAL ACCIDENT EVOLVING WITH RENAL INSUFFICIENCY AND COAGULOPATHY: CASE REPORT

Nayanna Láyza Oliveira de Sousa; Elaine Pereira de Andrade; Mirla Kalina Silva dos Santos; Nathalia Farias Pereira; Nícya Maria Paiva Batista Santana; Thais Costa Alves; Francisco Airton Veras de Araújo Júnior

Universidade CEUMA

BACKGROUND: Snakebite accidents represent a serious public health problem in tropical regions due to its high incidence and associated morbidity and mortality. According to the World Health Organization, approximately 2.5 million poisonous snake accidents are reported annually worldwide, resulting in 125,000 deaths. Recent studies estimate that the annual number of snake poisonings may reach 5.5 million, with up to 94,000 deaths. Most ophidian accidents occur in Africa and Asia, and Latin America appears in third place. The botrópico genus, of which the snakes are popularly known as jararacas is the most frequent, with $87.5 \%$ of the cases. Critical cases are uncommon and the most serious complications are acute renal failure (ARF) and blood clotting disorders. CASE DESCRIPTION: J.C.P.C., 40 years old, male, brown, farmer, natural and resident of Vitória do Mearim-MA, victim of botrópico accident for 2 days, used antibotrope serum after 24 hours of the event. It evolved with MID $2+/ 4$ +edema with locker, gingivorragia, abdominal pain, nausea, vomiting, asthenia and generalized myalgia making ambulation difficult. It also presents hematuria associated with oliguria that evolves with anuria. Deny comorbidities. On examination: REG, lucid, oriented, eupneic, acyanotic, tachycardic, febrile, normotensive Respiratory and cardiovascular devices without changes. Abdominal semiglobial, painful to palpation diffusely ecchymosis, edema at extremities: Laboratory tests of admission: $\mathrm{HB}: 14,4$, Ht: 44, Pqt: 30,000 , Leuco: 22,200, Ur: 102, Cr: AST: 710, CPK: 385, BI: 2.5, BD: 0.4, INR: 2.2, Na: $134, K: 3.7$. Ultrasonography of the urinary tract with signs of bilateral acute parenchymal nephropathy. During hospitalization he needed renal replacement therapy. CONCLUSION: In the case described, the patient presented some of the rarer complications such as ARF and coagulation disorder.

\section{Keywords: Botrópico Accident, Acute Renal Failure, Coagulopathy}

\section{ACHALASIA IN CONSEQUENCE OF MEGAESOPHAGUS CHAGASICO IN YOUNG PATIENT}

João Vitor de Oliveira Fernandes Santos; Lukas Pedrosa Duarte; Paulo Afonso de Oliveira Falcão Neto

Universidade Federal do Maranhão (UFMA), Centro Universitário do Maranhão (CEUMA)

BACKGROUND: Achalasia is a motor disease of the esophagus characterized by partial or absent relaxation of the lower esophageal sphincter (EIS) and nonperistaltic contractions in the esophageal body. The primary disease, when it compromises only the esophagus, has no known etiology. The secondary disease, when a systemic disease, causes the motor alteration of the esophagus, being the main consequence the Chagasic megaesophagus. Achalasia caused by Chagas disease, the leading cause in Brazil, affects $7 \%$ to $10 \%$ of people infected with Trypanosoma cruzi. PURPOSE: This study aims to report a case of achalasia secondary to a chagasic megaesophagus in a young patient in the city of São Luís, Maranhão. CASE DESCRIPTION: E.B.S., 29 years old, female, was attended at the outpatient department of Digestive System Surgery at the University Hospital Presidente Dutra with a history of conduction dysphagia with worsening in the last 3 months, presenting a weight loss of 20 kilos. Does not tolerate food, denies fever and other comorbidities. Physical examination: patient malnourished, hydrated, stained, normocardial, eupneic, afebrile and anicteric. Computed tomography without contrast: liquid distention of the thoracic esophagus, discretely thickened wall. At high endoscopic examination: bulky esophageal stasis, moderate intracatosis pangastriste. Serology for Chagas was positive. In the treatment, Heller-Pinotti cardiomyotomy was performed with partial antireflux valve addition. There was a complete solution of achalasia, with the patient being asymptomatic one and a half months after surgery. CONCLUSION: Surgery is recognized as the most effective form of treatment and with longer results, but it is accompanied by some morbidity, although in a low percentage. The one that presents the best result and safety, with a lower rate of complications and a low degree of achalasia, is the Heller-Pinotti Cardiomyotomy.

Keywords: Achalasia, Megaesophagus Chagásico, Cardiomyotomy

\section{NEW HYPODERMOCCLSE PUNCTURE SITE: CASE REPORT}

Rayanne Luiza Tajra Mualem Araújo; João Batista Santos Garcia; Ana Karolina Torres Mendes; Ana Ĺcia Maia e Silva; Hívena Maria Nogueira Lima; Thiago Durans Correia; Thais Alves Albarelli Freire Hospital de Câncer do Maranhão - Tarquínio Lopes Filho; Universidade Federal do Maranhão (UFMA)

BACKGROUND: Hypodermoclisis consists of subcutaneous fluid administration, indicated in clinical practice in the elderly and palliative care. It presents a lower rate of infectious complications and is easy to apply, implying lower costs. CASE DESCRIPTION: JSS, 61 years old, male, previous diagnosis of chronic lymphocytic leukemia, hospitalized in an Oncology Reference Hospital with diffuse exfoliative exfoliative bullous mucosal erythema (suspicion of Stevens-Johnson syndrome). It presented lesions on the face, anterior and posterior thorax, cervical region, upper limbs, abdomen and thighs. He reported generalized, intense and burning pain. The preparation of the dressing increased the intensity of the pain, causing a drop in oxygen saturation with a record of up to $78 \% .3 \mathrm{mg}$ morphine was started subcutaneously, due to the impossibility of puncturing peripheral or central vein. Due to the extension of the lesions, there was no site available for subcutaneous puncture according to sites described in the literature. Thus, hypodermoclisis was performed in the lateral distal region of the left thigh, with patient and family consent. During the hospitalization, two changes were made to the puncture site, in a region contralateral to the first one. Each puncture lasted 7 days. After administration of the first dose, it was observed an important control of pain and oxygen saturation, facilitating the accomplishment of dressings. The patient tolerated hypodermoclisis and morphine bolus administrations without hyperemia or site hardening. He evolved with resolution of the lesions and complete relief of pain, allowing his hospital discharge after 33 days of hospitalization. CONCLUSION: Although the hypodermoclisis is more used in palliative patients and in the elderly, there was benefit of this 
access since the impossibility of another route in the patient. The chosen area was chosen due to the impossibility of puncture in regions described in the literature. Thus, a new puncture site is created that will benefit othe patients.

Keywords: Hypodermoclase; Pain; Palliative care

\section{CASE REPORT OF GUILLAIN BARRÉ SYNDROME AFTER YELOW FEVER VACCINE}

Aneliza de Fátima Figuerêdo lima; Ana Luísa Oliveira da Silva; Letícia Pires Vilanova; Amanda de Oliveira Campêlo; Markus Vinicius Sá Cavalcanti Luz; Daniel Vieira Coimbra; Ana Valéria Santos Pereira de Almeida

Centro Universitário Uninovafapi; Centro Universitário do Maranhão;

BACKGROUND: The yellow fever vaccine is composed of attenuated virus and is contraindicated in immunosuppressed patients. A rare adverse effect to its use is the neurological complication, which may develop sequelae or lead to death. Clinical signs and symptoms usually occur within a month after vaccination and among them fever, headache, encephalitis, meningitis, focal neurological deficit or Guillain Barré syndrome. CASE DESCRIPTION: A 24-year-old male patient started a progressive picture of pain and ascending muscular weakness in LMW, paraesthesia in the 5th left heel and difficulty in walking. It evolved with worsening of the condition and onset of low back pain with irradiation to the posterior aspect of the thighs and ascending muscular paralysis with bilateral Achilles tenderness and bilateral patellar hyperreflexia. With a history of Crohn's Disease 5 years ago, he used Adalimumab, with prior use of Azathioprine for 2 years Preceding the symptoms referred immunization against Yellow Fever a month ago. Electronuromyography showed alterations compatible with early inflammatory demyelinating polyneuropathy, Guillain Barré Syndrome (GBS). He was hospitalized and used Immunoglobulin $400 \mathrm{mg} / \mathrm{kg}$ for 5 days. He currently denies pain or difficulty walking, presenting only mild tremors in MMSS. Complementary Examinations: Liquor-Glucose: 49, Total Proteins: 126, Cytometry: 152mm3, Total Leukocytes: 14\% Polymorphonucleated, $86 \%$ Mononucleated .; MRI of the encephalon: Hypersignal area in FLAIR affecting the cortical-subcortical region around the left pre-central sulcus. Rare hypersignal foci in periventricular white matter and bilateral occipital subcortical. CONCLUSION: It is important the knowledge of the health professionals about the contraindications of vaccination, in the case in question against yellow fever, in order to avoid adverse effects.

Keywords: Vaccine, Immunosuppressed, Guillain Barré

CASE REPORT: COMPLICATION IN GLUTEA REGION AFTER INTRAMUSCULAR ADMINISTRATION OF DICLOFENACO

Isabella Fróes Souza; Érico Brito Cantanhede; Germano Silva Moura; Larissa Balby Costa; Amanda Carvalho e Barbalho; Liza Brenda Corrêa Santos

Centro Universitário do Maranhão (CEUMA)

BACKGROUND: Intramuscular (IM) administration is performed when the disease or property of the drug prevents its use orally. Injections have disadvantages: injury of nerves, muscles and blood vessels. The areas for IM administration are: ventrogluteal region, dorsoglutea, anterolateral aspect of the thigh and deltoid. The application of irritating substances, mechanical injuries and contamination in the execution can cause abscess, which is the inflammation surrounded by a membrane from which the pus is generated, of traumatic or pyogenic origin, characterized by edema, pain heat, erythema. OBIECTIVE: To describe case of abscess due to administration of Diclofenac IM. METHODS: A descriptive study was carried out in a hospital in. RESULTS: KNS, 29 years old, female, brown, merchant. She sought first aid (PS) with myalgia, headache, fever, chills, being diagnosed with virose, medicated with plaslil, dipyrone IM in the left buttock and back in the right buttock (ND). He was discharged, however, on the same day, he started pain in ND, hyperemic gluteus right, edema and pain, returned to PS, diagnosed with infection, prescribed cephalexin. With worsening, she returned to PS, medicated with analgesics and underwent soft tissue ultrasonography, revealing abscess in ND. He was discharged. On the 8th day, he returns to the PS with fever, chills, sweating and scotomas, transferred to hospital and submitted to ND fasciotomy, followed by 2 surgical debridements, total ND muscle loss, within 5 days. Antibiotic therapy: vancomycin $500 \mathrm{mg}$, amikacin $1 \mathrm{~g}$, meropenem $1 \mathrm{~g}$, metronidazole $500 \mathrm{mg}$ and fluconazole $200 \mathrm{mg}$. Therapeutic institution with hyperbaric sessions. After the first session, patient in use of vacuum dressing, evolving with good prognosis. CONCLUSION: IM administration, when incorrect, can cause infection, abscess and major complications. Treatment should eliminate pus and prevent further contamination. Correct diagnosis and approach are essential for better patient prognosis.

Keywords: Intramuscular injection, infection, abscess

64. EPIDEMIOLOGICAL PROFILE OF LEPROSY IN THE STATE OF MARANHÃO

Riellen Vilanova Feitosa; Guilherme Alfredo Wilsen; Ingrid Maria Silva Reis; Rafael de Azevedo Silva; Thais Sant'ana Soares Silva Faculdade Metropolitana da Amazônia(FAMAZ)

BACKGROUND: Leprosy is a chronic/infectious disease caused by the etiological agent Mycobacterium leprae (also called Hansen's Bacillus). It has a slow evolution and several clinical categories such as Indeterminate, Virchowiana or Tuberculoid, besides being treated as paucibacillary or multibacillary. The low rate of detection, followed by a late diagnosis amplifies its magnitude, classifying it as a major public health problem. The objective of this abstract is to analyze the epidemiology of leprosy in the state of Maranhão from 2014 to 2017. METHODS: Epidemiological, retrospective, quantitative study using data from the Department of Informatics of the National Health System (DATASUS) and Epidemiological Bulletins of the Ministry of Health related to the period from 2014 to 2017. RESULTS: Maranhão had a detection rate of $53.91 \%$, with a male / female ratio of 1.3 per 100,000 inhabitants, predominance in males and in the elderly population followed by grade 2 of disability. Cases of leprosy have increased since 2014, with 359 cases (3\%) registered out of a total of 12,105 cases nationwide, to $4,103(34 \%)$ in 2015 , and decreasing in 2017 with 3,548 cases $(29 \%)$, being predominant in the city of São Luís (16\% of cases), followed by Imperatriz with 685 cases. The socio-demographic profile of the population diagnosed by leprosy in Maranhão is predominant in the male sex $(7,045$ cases) as opposed to the female sex, with 5060 . When related to age, a predominance is observed in the age group of 20-79 years with 9,923 cases $(82 \%)$. When analyzing the relationship between the sequelae of leprosy and the clinical forms, there was an increase of 8 cases in 2014 to 47 cases in 2017, possibly related to the predominance of multibacillary forms, Dimorfa and Virchowiana. CONCLUSION: Leprosy in Maranhão has an important epidemiology for the implementation of existing public policies, and should be further studied for the benefit of public health.

Keywords: Epidemiology. Leprosy. Public Health.

\section{ATYPICAL SPONDYLODISCITS: A REPORT CASE}

Carolina Almeida Silva Balluz; Andreia Coimbra Sousa; Francisco Airton Veras de Araújo Júnior Universidade Ceuma

BACKGROUND: Spondylodiscitis is a infection of intervertebral disc and contiguous vertebral bodies. Men are affected in a ratio of 3:14. The transmission path is hematogenous in $70 \%$ cases, and Staphylococcus aureus is the most frequent pathogen. The diagnosis is hard since the clinic is non-specific. Most patients have risk factors like diabetes or kidney failure. MRI is essential because of its greater sensitivity at earlier stages. Spondylodiscitis affects more the lumbar spine, then the thoracic and lastly the cervical. RESULTS: A 72-year-old female patient, with no prior comorbidities, had a chronic low back pain after a mean height fall 2 years ago. In 2 months, she evolved with worsening of back pain, with irradiation to the trapezius. In the neurosurgery department, she underwent a spine MRI that revealed spondylodiscitis in D6 and D7 characterized by fluid in the disc space, with gadolinium uptake and severe spinal edema with expansive extraosseous image, compressing the dural sac and spinal cord. She was hospitalized with an empiric venous antibiotic therapy with Cephalozine and Vancomycin. On the 3rd day of hospitalization, the patient presented crural paraparesis and reduction in level of consciousness and was then transferred to a larger complexity hospital. Admission exams: Leukocytosis: 16,120, elevated CRP, Cr 2,43, Ur 67; discrete leucocyturia, hematuria and frequent bacteria; uroculture and blood cultures were negative. Cranial CT scan was normal. After antibiotic therapy, she underwent a decompressive laminectomy. CONCLUSION: The case reported calls attention to its peculiarities, mainly because it's a patient without comorbidities and of infrequent location. Therefore, it's necessary to consider spondylodiscitis as a differential diagnosis of cases with back pain, undetermined fever and constitutional symptoms. Finally, it was described 
a successful treatment, despite empirical antibiotic therapy and the need for associated surgical treatment.

Keywords: spondylodiscitis, back pain, infection
EPIDEMIOLOGICAL PROFILE OF PATIENTS WITH POST-LEPROSY NEUROPATHY FROM A PAIN CENTER IN SÃO LUÍS

Beatriz Morais Costa; João Batista Santos Garcia; Thiago Alves Rodrigues: Melina Machado de Oliveira; Lara Melo Soares Pinho de Carvalho; Leonardo Victor Galvão Moreira; Luís Eduardo Oliveira Ribeiro

Universidade Federal do Maranhão (UFMA)

BACKGROUND: Leprosy is an infectious disease caused by Mycobacterium leprae, which affects the skin and peripheral nerves, which can lead to neuritis. This study aims to describe the epidemiological profile of patients with post-leprosy neuropathy treated at the Pain House of the University Hospital of UFMA (HUUFMA). METHODS: A cross - sectional study was carried out based on the analysis of the medical records of 20 patients diagnosed with post - leprosy neuropathy and assisted at the Pain House of HUUFMA São Luís - MA, from 2006 to June 2017. age, color / race, schooling, residence, clinical manifestations and treatment of leprosy. RESULTS: Regarding the gender, $60 \%$ of the patients attended were female, and $40 \%$ male. As to age, $15 \%$ of the patients were 31 to 40 years old; $40 \%$ from 41 to 50 years; $20 \%$ from 51 to 60 years; $20 \%$ from 61 to 70 years; and $5 \%$ from 71 to 80 years. Regarding color / race, $65 \%$ of the patients were classified as brown $15 \%$ as white and $15 \%$ as black. In terms of schooling, $5 \%$ of the patients were illiterate; $30 \%$ had incomplete primary education; $15 \%$ had completed elementary education; $5 \%$ incomplete high school: $20 \%$ of high school; and in $25 \%$ of cases there was no record. It was observed that $85 \%$ of the patients were residents in the capital, and $15 \%$, in the other cities of the State of Maranhão. Regarding the clinical picture, $100 \%$ of patients reported pain, $75 \%$ paraesthesia, $70 \%$ hypoesthesia, $50 \%$ had muscle strength reduction, 35\% limb edema, $20 \%$ allodynia and $15 \%$ had frequent cramps. Regarding the treatment of leprosy, it was observed that $75 \%$ of the patients were treated and $25 \%$ did not have a medical record on the treatment. CONCLUSION: Post-leprosy neuropathy is characterized as a frequen condition in the HUUFMA pain service, representing an important clinical condition that affects individuals in the adult and economically active age groups, bringing important damages in their daily lives.

Keywords: peripheral neuropathy, leprosy, pain, epidemiology

\section{PERCEPTION OF THE PROFILE OF PATIENTS IN HEMODIALYSIS IN A} HOSPITAL DE SÃO LUISS, MA

Dina Stefany de Oliveira Moreira; Adriana Leite Martins; Filipe Tamburini Brito; Livia Anniele Sousa Lisboa Universidade Federal do Maranhão (UFMA)

BACKGROUND: Chronic kidney disease (CKD) is characterized by a decrease or progressive loss of kidney function. One of the main methods of treating the disease is hemodialysis, a process capable of removing catabolites from the body and correcting changes in the internal environment through specialized equipment. This therapy leads to significant changes in the patient's lifestyle. From this perspective, a visit to the nephrology center of the Presidente Dutra University Hospital (HUUFMA) was carried out by medical students who made it possible to observe the profile of the patien on hemodialysis. The analysis of this profile has great importance for the maintenance of the dialysate's life, since it is possible to develop strategies that facilitate coping and better coexistence with the disease. RESULTS: Through a round of conversations held in April 2018 between university students and HUUFMA staff, it can be noted that the majority of patients attended at the center were adults from the interior of the state seeking treatment in the capital of Maranhão. An expressive number of children also came from the interior, even among them indigenous. In this context, it was observed that some patients came from cities that had hemodialysis centers, but because of the lack of information, they ended up traveling long distances in search of care. This is a very exhausting affair because their socioeconomic status largely seems to be low income, making it difficult to maintain them outside the home. CONCLUSION: It was noticed that the dialysates need to have more information about the treatment in which they are submitted, so that it can avoid access difficulty and excessive displacement. In addition, analyzing their profile is an important management tool for hemodialysis centers, since the obstacles to effective therapy can be identified and, in this way, strategies to prevent these problems can be created.

Keywords: Chronic renal disease; Hemodialysis, Perception; Profile

\section{EXTENSIVE CERVICAL TRAUMA WITH ZONE I INJURY}

Stefani e Silva Lima; Isabella Caldas Bastos; Daniel de Brito Pontes; Antenor Bezerra Martins Neto; Luana Bogéa Ribeiro; Clara Albino de Alencar: Suzane Katy Rocha Oliveira

Centro Universitário do Maranhão (CEUMA)

BACKGROUND: Penetrating cervical injuries represent $1 \%$ of all trauma. Penetrating cervical trauma, even when punctiform, can lead to injuries with a high risk of morbidity and mortality. Some signs and symptoms are relevant and guide the diagnostic investigation and the immediate surgical exploration, but also this type of trauma can be oligosymptomatic, even with a high complication rate.Zone I comprises the area between an imaginary horizontal line passing through the clavicles and sternal furcula to another line passing over the cricoid cartilage, this area containing structures such as the large vessels at the base of the neck, the trachea, the pulmonary apices, the esophagus and the thoracic duct. CASE DESCRIPTION: A 28-year-old male, a victim of white-arm drilling, admitted to the Municipal Hospital Dialma Marques - Socorrão I, from São Luís-MA brought by SAMU, without cervical immobilization, wandering. On examination: $\mathrm{A}=$ patent airways; $\mathrm{B}=$ eupneic; $\mathrm{C}=$ hemodynamically stable; $\mathrm{D}=$ Glasgow 15 . It presented extensive incised incision, with linear borders, in anterior region - sternocleidomastoidea - and posterior, which extended to the trapezoid musculature, without bone deformities or vascular compromise. Plan suture was performed. The patient had a good prognosis with this approach. CONCLUSION: Cervical puncture wounds need to be carefully evaluated for a better approach decision, even if it is only suture by planes in lesions without compromising noble structures.

Keywords: trauma, cervical, zone 1

\section{TREATMENT OF POST-HERPETIC NEURALGIA IN THE PAIN SERVICE OF} UFMA UNIVERSITY HOSPITAL

Marcelo Ribeiro Mendes Júnior; João Batista Santos Garcia; Thiago Alves Rodrigues; Gabriel Santana Machado; Thais Alves Albarell Freire; Leonardo Victor Galvão Moreira; Luis Eduardo Oliveira Ribeiro Hospital Universitário da Universidade Federal do Maranhão (HUUFMA)

BACKGROUND: Post-herpetic neuralgia (NPH) is defined as pain with neuropathic characteristics maintained for more than three months after resolution of herpes zoster skin manifestations, characterized as a response to the damage suffered by the peripheral nerves during the reactivation of the varicella- zoster. Antidepressants, anticonvulsants, opioids and lidocaine topical are among the first lines of treatment, while radiofrequency and spinal cord stimulation are some of the other therapeutic possibilities currently available. METHODS: A descriptive study was carried out by reviewing the medical records of the patients treated at the chronic pain service of the University Hospital of the Federal University of Maranhão (HUUFMA). We included all the patients diagnosed with NPH whose last consultation occurred between January of 2013 and April of 2017, totaling 12 medical records. The analyzed variables were indicated treatment, response to medication, adherence to treatment and reason for non-adherence of these patients. RESULTS: The drugs most prescribed in the initial treatment were gabapentin $(69.2 \%)$, amitriptyline $(46.2 \%)$, pregabalin $(30.8 \%)$ and topical lidocaine $5 \%(30.8 \%)$. In current treatments, pregabalin $(46.2 \%)$ and amitriptyline $(46.2 \%)$ are the most prescribed, followed by gabapentin (38.5\%) and topical lidocaine $5 \%(30.8 \%)$. Complete or partial improvement was more frequent in patients taking gabapentin (80\%), amitriptyline (67.6\%) and topical lidocaine at 5\% (50\%). No improvement was reported more frequently in those taking pregabalin (50\%) and $5 \%$ lidocaine (50\%). There was no fidelity to treatment in $30.7 \%$ of the cases, of which $25 \%$ were due to adverse effects and another $25 \%$ due to financia conditions. CONCLUSION: This study demonstrates that the drugs used in the HUUFMA pain service follow the main recommendations of the current guidelines. It also shows that the cost of medications can negatively impact adherence to treatment.

Keywords: Pain, Neuralgia, Herpes Zoster 
VISCERAL LEISHMANIASIS - EPIDEMIOLOGICAL PROFILE IN MARANHÃO, PERIOD FROM 2013 TO 2017

Danilo José Brito de Arruda; Dante Rodrigues de Barros Vieira; Pedro Paulo Souza Chaves; Samuel Rodrigues de Morais Cunha Universidade Federal do Maranhão (UFMA)

BACKGROUND: Visceral Leishmaniasis (LV) is a serious public health problem with a wide distribution worldwide. Brazil is responsible for $90 \%$ of the cases of LV registered in Latin America, being considered the third country with the highest occurrence in the world. Maranhão is among the states of the federation with the highest number of LV cases. Therefore, the objective of the present study is to trace the epidemiological profile of visceral leishmaniasis in Maranhão from 2013 to 2017. METHODS: This is a retrospective observational study on the epidemiological profile of visceral leishmaniasis in the state of Maranhão, in the period from 2013 to 2017. The data obtained were collected in the Notification of Injury Information System (SINAN). RESULTS: Maranhão consists of the Brazilian state with the highest number of notifications in the period from 2013 to 2017, accounting for 3439 cases, followed by Minas Gerais with 2676 cases and Ceará with 2362 cases. In relation to sex, in Maranhão, there is a predominance of males with $64.9 \%$ of the cases in females, with $35.1 \%$ of cases. As for race, there was a superiority in the number of cases for the brown race, accounting for $76.28 \%$ of the total, followed by black race $(9.42 \%)$, white race $(8.73 \%)$, indigenous race $(2.58 \%)$, yellow race $(0.81 \%)$, others $(2.18 \%)$. A greater number of cases occurred in the age group of $1-9$ years of age with $40.13 \%$ of the total, followed by the age group of $20-39$ years with $20.62 \%$, less than 1 year of age. age group with $14.45 \%, 40-59$ years with $12.01 \%, 10-19$ years with $7.85 \%, 60-79$ years with $4.5 \%$, over 80 years with $0.35 \%$, and ignored / in white with $0.09 \%$. CONCLUSION: In the state of Maranhão, in the period of 2013-2017, the population most affected by visceral leishmaniasis comprises males, of the brown race and in the age range of 1 to 9 years.

Keywords: Visceral leishmaniasis, Calazar, Maranhão.

71. NURSING DIAGNOSIS IN PATIENTS SUBMITTED TO CARDIAC SURGERIES Alianna Christine Assunção Pinto; Aline Barros Silva; Alana Jéssica Pinheiro Oliveira; Samyra Marjoyreanne Alvares da Silva; Clara Costa Fontes; Santana de Maria Alves de Sousa Universidade Federal do Maranhão (UFMA)

BACKGROUND: Cardiovascular diseases are among the main causes of morbidity and mortality in Brazil. With the technological advances some of these diseases are already treated by minimally invasive procedures, however the majority of patients are still submitted to cardiac surgeries, which in these cases are considered the only form of treatment for the survival of these individuals. In this sense, the objective of this report is to identify nursing diagnoses by the NANDA taxonomy in the perioperative of three cardiac surgeries. RESULTS: In the preoperative period of the pacemaker surgery, 5 diagnoses were identified, one of which was risk: Anxiety, Impaired sleep pattern, Unbalanced nutrition: less than body needs, poor knowledge and risk of infection. In the transoperative period of the Valve Exchange surgery, 8 diagnoses were recorded, 4 of which were at risk: Risk of infection, Risk of perioperative hypothermia, Risk of perioperative positioning injury, Impaired cardiac output risk, Impaired spontaneous ventilation, Impaired tissue integrity, Impaired urinary elimination and Mobility impaired. In the postoperative period of myocardial revascularization surgery, 7 diagnoses were identified, one of which was a risk: Infection risk, Impaired tissue integrity, Impaired transfer ability, Ineffective respiratory pattern, Unbalanced nutrition: less than bodily needs, Ineffective gastrointestinal motility and Pain acute CONCLUSION: In the study, 20 different nursing diagnoses were identified in patients submitted to cardiac surgeries, which were defined based on the care needs in which the patients presented. These results mean the importance of a nursing team attentive to the problems that patients develop or may develop in the perioperative period so that there are timely interventions and minimization of harm to them.

Keywords: Cardiac disorders. Perioperative Care. Nursing Diagnosis

\section{2. \\ COINFECTION BETWEEN HEPATTIS C, KAPOSI'S SARCOMA AND HUMAN} IMMUNODEFICIENCY VIRUS

Fabrício Silva Souza; Mirelly de Souza Rosa; Adriano Rêgo Lima de Medeiros

Hospital São Rafael (HSR), Universidade Federal do Maranhão (UFMA)

BACKGROUND: HIV-positive individuals are at high risk of developing Kaposi's sarcoma (SK), a neoplasm that develops in connective tissue, the associated agent of which is Herpesvirus type 8 (HHV-8). However, a coinfection between the two mentioned diseases and Hepatitis $\mathrm{C}$ virus (HCV) may occur among injecting drug users, since HHV-8 can be transmitted through needle sharing, albeit with less efficiency than HCV or HIV. The present study reports the case of a 55 year old male, black color / race, who sought oncological care for the treatment of cutaneous lesions in the hands and feet due to recurrent Kaposi's sarcoma. It shows to be diagnosed of Human Immunodeficiency Syndrome (AIDS) 7 years ago and of Kaposi Sarcoma (Stage IV) 4 years ago. Refers to previous non-completed 1st, 2nd and 3rd line chemotherapy treatments using antiretroviral therapy irregularly. It states past history of risky sexual behavior and injecting drug use. RESULTS: Normal hemogram. Chest CT scan demonstrated mediastinal, axillary lymphadenomegaly and diffuse bullous emphysema. Computed tomography of the whole abdomen revealed splenomegaly, mesenteric and inguinal lymph node enlargement. Serological test for anti-HCV antibody reagent. It awaits infectology results for the current burden of CD4 lymphocytes and HCV nucleic acids. CONCLUSION: Although Kaposi's sarcoma and hepatitis $\mathrm{C}$ are not proven to be cofactors, it is important to investigate clearly the common means of transmission of both diseases: injecting drug use. Thus, an adequate orientation of patients at risk regarding the pathological potential and the search for rehabilitation of this factor, when necessary, is essential not only for the resolution of the pathological situation, but also to stimulate the prevention of other cases

Keywords: Kaposi's sarcoma, HIV, Hepatitis C

\section{THE PATIENT OF THE 21ST CENTURY AND DR. GOOGLE: A NEW} PERSPECTIVE?

Isadora Yashara Torres Rego; Ana Carine Guedes Pinheiro; Karla Kalene Fernandes Melo; Ricardo Nunes da Silva; Carinina Jucá Guedes Pinheiro

Universidade Federal do Maranhão (UFMA), Universidade Federal do Rio Grande do Norte (UFRN), Universidade Potiguar (UNP).

BACKGROUND: The search for information, mainly about symptoms and diseases, has become a habit. Thus, the term "expert patient" emerges and the concerns that emerge along with it, such as erroneous self-diagnosis and self-reproach. Thus the objective of this work is to evaluate the use of the Internet as a tool in the search for self-knowledge about the diseases and the therapeutic use of the drugs. METHODS: A cross-sectional, quantitative and descriptive study was carried out with 171 high school students from two public schools in Pau dos Ferros, Rio Grande do Norte. A self-answered and anonymous electronic questionnaire was used as a research tool. The data obtained were statistically treated by SPSS software (version 22). Participation in the research was consented through the acceptance of the Informed Consent Term. RESULTS: The average age of the interviewees was $16.6( \pm 1.37)$ years, being $66.9 \%$ female and $42.1 \%$ with monthly family income up to a minimum wage. Of the youngsters, $47.1 \%$ stated that they first search the Internet with source of information about diseases that affect them, later doctors with $32.6 \%$. In addition, $77.3 \%$ stated that their research resulted, at least once, in misdiagnoses about their pathologies. Regarding medicines, $67.4 \%$ stated that they did not take medicines indicated by the Internet; however, the other $32.6 \%$ said they had taken them one or more times; of these, $81.7 \%$ were successful at improving their illness at least once. In addition, $50 \%$ of the interviewees reported that after a medical visit they sought information about prescription drugs, the main reasons being curiosity and lack of medical clarification. CONCLUSION: Although the Internet is an inexhaustible source of information, because users can not filter it correctly, it still does not replace the role of the doctor in the 21st century.

Keywords: Patient expert, Self-medication, Internet, Misdiagnosis. 
74. PROFILE OF THE NEOPLASIA CASES OF THE INTESTINAL GASTROUS TREATMENT: SELF-BASED STUDY

Marcus Vinicius Lindoso Silva Veloso; Déborah Costa Alves; Larissa Machado Neme; João Vitor Sanches Costa; Isabela de Angelles Floro Alonso; Luan Henrique Honório Rocha; Gyl Eanes Barros Silva Universidade Federal do Maranhão (UFMA)

BACKGROUND: Early diagnosis of gastrointestinal tract cancers is one of the most difficult due to the non-specific symptoms. Therefore, they are usually diagnosed in advanced stages, which contributes to high their high mortality. Tumor neoplasm, for example, becomes the third leading cause of death worldwide. The objective of the present study is to describe the profile of gastrointestinal tract tumors in the São Luis-MA death verification service. METHODS: This is a descriptive study, based on the retrospective data of the death certificate of the Death Verification System of São Luís, MA, Brazil, from 2011 to 2017, where epidemiological information and associated factors were collected. The analyzes were performed in STATA 14.0. RESULTS: There were 157 deaths due to neoplasms, and in $47.77 \%$ of the cases the tumor site was in the gastrointestinal tract (GIT). $54.60 \%$ were male. The age ranged from 1 to 104 years (mean of $66.53 \pm 17.46$ years), and a large part $(48.77 \%)$ were older than 70 years. The majority of the deaths were at home $(56.75 \%)$. Among the tumors of TGl, the most affected sites were stomach $(24 \%)$, pancreas $(17,33 \%)$ and colorectal $(14.67 \%)$. The main comorbidity was smoking $(53.85 \%)$. Regarding the complications of the neoplasias that caused the death, the most prevalent were cachexia $(45.61 \%)$, septic shock (22.81\%) and hypovolemic shock (12.28\%) CONCLUSION: This information allows the implementation of a better clinical management, mainly because it is a neoplasm that presents high mortality and late diagnosis in the country. Thus, knowledge about the complications that lead to death may help to avoid the same outcome

Keywords: Autopsy, Neoplasia, Gastrointestinal tract, Profile

\section{PORTRAIT OF INCIDENCE AND MORTALITY OF CHRONIC RHEUMATIC} CARDIOPATHY IN THE NORTHEAST

Ana Luisa Oliveira da Silva; Amanda de Oliveira Campêlo; Letícia Pires Vilanova; Ingrid Leal Araújo; Bruna Afonso dos Santos; Mariana Pinto de Sousa Pacheco; Dennise Carvalho da Silva Centro Universitário Uninovafapi

BACKGROUND: Rheumatic heart disease is a serious non-suppurative complication after infection with Streptococcus pyogenes. Acutely, rheumatic carditis generates lesions that, if untreated, progressively evolve due to the fibrosis process with consequent valve stenosis. Chronic sequelae in the heart valves are called chronic rheumatic heart disease (CRC), which can lead to heart failure and progressive myocardial dysfunction. In Brazil, echocardiographic screening studies performed in schoolchildren in Belo Horizonte (MG), showed a prevalence of around $40 /$ 1,000, which represents an important public health problem. METHODS: An epidemiological, quantitative and retrospective study was carried out in which data on the incidence and mortality of chronic rheumatic heart disease in the Northeast region of Brazil were collected through DATASUS data analysis between 2008 and 2017. The variants analyzed were sex, race, age group and number of deaths and hospitalizations. RESULTS: 21,293 hospitalizations for chronic rheumatic disease were recorded in the northeast region and 4,135 cases were reported in the age group 40-49, followed by 3,967 cases between 30-39 years and 3,420 cases aged 50-59 years. From 2008 to 2017 there is variation between the age groups. Regarding gender, females were the most affected in the period studied corresponding to $58.2 \%(n=12,396)$, with a higher incidence in 2013 with 1,484 females and 1,113 males in the same year. The most affected race was brown with $31.9 \%$ ( $n=6,811$ ) of the cases. There were 1,326 deaths. CONCLUSION: The number of hospitalizations is significant in the northeast, the second largest in relation to the other regions. The CRC profile in the northeastern region is female, between $40-49$ years and brown. There is insufficient data to analyze the character of care and hospitalization to correlate with the causes of death.

Keywords: Rheumatic cardiomyopathy, mortality, hospitalization BRAZIL FROM 2012 TO 2016

Larissa Chaves de Carvalho; Lorena Natali Cardoso Fernandes Caldas; Louise Paola Nichilatti; Consuelo Penha Castro Marques
Universidade Federal do Maranhão (UFMA)

BACKGROUND: External causes are growing and they are one of the most frequent causes of death in the world. This growth occurred from the 80 's, when they came to occupy the second position among the deaths in general. In Brazil, in 2000, there were 118,367 deaths from these causes, which represented $12.5 \%$ of all deaths. Complications for medical and surgical care (CMC) are in Chapter XX of the ICD-10, but studies about them are still scarce. This study proposes to analyze the mortality rate by CMC in 5 regions of Brazil from 2012 to 2016. METHODS: Cross-sectional study, with secondary data from the years 2012 to 2016, from SINAN (National Institute of Public Health Information System). All Brazilian regions were analyzed: North, Northeast, Southeast, South and Center-West. Statistical analysis included Kruskal Wallis tests and Pearson correlation tests ( $\alpha=5 \%)$. RESULTS: The average CMC mortality rate of the regions was: North (NO) 3,14; Northeast (NE) 3.68; Southeast (SE) 2.84; Sul 2.57; Center-West (CO) 2,56 and Brazil - 2,96. The highest national rate was in 2014: 3.07 . In the same year, Northeast was highlighted: 4.11, the highest among all regions. A statistically significant difference was observed between mortality rates among all regions and the general Brazilian total $(p=0.0095)$; there was a correlation between mortality rates: NO and SE $p=0.0196$; NO and south $p$ $=0.0458$; NE and total Brazilian total $p=0.005$; SE and South $p=0.0026$. CONCLUSIONS: There is a high mortality rate due to CMC. The NO and NE lead above the national average, the NE has the lead. CMC death is not related to population numbers, they are due to factors intrinsic to the practice of medicine. Improving medical and surgical care in the NO and NE regions is a major factor in reducing these rates.

Keywords: Mortality, Epidemiology, External Causes

\section{REPORT OF DIAGNOSTIC EXAMINATIONS FOR BREAST CANCER IN MARANHÃO}

Felipe Moraes da Silva; Paula Cristina Alves da Silva; Laine Silva Serra; Mayssa Jane Dias Ribeiro; Thanmyris da Silva Cutrim Universidade Federal do Maranhão (UFMA)

BACKGROUND: Breast cancer constitutes a serious public health problem being the second most common carcinoma in women in Brazil and worldwide. In the Plan of strategic actions for coping with chronic noncommunicable diseases, neoplasia control is present with actions that highlight early detection, using mammography as the main tool in the screening. Thus, the objective of this research is to know the numbers of diagnostic exams for breast cancer performed in Maranhão. METHODOLOGY: This is a quantitative descriptive study, based on secondary data collected from DATASUS / Breast Cancer Information System (SISMAMA) with a cut from January 2010 to April 2014. It was determined as criteria for the obtaining the data, the state of Maranhão and the diagnostic methods represented by cytopathology and mammography. RESULTS: Between January 2010 and April 2014, 253 breast exams were performed in Maranhão, and the city of São Luís presented the highest percentage (79.45\%). Regarding mammography, when the number of exams was evaluated according to the municipality of residence, in the same time interval, we can observe that 86,297 examinations were performed in the state, the capital presented an absolute value of $n=35,716$. In Brazil, data from the National Cancer Institute (INCA) for the biennium 2016-2017, indicate that the estimate of new cases of tumors with primary location in the female breast represent 57,960 women who were affected. CONCLUSION: It is possible to notice the lag of the data available in SISMAMA, which may imply a non-realistic view of the scenario under study. The main function of breast cancer screening is to enable early diagnosis, with less aggressive and more effective treatments, reducing the mortality rate.

\section{Keywords: Breast Cancer, Diagnostic Tests, Mammography}

\section{GASTRIC ULCER IN LESSER CURVATURE CAUSED BY INSTRAGASTRIC BALOON: CASE REPORT \\ Thalita Martins Bezerra}

Centro Universitário do Maranhão; Clínica Gastrocentro.

BACKGROUND: In patients with morbid obesity, the use of an intragastric balloon (IG Balloon) may be the intermediary for a bariatric surgery or a temporary therapeutic conduct to patients that aren't eligible for the surgical procedure. However, complications may occur during use of the IG Balloon - such as a gastric ulcer, which has been noted in about $8 \%$ of 
patients, one of which will be reported below. LANF, 58 years old, male, white, married, resident of São Luís - MA, looked for private service in gastroenterology for the treatment of Class I Obesity two years ago. The patient, who presented a BMI of 35.3, was clarified about the installation procedure for the Spatz IG Balloon, oriented about the liquid-pasty diet and, in case of any discomfort, to follow the prescription's guidelines. 27 days after the procedure, he proceeded with the diet, presented a BMI of 33.0 and related hunger before and after lunch, nausea and vomiting. An Upper Gastrointestinal Endoscopy (EGD) demonstrated remainders of food and a displacement of the IG Balloon, which had been positioned at the gastric fundus. The patient was readvised about diet and medications. RESULTS: Ten months after the gradual volume increase of the IG Balloon - which has now $1,100 \mathrm{ml}$ - patient had a BMI of 25.9. The Balloon was then removed and a different EGD presented an acute ulcer with necrosis in the lesser curvature. After two months of treatment with Tecta and Motilium, patient presented an ulcerated lesion in healing in EGD and evolved well. CONCLUSION: IG Balloon is an effective method in the process of weight loss in patients with morbid obesity. Nausea and vomiting are expected complications and with the proper treatment and follow-up, complications such as ulcers can be avoided.

Keywords: Ulcer. Intragastric balloon. Obesity.

79. CASE REPORT: KEARNS SAYRE SYNDROME

Ana Paula de Castro Ahid; Carolina Almeida Silva Balluz; Maria Juliana Rodovalho Doriqui

Universidade CEUMA; Hospital Infantil Dr. Juvêncio Mattos.

BACKGROUND: Kearns Sayre Syndrome (KSS) is caused by a deletion in mitochondrial DNA (mtDNA), which usually occurs sporadically with prevalence of 1.6 per 100000 . It is characterized by starting before 20 years old, progressive external ophthalmoplegia and retinitis pigmentosa, and may also affect the cardiac, nervous and endocrine systems. This case report aims to contribute to early diagnosis and morbidity and mortality reduction. RESULTS: male patient, 11 years old, with astigmatism, bilatera palpebral ptosis, short stature, tremors, fatigue after exercise, total atrioventricular block and bilateral deafness. Non-consanguineous parent and no personal or family background. At the clinical examination: bilatera palpebral ptosis, cutis marmorata, ataxic gait, climbs stairs with support, weight and height inferior to the age standarts, with no other alterations. Complementary tests: neonatal screening indicated just sickle cell trait. Brain magnetic resonance imaging showed lesions on pale globes, substantia nigra and pontine tegmentum, cerebellar white matter alteration Electroneuromyography showed initial myopathy; echocardiogram showed mitral prolapse with mild reflux; audiometry revealed right mixed hearing loss and left conductive hearing loss; fundoscopy showed atrophy area adjacent to the inferior temporal vascular arcade and perimacular area. I the CGH array no pathogenic chromosomal segments were detected and molecular analysis detected 6.8Mb deletion in the mtDNA in heteroplasmy in the MT-ATP6 gene. CONCLUSION: The KSS diagnosis can be established by clinic, genetic and imaging studies, in general, and the muscle biopsy is dismissed. There is no specific treatment, however, it's recomended to avoid substances that are toxic to the mithocondrial respiratory chain. Although coenzyme Q10and L-carnitine are commonly employed, furthe studies are needed. The genetic counseling and a regular multiprofessional follow-up are fundamental.

Keywords: Kearns Sayre Syndrome, Deletion of Mitochondrial DNA Progressive External Ophthalmoplegia, Pigmentary Retinosis, Hearing Loss.

\section{CLINICAL STUDY OF PRUNE BEUY SYNDROME: A CASE REPORT}

Ronald Mendes Silva; Maria de Jesus Torres Pacheco; Amanda Pereira Carvalho; Talyta Garcia da Silva Ribeiro; Tárcia Heliny Nojoza Mendonça Gonçalves; Thalisson Paulo Sousa Madeira; Israe Amâncio Mendes

Universidade Federal do Maranhão (UFMA)

BACKGROUND: Prune Belly syndrome (SPB) or abdomen in prune is a rare congenital condition characterized by the triad: agenesis, deficiency or hypoplasia of abdominal wall muscles, bilateral cryptorchidism and urinary tract abnormalities. With no defined etiology, it affects more males and presents an incidence of $1: 35,000$ to $1: 50,000$ live births, according to Guerrero et al. In addition, other malformations may occur, such as: heart disease, pulmonary hypoplasia, orthopedic and musculoskeletal disorders
CASE DESCRIPTION: Patient M.V.D.S.S, male, 1 year and 6 months, brown mother of 21 years, gesta II for II (n) abortion zero. During gestation, prenatal care was started late, gestational ultrasonography revealed increased fetal kidneys (bilateral hydronephrosis) and megabexiga, suggestive of PBS. She was born of normal term birth and weight of 3.040g; after birth, was referred to the Dr. Juvêncio Mattos Children's Hospital (São Luís-MA) with renal insufficiency, being submitted to peritoneal dialysis. It presents with complete vaccination situation, tests of neonatal screening carried out and normal physiological elimination. At physical examination: bilateral cryptorchidism, thin and wrinkled abdominal wall. During the hospitalizations, urinary tract ultrasonography and renal scintigraphy were also performed, which corroborated the clinical suspicion of SPB. Over a year, he had been hospitalized for recurrent urinary tract infections, developing with hydroelectrolytic disorders, metabolic acidosis, hypovolemia and sepsis, requiring hospitalization in a pediatric ICU. After clinical improvement, he was discharged from hospital and was referred for outpatient follow-up with a nephrologist and pediatrician. CONCLUSION: In SPB survival depends on the degree of anatomic and functional impairment of the involved organs. However, rigid prenatal care, early intervention and multiprofessional care can guarantee a better prognosis for the child.

Keywords: Prune Belly, malformations, cryptorchidism, abdominal wall

81. EPIDEMIOLOGICAL PROFILE OF LEPROSY CASES IN THE STATE OF MARANHÃO IN THE YEAR OF 2017

Reivax Silva Do Carmo; Marina Santiago Frias; Bruna Caroline Silva Falcão; Pabline Medeiros Verzaro; Julyana Corrêa Silva Faculdade Estácio São Luís

BACKGROUND: Leprosy is a chronic disease of compulsive notification, infectious and contagious, having as its etiological agent mycobacterium leprae, it has high infectivity and low pathogenicity, affecting skin and peripheral nerves, ranging from simple symptoms to major disabilities. The mechanism of transmission is based on the direct contact of a healthy person with a bacilliferous patient through the upper airways. The present article aims to raise the epidemiological profile of leprosy in the state of maranhão in the year 2017. METHODS: This is a quantitative research carried out in the databases of the Department of Informatics of the Brazilian Unified Health System (DATASUS). Based on the state of maranhão, the year of notification, sex, and the operational classification of leprosy. At the end the data were tabulated and presented in exact numbers. In the case of public domain data with unrestricted access to said research is exempt from analysis in ethics committee. RESULTS: There were 4067 cases of leprosy in the state of Maranhão in 2017, of which 2336 were women and 1731 were men, with ages ranging from 1 to 80 years or more, the highest prevalence among those aged 30 to 39 years. What draws attention are the case numbers among children in the age group of 1 to 14 years and a total of 383 cases. Regarding the operational classification, 825 were paucibacillary and 3240 multibacillary. CONCLUSION: We can conclude that leprosy still registers a large number of cases in the Brazilian population. Being the male, the age group of 30 to 39 years, and the multibacillary form the largest number of cases. Thus, we can conclude that even with outpatient treatment policies, control campaigns and guidelines, such as the institution of polychemotherapy and early diagnosis actions, leprosy still presents a serious problem as a major public health challenge.

Keywords: Leprosy, Epidemiology, Public Health.

82.

\section{RESEARCH DESIGN OF VISUAL ACUITY DECREASE IN PEDIATRIC PATIENT} DUE TO ZIKA

Beatriz de Sá Mota; Thaíse Maria de Morais Carvalho; Ada Cristina Mendes Freitas; Jorgeanne Clarindo Veloso Franco; Raissa Ribeiro de Queiroz Chaves; Rayssa Mayara Rodrigues de Souza; Maria do Perpétuo Socorro Balby Pires

Centro Universitário do Maranhão (CEUMA)

BACKGROUND: This paper describes the case of a pediatric patient with decreased visual acuity whose mother reports a diagnosis of zika during pregnancy. Zika virus is considered an emergent arbovirose with possible permanent clinical repercussions in the central nervous system, affecting neonates whose mothers were infected during pregnancy. An early followup of pregnant women through prenatal care is essential for both initia diagnosis and to alert about the risks and complications of this disease in order to effectively carry out the prevention. CASE DESCRIPTION: IWFP, male 
White color; 1 year and 11 months; from São José de Ribamar - MA. Mother sought a referral service in Neurodevelopment, Assistance and Rehabilitation of Children (Ninar) with an 11-month-old infant, reporting suspected blindness. During anamnesis, she reported late prenatal onset and Zika's history in the first trimester of gestation. Exclusive breastfeeding up to six months. At physical examination he presented implantation of normal ears, decreased babinski reflex, normal eye test, normal plantar and palmar grip. For a better investigation, he was referred to the ophthalmologist and returned to the pediatric consultation with an ophthalmological opinion of nystagmus, strabismus, optic nerve hypoplasia and diagnosis of partial visual acuity impairment. CONCLUSION: The Brazilian Ministry of Health was a pioneer in recognizing the implication of the ZIKA virus in the occurrence of the microcephaly outbreak, an unprecedented association of the scientific literature. Despite the significant expansion of scientific publications on the subject since 2015, many unanswered questions remain. Thus, the work aims to make public one more possible consequence of arboviruses, and to alert society to the implications of inadequate prenatal care within this context.

Keywords: Zika Virus, Optic Nerve Hypoplasia, Nistagm

\section{DISSECTING ANEURYSM OF THORACIC AORTA BY BLUNT TRAUMA}

Gleyce Vidal Cutrim; Chelsea Magalhães Tavares da Silva; Tiago Rodrigues Cavalcante

Centro Universitário do Maranhão (CEUMA)

BACKGROUND: Aneurysm is defined as a localized dilatation of a vessel. In the dissection of the aorta, there is a laceration of the intima, exposing the middle layer, and the separation of these layers, due to the infiltration of blood into a false lumen with the formation of a hematoma. It is a rare, usually fatal, disease that usually affects older men. Among the main causes we have arterial hypertension and iatrogenic traumas, which usually occur in the ascending aorta with clinical picture of chest pain and sweating, making confusion in the differential diagnosis with acute myocardial infarction. This study aims to address a clinical case of dissecting thoracic aortic aneurysm due to automobile trauma. CASE DESCRIPTION: Patient RLRA, male, 43 years old, victim of car-truck collision on 04/20/18, with history of chest pain associated with dyspnea. Hemodynamically stable, flaccid abdomen, no visceromegalias. He reported being hypertensive. Chest X-ray revealed chest fracture of right costal arches, left pleural effusion with pulmonary atelectasis, and widening of the mediastinum. The electrocardiogram did not change. When a computerized angiography of the abdominal and thoracic aorta was requested, the latter revealed intimate flaps in the transition from the aortic arch to the proximal segment of the descending aorta, $2 \mathrm{~cm}$ away from the left subclavian artery (Stanford B). The patient was hospitalized and on $05 / 05 / 18$, endovascular correction of thoracic aortic dissection with a Zenith $22 \times 115 \mathrm{~mm}$ endoprosthesis was performed. Control arteriography confirmed the absence of intercurrences in the postoperative period and the patient was referred to the ICU using Profenid and Cephalotin. He was discharged from hospital in the 2 nd postoperative period. CONCLUSION: Aortic dissecting aneurysm is not a common condition, but it should be considered as a possibility in patients with chest pain in the emergency department, since the evolution without treatment has a high potential for lethality.

Keywords: Dissecting aneurysm, Dilation, Aorta

FLOPPY EYELID SYNDROME

Amanda Araújo de Sousa; Acácia Pinto Morais; Illana Catharine de Araújo Martins; Juliana Ferreira Silva Moraes; Lianna Paula Guterres Corrêa; Luma Solidade Barreto; Adriana Leite Xavier Bertrand Centro Universitário do Maranhão (CEUMA); Universidade Federal do Maranhão (UFMA); Universidade de São Paulo (USP)

BACKGROUND: Described in 1981 by Culbertson and Ostler, great looseness and distensibility of the upper eyelid that is easily everted with slight digital traction. The tarsus is extremely malleable, with loss in usual tonicity, folding over itself. The lateral cantal tendon may be elongated. More frequent in middle-aged men, with no predilection for race. 5-15\% associated with sleep apnea or collagen diseases and obesity. Generally bilateral, but can be isolated in one of the eyelids. It can affect even the lower ones. It can lead to ectropion, ciliary ptosis, tarsal ulcers, meibomian gland dysfunction, palpebral ptosis or blepharocalase. Spontaneous, nocturnal, palpebral eversion with direct eye contact with sheets and pillowcases has already been well documented by most authors. CASE DESCRIPTION: A 57-year-old male, male, from Buriticupu-MA, referred by a colleague from the region with a diagnosis of bilateral ectropion. He had been referring for more than 40 years to red eye, photosensitivity, mucus secretion, foreign body sensation, dryness and visual haze worsened five years ago. At the ophthalmologic examination: bilateral cataract, severe ptosis, lower ectropion, normal intraocular pressure, unopposed funduscopy, conjunctival papillae, conjunctival hyperemia, mucoid secretion, visual acuity of $20 / 60$ and $20 / 40$ with correction in right and left eyes, respectively. Presence of xanthelasma on the right. CONCLUSION: Although not classified as common, it is not so rare and should always be considered in the presence of chronic ocular inflammation refractory to previous treatment, in which other causes have already been excluded.

\section{Keywords: Eyelid, Distensibility, Eversion, Ectropion, Blepharocálase}

\section{EVOLUTION OF ALZHEIMER'S M ORTALITY IN THE NORTHEAST COMPARED} TO OTHER COUNTRY REGIONS

Artur Costa Cruz; Eder Soares de Alencar; Debora Fontenele Alves; Andreza Brandão Theophilo Lima; Lya de Oliveira Coelho; João Victor Muniz Vasconcelos; Amanda Oliveira Silva

Universidade Federal do Ceará (UFC)

BACKGROUND: Alzheimer's disease is one of the most serious neuropathologies affecting the elderly population of the country, since it is quite common and causes great mental limitations, affecting the social and family life of the affected person, and in more extreme cases leading to death. The objective of this study is to compare the evolution of Alzheimer's mortality in the Northeast with that of the other Brazilian regions, from 2011 to 2015. METHODS: This is an ecological and analytical study, in which the data collection was done in the System (TABNET) using the vital statistics tab in the general mortality section. In the line option the region variable was searched; in the content option, deaths per residence were chosen; in the available selection option, CID-BR-10 Alzheimer's disease was chosen and the years 2011 to 2015 were chosen. RESULTS: The annual deaths caused by this disease increased during this period, a growth of $85.10 \%$ in the Northeast, $103,70 \%$ in the North, $34.34 \%$ in the Southeast, $37.52 \%$ in the South and $62.58 \%$ in the Midwest. There was also an increase in the ratio between Alzheimer's deaths and total deaths by region, with a growth of $67.27 \%$ in the Northeast, $75.00 \%$ in the North, $26.72 \%$ in the Southeast $32.30 \%$ in the South and $45.68 \%$ in the Midwest. CONCLUSION: In all regions, the number of deaths due to Alzheimer's disease has increased every year. Thus, the growth of the ratio between death by disease and the total number of deaths shows that the increase in deaths is not only a consequence of population growth, but also of the aging population and the progression of this disease in the elderly. This, in turn, demands more public attention for this population, especially in the Northeast, which is the second region in which there is more growth of Alzheimer's deaths.

Keywords: Epidemiology; Alzheimer; Deaths;

\section{BILATERAL EXTRADURAL HAEMATOMA BY INJURY OF UPPER SAGITTAL} SINUS

Kevin Waquim Pessoa Carvalho; Ellano de Brito Pontes; Wallace de Almeida Alves; Daniel de Brito Pontes; Isabella Caldas Bastos; Antenor Bezerra Martins Neto; Mateus Guimarães Benvindo UFMA, UNICEUMA Y HOSPITAL JOÃO XXIII

BACKGROUND: Extradural hematoma (HED) is characterized by bleeding within spaces around the brain and spinal cord. HED is uncommon, but it is a serious complication of Cranial Brain Trauma (TBI). This is found in 1 to $4 \%$ of cases of TBI. It has a higher incidence in adolescents and young adults, mainly related to car accidents and falls. CASE DESCRIPTION: Patient of $41 \mathrm{a}$, male, with a report of fall of height for more than $12 \mathrm{~h}$, found unconscious at home. He was admitted to the intubated emergency room, presenting nonspecific withdrawal to the painful stimulus in the 4 limbs, and without ocular opening (ECG $6 T$ - AO 1, RV IT, RM 4), with anisocoric pupils (Right Dysrhythmia). Computed tomography of the skull was performed, evidencing an extensive bilateral frontal HED. Patient was then referred to the surgical block and submitted to craniotomy for drainage of the hematoma. During the surgical procedure, it was decided to keep part of the hematoma located above the superior sagittal sinus, fill the subdura space with saline and anchor the dura mater, filling the extradural space with hemostatic foam (Gelfoam). After 11 days of ICU stay, the patient was 
unable to protect the airway. Therefore, he underwent tracheostomy. Patient was placed in the ward, in the process of decannulation, with spontaneous ocular opening, obeying commands, without appendicular deficits and awaiting further evaluations. CONCLUSION: Bilateral traumatic frontal HED resulting from sagittal sinus lesion is rare. In such cases, surgical evacuation is urgent and necessary.

Keywords: Extradural hematoma, Cranioencephalic trauma, Upper sagittal sinus lesion

\section{NORWEGIAN SCABIES - AN EXUBERANT CASE WITH UNFAVORABLE} DEVELOPMENT.

Thállisso Martins Da Silva Rodrigues; Taciana Gabrielle Pinheiro De Moura Carvalho; Leonardo Bezerra Maciel; Nicolle Matos Costa; Thiago Vieira Santos; Brenna Carolina Sousa Braga; Walter Da Costa Baldez Neto

Universidade Federal Do Maranhão (UFMA). Hospital Geral De Alto Alegre Do Maranhão.

BACKGROUND: Human scabies affects all social classes and different races throughout the world. It is highly contagious. Norwegian scabies is a rare and severe form of infestation by Sarcoptes scabiei var. hominis characterized by a large number of parasites on the skin. It is commonly seen in immunocompromised patients, including AIDS, but it also occurs in institutionalized patients with neurological disorders. The lesions are crusty, thick, grayish, and extend beyond Hebra's circle, affecting the scalp, palms of the hands, plantar and subungual regions. Severe erythroderma may be present on more than $90 \%$ of the body surface, with erythema and severe desquamation. CASE DESCRIPTION: A case of a 64-year-old man, born and living in Alto Alegre-MA, who complained of pruritus in the body for one year with worsening in the last month, in addition to fever and fatigue one week ago. Physical examination shows malnourishment, erythrodermic with thick and diffuse scabs all over the body, including face, hands, feet and nails. Based on the Norwegian scabies hypothesis, material was collected for direct examination and the diagnosis confirmed. Ivermectin $9 \mathrm{mg}$ Ceftriaxone and Oxacillin were started and serologies were requested, which were positive for hepatitis $C$ and syphilis, but the patient evaded. Five days later, he was admitted again with severe sepsis, requiring orotracheal intubation and was transferred to Getúlio Vargas Hospital in São Luís, where we lost the follow-up. CONCLUSION: it is important to note that late diagnosis and treatment of Norwegian scabies can lead to severe conditions such as this, in which the patient reached at a very advanced stage, malnourished and with secondary infection, being necessary his transfer to a hospital with Intensive Care Unit.

Keywords: Norwegian scabies, Parasitic diseases, Malnutrition

\section{EPIDEMIOLOGICAL PROFILE OF SEPTICEMIA ODPES IN CHIDREN IN} MARANHÃO BY REGIME

Ana Luíza Morais Batista; Douglas Silva de Oliveira; Artur Costa Cruz; Matheus Sales Ferreira Lima; Gustavo Pessoa Pinto; Hellen Gomes Fernandes: Camila Teles Novais

Universidade Federal do Ceara (UFC)

BACKGROUND: Septicemia is characterized by a complex and generalized reaction of the immune system caused by the presence of microorganisms and their toxins in the bloodstream, being one of the main causes of death in children in Brazil. The objective of this study is to create an epidemiological profile of the deaths caused by septicemia in children, making a parallel between the public and private health system in Maranhão, in order to contribute to the reduction of these pictures. METHODS: This is an ecological and descriptive study, using data from the Health Information System (TABNET) provided by the Department of Informatics of the Brazilian National Health System (DATASUS) from January 2011 to April 2018. state of Maranhão and obtained data from the Epidemiological and Morbidities tab. In the "Line" option, Age Range 1 was selected, already in the "Column" option, Regime was selected and in the "Content" tab, Deaths. In the "ICD-10 Morbidities" option, Septicemia was selected and the age range was between 0 and 14 years. RESULTS: 502 deaths were recorded, $53.58 \%$ of this total in Public Regime, $7.37 \%$ in Private Regime and $39 \%$ were ignored. Among the Public Regime, $63.94 \%$ of the deaths occurred in children under one year, $16.72 \%$ between 1 and 4 years, $8.55 \%$ between 5 and 9 years and $10.78 \%$ between 10 and 14 years. In Private, $78.37 \%$ in children under one year, $13.51 \%$ between 1 and 4 years,
$5.4 \%$ between 5 and 9 years, and, finally, $2.7 \%$ between 10 and 14 years. $O$ those ignored, $74.48 \%$ were under one year old, $14.79 \%$ were between 1 and 4 years old, $5.61 \%$ were between 5 and 9 years old, and $5.1 \%$ were between 10 and 14 years old. CONCLUSION: It is concluded, therefore, that the number of deaths of children between 0 and 14 years, in Maranhão, is significant, especially in the public health network, being more expressive in individuals younger than one year. From the study data, it is evident, therefore, the need to improve health services, in order to mitigate this scenario.

Keywords: Epidemiological profile, Septicemia, Deaths

89. PALATO INJURY INJURY AND NASAL ASA BY PARACOCCIDIODOMYCOSIS João Víctor Pacheco Florentino; Ana Clara Sampaio Lima Vasconcelos; Rayla Bezerra Rocha; Wesley Costa Barros; José Helder Vasconcelos Filho

Centro Universitário do Maranhão (CEUMA)

BACKGROUND: Paracoccidiodomycosis (PHC) is a systemic mycosis caused by the thermo-dimorphic fungus Paracoccidioides brasiliensis, being the age group more affected from 30 to 50 years, preferentially reaching the male sex. It has chronic clinical forms - predominant in adults - and acute or subacute - in children and adolescents. When undiagnosed and properly treated, it can lead to severe and lethal disseminated forms involving the lungs, integument, lymph nodes, spleen, liver and lymphoid organs of the digestive tract. CASE DESCRIPTION: BM, male, 63 years, faiodermo, farmer, natural and resident of Cedral-MA. He was referred to a reference hospital in oncology in the city of São Luís-MA, with lesion of inflammatory aspect of soft palate and left nasal wing suggestive of tegumentary leishmaniasis, with IgG positive for Leishmania.Laboratory tests requested prior to biopsy revealed eosinophilia $\left(1,369.80 / \mathrm{mm}^{2}\right)$, present in granulomatous reactions, such as the patient's. The patient was submitted to skin biopsy of the back of the nose and soft palate that presented inconclusive. A second biopsy was performed 3 months later and the patient progressed well. The material was sent for histopathological analysis with dorsal skin of brownish color, elliptical form and firm consistency, measuring 1.4 to $0.6 \mathrm{~cm}$; and soft palate with irregular fragment of brownish color, firm and elastic consistency, measuring $1.4 \times 0.6 \mathrm{~cm}$. The final diagnosis by histopathological report was paracoccidioidomycosis, presenting chronic granulomatous inflammatory process, associated with fungal structures compatible with Paracoccidioides brasiliensis. CONCLUSION: This infection is an important public health problem due to its high limiting potential and the number of early deaths caused, especially in specific social strata, such as rural workers, who have access to restricted health, making it difficult to diagnose early.

Keywords: Ringworm, Paracoccidiodomycosis, Leishmaniasis, nasal wing, soft palate

\section{ACUTE CONTROL IN ARNOLD-CHIARI SYNDROME: A CASE REPORT}

Marcelo Serley Mondego Macedo Silva, Renata Coelho Chaves Gaspar, João Batista Santos Garcia, Thiago Alves Rodrigues, José Rodolfo Teixeira da Cunha, Luiz Nycollas Carneiro Oliveira e Abner Oliveira Freire Universidade Federal do Maranhão (UFMA)

BACKGROUND: Arnold-Chiari I malformation is a rare, difficult to diagnose clinically unspecific and sporadic / congenital severe condition in which there are herniated cerebellar structures that may or may not involve the brainstem. It is characterized by: headache, progressive loss of strength, dizziness, dysphagia, paresthesia, gait ataxia and visual and respiratory changes. CASE DESCRIPTION: ECGL, mechanic, 38 years old, brown, ex-smoker for 6 years. In July 2009, she reported progressive cervicalgia with irradiation for $3^{\circ} / 4^{\circ} \mathrm{MSD}$, left unilateral headache and paresthetic lombociatalgia for MMII for more than 10 years. He denied chronic diseases. To the exams: Lasegue + , muscle strength $4+/ 5+$ in MMSS and RNM informing Sd. of Arnold-Chiari I, associated with vertebro-basilar invagination. After surgical treatment of herniation in 2010, returned to the Pain Service with worsening and headache change, which became bilateral, in tightness and shock. Started codeine $30 \mathrm{mg} 6 / 6 \mathrm{~h}$, Miosan $10 \mathrm{mg}$ at night, physical therapy and acupuncture, however with limitations. After addition of methadone $10 \mathrm{mg}$ 12 / $12 \mathrm{~h}$ and $25 \mathrm{mg}$ amitriptyline at night, there was moderate improvement of headache and good adherence to treatment. One half-year after adjusting for methadone in $10 \mathrm{mg}$ of $8 / 8 \mathrm{~h}$, there was a reduction in the frequencies of low back pain and a significant improvement in headache, however with a sensation of hand edema and postural imbalance. In 2016, 5mg of 
methadone $8 / 8 \mathrm{~h}$, amitriptyline $25 \mathrm{mg}$ at night and the addition of gabapentin $300 \mathrm{mg} 8 / 8 \mathrm{~h}$ allowed the report of effective pain control and little impact on daily activities. In 2017, with physiotherapy and maintenance of doses, the repair of sleep and the fine adjustment of pain symptoms were achieved. CONCLUSION: The singularity of Sd. of ArnoldChiari which requires careful technical accuracy, fine management for analgesic adjustments and the beneficial impact of refractory pain control on the quality of life in patients with difficult pain control symptoms.

Keywords: Arnold-Chiari syndrome, algic control, anesthesiology

91. ABDOMINAL TRAUMA CONTENT WITH SPLENDID AND RENAL INJURY CASE REPORT

Thiago Sousa Dourado; Vitoria Gonçalves Alves de Oliveira; Paulo Gabriel Sacramento Silva; Rodrigo Lira Sousa Lima; Hyroan Brandell Pereira Correa

Universidade Federal do Maranhão (UFMA)

BACKGROUND: Trauma represents a serious public health problem in the world and is among the main causes of mortality and disability in developed countries. Among the types of trauma, the abdominal is one of the most prevalent in the context of polytrauma, being classified as open or closed. The success in the management of this pathology is characterized by the efficiency of the initial approach that allows to establish the early diagnosis and the timely treatment of the intra-abdominal injuries, when present. RESULTS: L.S.E.S, female, 21 years old, victim of a motorcycle accident with a history of blunt abdominal trauma in the left flank. Admitted to hospital in the interior of the state of Maranhão with abdominal pain at deep palpation, without signs of peritonitis. He performed a total abdomen ultrasonography, in which splenic hematoma was associated with subcapsular left renal hematoma. A computed tomography scan of the abdomen with contrast was suggested, which found laceration in a $3 \mathrm{~cm}$ deep spleen not involving trabecular vessels (Grade III) and enlarged left kidney with severe lesion (Grade V) by avulsion of the renal wire with devascularization. She was transferred to a public health service in the state capital on the same day, with no signs of hemorrhagic shock. Exploratory laparotomy and left total nephrectomy were performed to correct the above mentioned lesions. In the postoperative period, the patient remained hospitalized for 4 days on antibiotic and symptomatic use. She presented good evolution and was discharged in good general condition. CONCLUSION: The assessment of the abdomen is one of the most crucial segments in the initial approach of the traumatized. Undiagnosed intra-abdominal injury is a common cause of avoidable deaths. Any patient suffering from blunt or penetrating abdominal trauma should be regarded as having a surgical lesion until proven otherwise.

Keywords: trauma, abdomen, injury, renal

92. BYPASS AORTO-FEMORAL IN PATIENT WITH LERICHE SYNDROME

João Victor Pimentel de Oliveira; Cláudio Henrique de Melo Pereira Filho; Beatriz Matos Costa; Ana Beatriz Santos Catanhede; Lidmar Costa Lima Junior; Vanisse Portela Ramos; Larissa Ferracini Andrade Souza

Universidade Federal do Maranhão (UFMA) Hospital Universitário da Universidade Federal do Maranhão (HUUFMA)

BACKGROUND: Leriche's syndrome is a chronic bilateral aorto-iliac occlusion (OCAl) due to the presence of a thrombus in the aortic bifurcation. It is an unusual variant of arterial disease that affects the Abdominal Aorta and / or both iliac arteries. Characterized by the triad: absence of bilateral femoral pulse, gluteal claudication, impotence in men and secondary amenorrhea in women. The case reported here explains about a case conducted at Presidente Dutra University Hospital (HUPD). CASE DESCRIPTION: JMR, male, 66 years old, presenting extensive lesion in the lower left leg, diagnosed with OCAl. Patient admitted to HUPD to undergo aorto-bifemoral bypass with a bifurcated prosthesis. Firstly, inguinal longitudinal incisions were made, dieresis planes with dissection and repair of the common femoral artery (AFC), superficial and deep. After that, the retroperitoneum was opened with dissection and isolation of the infrarenal abdominal aorta and left common iliac, and then proceeded with the confection of the retroperitoneal tunnel communicating with the bilateral inguinal accesses. Systemic heparinization and infrarenal aortic clamping were initiated. Then, aortic arteriotomy, aortic anastomosis and passage of legs of the bifurcated prosthesis through the retroperitoneal tunnel to the femoral ones.
Continuing, right and left AFC clamping and arteriotomy were performed, as well as anastomoses. Finally, the prosthesis and release of the aortic and femoral clamp were removed, with palpable pulses after a distal anastomosis. The patient progressed satisfactorily in the postoperative period, with left leg granulation. On discharge, patient without complaints and with wounds without phlogistic signs. CONCLUSION: The described behavior was efficient for the treatment of symptoms of Leriche Syndrome with improvement in the quality of life of the patient. In addition to a small exposure to blood loss and a good postoperative and also the improvement of the ulcer present in the left leg.

Keywords: abdominal aorta; thrombosis; surgical procedures

\section{LATE DIAGNOSIS OF ECTOPIC PREGNANCY}

Ada Cristina Mendes Freitas; Ana Karollyne de Araujo Ana Pontes; Bruna Caroline Rodrigues da Silva; Valéria Carvalho Ribeiro; Jessica Fernanda Gomes Rolim; Flavia Carneiro Pereira

Centro Universitário do Maranhão (CEUMA); Serviço de Verificação de Óbitos (SVO)

BACKGROUND: This paper describes the case of a patient with tuba pregnancy who evolved to death after hypovolemic shock and cardiorespiratory arrest (CRA). The relevance of this case is justified by the complications resulting from the pathological finding that has a simple diagnosis, but when it is late, it progresses fatally. CASE DESCRIPTION: SDPA 43 years old, female, married, white, administrator, chronic smoker and from São Luís. On July 13, 2018, she was receive at the Death Verification Service due to CRA at the Emergency Care Unit (UPA) of Araçacy. After being rescue and performing the resuscitation maneuvers, she persisted with asystole and thus declared her death at 08:33 in the morning. In the initial evaluation, distended abdomen, cutaneous pallor and mucosa were observe, with no other changes relevant to physical examination. On necroscopic examination, an area of intense hemorrhage was observe in the pelvic cavity, and death was evidence due to hypovolemic shock with CRA The investigation identified right ovary cystic and left ovary and ruptured trunk with extensive area of blood clots due to ectopic pregnancy, being evidenced male fetus, $3.5 \mathrm{~cm}$ indicative of about 10 weeks. Other findings include mild anthracosis in the lungs, gallstones and right ventricular hypertrophy and mild atherosclerosis in the heart. CONCLUSION: Ectopic pregnancy corresponds to the nidation of the ovum outside the uterine cavity and it is considered the major cause of maternal death in the first trimester of gestation. Among the associated risk factors, we highlight the use of intrauterine device, emergency contraception, smoking, previous ectopic pregnancy and endometriosis. The clinical manifestations are abdominal pain, menstrual delay and irregular vaginal bleeding. Diagnosis occurs after HCG and transvaginal ultrasound, and the standard treatment is surgery.

Keywords: ectopic pregnancy; tubal

\section{BEHAVIORAL PROFILE OF WOMEN AT THE CENTER OF BASIC AND} APPLIED IMMUNOLOGY/UFMA

Ana Josephy da Silva Costa Oliveira; João Victor de Sousa Garcia; Saphyra Medeiros Salem; Gelson Farias Arcos Junior; Graça Maria de Castro Viana; Jéssica da Silva Prates; Thalyta Batista de Sousa Universidade Federal do Maranhão (UFMA)

BACKGROUND: Cervical-uterine cancer results from disordered replication of the lining epithelium of the organ. Although not the only risk factor, Human Papillomavirus (HPV) infection is imperative for the development of cancer. It is considered a public health problem, and its detection and prevention are easy. The present study aims to characterize the behavioral profile of women submitted to Pap smears attended in the University Extension Program linked to the Pathology Department of the Federal University of Maranhão in the city of. METHODS: A cross-sectional, analytical-descriptive and quantitative study was carried out with 97 women attended by university extension programs linked to the Pathology Department of the Federal University of Maranhão (UFMA), Bacanga campus. Data collection was initiated through a structured questionnaire, whose questions addressed the behavioral characteristics of these women. The data was compiled into a Microsoft Excel 2010® spreadsheet for both exploratory and descriptive analysis. RESULTS: 95 women between the ages of 18 and 73 years were included in this study, being more prevalent women who started sexual activity between 16 and 18 years (41.05\%); who had only one sexual 
partner $(41.05 \%)$; who never use condoms $(57.89 \%)$ who had one to three births (68.42\%); who did not present a history of Sexually Transmitted Infection (82.11\%); who reported going to the gynecologist once a year $(43.16 \%)$ and did not use cigarettes (89.47\%). CONCLUSIONS: Even when performing the Pap smear, it is important to note that most women still have behaviors considered at risk, such as non-use of condoms. Therefore, counseling with a focus on these behaviors that are considered at risk for the transmission of sexually transmitted infections, among them HPV is necessary.

Keywords: Behavior; Prevention; Cervical-uterine cancer; HPV
AGE OF MENARCHE IN THE MOTHER-DAUGHTER BINOMIAL: A CROSS SECTIONAL STUDY IN SÃO LUÍS, MA.

Thállisso Martins Da Silva Rodrigues: Maria Bethânia Da Costa Chein; Leonardo Victor Galvão-Moreira; Matheus Veras Guterres Mendes; Taciany Silva Costa; Clariano Pires De Oliveira Neto; Luciane Maria Oliveira Brito

Universidade Federal Do Maranhão (UFMA). Hospital Universitário Materno Infantil (HUMI)

BACKGROUND: The sexual maturation in the girl includes the telarche (appearance of the breasts), the pubarche (appearance of pubic hair), the development of the genital apparatus, menarche (first menstruation) and finally, the beginning of ovulation, which determines the capacity reproduction. Menarche has occurred three to four months earlier every decade for the same population. The aim of the research is to investigate possible differences in the age of menarche in adolescents and their mothers. METHODS: A cross-sectional study was carried out in São Luís, Maranhão, Brazil, with girls aged 12 to 17 years $(n=510)$ in whom menarche had already occurred, and their mothers. A questionnaire was applied to each adolescent and each mother in order to verify socio-demographic and behavioral factors, as well as the age of the menarche of the motherdaughter binomial. Data analysis included descriptive statistics and Student's t-test. RESULTS: The mean age of menarche in adolescents was 12.1 years $(S D \pm 1.2)$ and its occurrence at 13 years was more frequent $(32.5 \%)$. There was a statistically significant difference $(p \$ .01)$ in mean age of menarche between adolescents and their mothers. CONCLUSION: In the present study, menarche occurred earlier in adolescents when compared to their mothers, showing a tendency to decrease the age of menarche over time in the local population.

Keywords: Menarche, Age, Maturation, Sexual

\section{PROFILE OF THE PAWLERY IN MEDICAL STUDENTS OF A PRIVATE} INSTITUTION

Eduardo da Silva Pereira; Cícera Natália da Silva Rodrigues; Francisco Renan Pontes Barroso; Antônio Paulino Frota Júnior: Jesimarcus Guerra de Oliveira; Joaquim José da Silva Neto; Aldicleya Lima Luz

Universidade Federal Do Maranhão (UFMA); Faculdade de Medicina de Juazeiro do Norte (ESTÁCIO/FMJ)

BACKGROUND: Headache is an important public health problem in Brazil and in the world due to the individual and social impact that this clinica condition entails. It is a limiting condition that interferes with the quality of life and productivity, as well as compromising the social and affective relationship. OBJECTIVE: To analyze the prevalence and profile of headache in medical students. METHODS: This was a descriptive and quantitative field study, where 71 medical students enrolled in the first (51) and seventh semester (20) of the Faculdade de Medicina Estácio in Juazeiro do Norte were investigated, requesting participation of the person with prior consent (ICF). A previously tested form was used to collect the data. RESULTS: The most prevalent headache profile is the type of tension pain, presented by $69.7 \%$ of women and $50 \%$ of men. Regarding the classification of headache according to the site of the head, the most frequent type is the pain felt in the frontal region of the skull, being reported by $45.5 \%$ of the women and $47.1 \%$ of the men. Regarding the triggering factors, $81.8 \%$ of the women and $90 \%$ of the men present the complaint of headache triggered by stres peaks, while $54.5 \%$ of the women and $45.7 \%$ of the men present the pain triggered by the sleep disorders. In the relationship between headache and academic activities, $78.8 \%$ of the women interviewed adding the variables during and after the academic activity confirm this association, whereas among men there is a percentage of $60.0 \%$. CONCLUSION: Headache is a very frequent symptom, which is more prevalent in females. The clinical aspects found in this study were that the most prevalent profile is tension-type headache, of moderate intensity and location in the frontal region of the skull.

Keywords: Headache, Medical Students, Pain

\section{KLATSKIN TUMOR: A CASE REPORT}

JESSIKA FREITAS DE SOUSA; Bruno Alencar Noleto; Bruna Manjabosco Wachter; José Arruda Lima Silva; Everton P. D. Lopes UNITPAC

BACKGROUND: Cholangiocarcinomas have an incidence around $0.01 \%$ to $0.8 \%$ of gastrointestinal neoplasms, and among these, Klatskin tumors, also called hilar cholangiocarcinomas, are tumors of the proximal extrahepatic biliary bifurcation of the hepatic duct, correspond to $25 \%$ of the total number of cases. Its main clinical presentation is the presence of obstructive jaundice, abdominal pain, pruritus, coluria and acolyte. The objective of this study is to report a case of Klatskin's tumor diagnosed after surgical intervention. CASE DESCRIPTION: A 71-year-old male, hypertensive was admitted with abdominal pain in a right hypochondrium region, a type of colic, a Murphy's signal present on abdominal palpation, associated with vomiting. USG of total abdomen was performed, which showed cholelithiasis, and a conventional cholecystectomy was performed. In the postoperative period, the patient still complained of abdominal pain, epigastric, tightness, severe intensity, associated inappetence, intense asthenia, and weight loss of 4 kilos in 2 weeks. On the 24th postoperative day, the patient underwent cholangiorononography, showing dilatation of the intrahepatic biliary tract and enhancement of the wall of the common hepatic duct (inflammatory process), segmental signal failure, linear (without calculation aspect), supraduodenal choledochus measuring 7.0 $\mathrm{mm}$ longitudinal, $7,3 \mathrm{~mm}$ in the retroduodenal portion and $5,0 \mathrm{~mm}$ in the intrahepatic portion, thus, surgical resection was indicated, performed without intercurrences and subsequent improvement of the patient's symptoms. CONCLUSION: Klatskin tumor is a rare and difficult disease with high morbidity and mortality, so its early diagnosis for the appropriate management of these patients is extremely important.

Keywords: Tumor, Cholangiocarcinoma, Klatskin

98. PIOGENIC SPONDYLODISCITSS IN VERTEBRAL COLUMN: CASE REPORT Cindy Dannyelle Ferreira Brandão Silva; Jessika Freitas de Sousa; Jane Augusto Guimarães Gonçalves UNITPAC

BACKGROUND: Spondylodiscitis is an inflammatory process that affects the vertebral discs and the vertebrae of the vertebral column. It occurs in about 0.5 to 2.5 cases per 100,000 inhabitants per year, the male being the most affected in a ratio of 3:14. It has a higher incidence in patients over 50 years of age, and is related to complications such as intense pain and persistent neurological deficits. Piogenic spondylodiscitis affects the lumbar spine more frequently (60\%) in a more localized way, affecting only one vertebral segment. The objective of this study is to report a case of a patient with spondylodiscitis in the vertebral column, whose diagnosis can be quite difficult due to the rarity of the disease and the high prevalence of low back pain in the general population. RESULTS: Patient, 61 years old, was admitted with low back pain for approximately 2 months, with a high intensity, continuous, worsening of movement. At physical examination, cutaneous lesions of the right thorax, dorsum and forearm, irregular, of a heterogeneous color, greater than $5 \mathrm{~mm}$. Laboratory tests were requested resulting in increased anemia, HSV and CRP, and unchanged EAS. Image exams, including computed tomography of the chest with signs of spondylodiscitis and magnetic resonance imaging of the thoracic spine with findings of an infectious process (spondylodiscitis). Conservative treatment is indicated in cases of recent infection, absence of neurological deficit or comorbidities that prevent surgery, and antibiotic therapy is initiated in the patient in question. CONCLUSION: Agility in diagnosis allows appropriate treatment and can avoid complications. Imaging tests are essential for the diagnosis and follow-up of the lesions, and magnetic resonance imaging is the exam of choice. Treatment of spondylodiscitis is based on eradicating the infection, relieving pain, and restoring or preserving the function and structures of the spine.

Keywords: Spondylodiscite, pyogenic, spinal column. 
99. INTERVENTION REPORT ABOUT STIMULATION OF THE ELDERLY FROM PINHEIRO-MA TO THE PRACTICE OF EXERCISES

Glaucia Galindo Silva; Mateus de Sousa Cavalcante; Marcelo Batista Suehara; Ana Clara Sousa Cruz; Sanny Pinheiro Oliveira; Thayná Rocha Coimbra

Universidade Federal do Maranhão

BACKGROUND: The practice of physical exercise in the elderly presents several benefits, being an important agent promoting health and improving the quality of life. In addition to disease prevention, its practice for the elderly still provides benefits both physically and mentally and socially. The objective is to report an intervention that focused on the awareness and stimulation of the elderly of the Pinheiro-MA city to the practice of physical exercises. METHODS: A situational analysis was carried out in which the sedentary lifestyle of the elderly population in this area was observed followed by a more adequate intervention planning. With a partnership with the Pastoral of the Elderly Person, Nutritionist of the Family Health Support Center and a physical education teacher, an action took place in the neighborhood of Leonor Island. Then, on the Elderly day were provided interactive lectures, screening for observation of blood pressure and identification of the elderly hypertensive and finally a small class demonstrating exercises; the action served 28 elderly in the area. RESULTS: Although this population layer is sedentary, becoming aware of the importance of its practice through professionals has generated great acceptance and adherence, in which the elderly have committed themselves to a change of habits of life. During the action it was possible to observe their engagement with the proposal, besides the interest in deepening the knowledge through questions about a healthy life and its benefits. CONCLUSION: Even with a great benefit, it was observed that a large part of the elderly population of this city of the Maranhão state is sedentary. This experience demonstrated that a possible cause of this sedentary life would be due to lack of stimuli, since empirical knowledge does not motivate them enough.

Keywords: Elderly, physical exercise and health. Júnior; Fernando Cleydson Lima Paiva Filho; Lorena Lis Nolêto Sá Corrêa; Vanessa Thaylla Coelho Silva Pinto; Pedro Emanoel Rodrigues da Silva

Universidade Estadual do Maranhão (UEMA); Universidade Estadual do Piauí (UESPI); Universidade Federal do Maranhão (UFMA)

BACKGROUND: Fetal death is characterized as the death of the product of conception, occurring before its complete expulsion or extraction from the maternal organism, independently of the time of gestation. It is diagnosed when, after the separation of the maternal organism, the fetus does not breathe or show any other sign of life. Thus, this study aimed to characterize the cases of fetal deaths occurred in Brazil between the years 2010 to 2016. METHODS: This is an exploratory-descriptive study with a quantitative approach. Data collection was performed through data collection from the Mortality Information System - SIM, made available by the Department of Informatics of the Unified Health System (DATASUS). RESULTS: During the study period, 222,101 fetal deaths occurred in the country, with the Southeast Region having the highest number of deaths, with 82071 (36.95\%). Regarding the frequency of fetal deaths according to maternal age, it indicates the predominance of occurrence in pregnant women aged 20 to 24 years, representing $20.99 \%$ of the cases. The majority of deaths $(23.89 \%)$ occurred mainly between 32 and 36 weeks of gestation. It was observed that in $24.97 \%$ of deaths are related to intrauterine hypoxia, followed by unspecified (22.22\%) fetal death and by fetus and newborn affected by complications of the placenta, umbilical cord and membranes with $19.12 \%$ of the cases. CONCLUSION: Fetal deaths in Brazil occurred in the majority of cases in 2014, but there was no significant change in the quantity in the previous years and in subsequent years and were caused in greater quantity by intrauterine hypoxia. In this way, the need for solid prenatal measures is known, with a view to the early identification of risk factors for fetal death. In addition, individualized procedures should be drawn up and detailed, with a view to defining behaviors that may minimize the high rates of fetal intrauterine mortality.

Keywords: Epidemiology, Fetal death, Mortality records.

\section{DEEP VENOUS THROMBOSIS IN THE PUERPERAL PREGNANCY CYCLE}

Matheus Sousa Miranda; Priscila Isabelita Veloso Da Silva; Adriano Ernesto Rosa De Lima; Ana Valquíria Santos e Gomes; Manoel Ilton Sarmento Neto; Montanaro Mauricio Pacheco Araújo; Letícia Evelyn Oliveira De Souza

Faculdade Santa Maria (FSM)

BACKGROUND: Deep venous thrombosis is the formation of thrombi within the deep veins. Partial or complete blockage of the lumen of the vessel may occur, which is more frequent in the lower limbs (80-95\%). In pregnancy, there are intensification of the 3 etiopathogenic factors of the virshow triad they are: Venous stasis, due to venous compression by the gravid uterus and reduction of venous tone due to myorelaxant action of progesterone; hypercoagulability, stimulated by induction of hepatic synthesis of coagulation factors by placental estriol, increase of fibrinogen and inhibitor of plasminogen activator type I and II, in addition to the decrease of protein $S$ synthesis; and endothelial injury, which occurs in the nidation. This explains the six-fold increased risk of DVT in pregnancy, in which there is an incidence of 1 to 2 cases per thousand pregnancies. This is an exploratory field study of the case report that aims to describe the association of risk of deep vein thrombosis with the gravid cycle. CASE DESCRIPTION: The patient, RCFS, 40 years old, female, born and resident in the city of Cajazeiras-PB, was admitted at 2:00 pm on 08/11/2018 at the maternity unit Dr. Deodato Cartaxo and submitted at 3:30 pm the same day cesarean delivery of her second child. During the puerperium, the patient began to report pain that intensified when she wandered and paraesthesia in the right lower limb, in addition to headache. On the physical exam of the patient, edema $(\mathrm{HH} / \mathrm{HH})$, muscle tenderness and pain on palpation, and varicose veins (CEAP III) were also observed in the lower limbs, which raised the suspicion of deep vein thrombosis. Patient was referred on August 12 2018 for vascular evaluation, and Ultrasonography with Venous Doppler of the inferior limb in question was requested. In view of the clinical picture and a high probability of DVT diagnosis up to the present moment, resting was indicated and Enoxiparin $2 \mathrm{mg} / \mathrm{kg} 2 \mathrm{x}$ daily was started until confirmation of the ultrasonographic examination.

Keywords: puerperium, deep venous thrombosis, pregnancy

\section{EXPERIENCE REPORT ABOUT THE EARLY INSERTION OF THE MEDICAL} STUDENT IN SEMIOLOGICAL PRACTICE

Marcelo Batista Suehara; Thayná Rocha Coimbra; Mateus de Sousa Cavalcante; Ana Clara Sousa Cruz; Sanny Pinheiro Oliveira; Glaucia Galindo Silva; Michelline Joana Tenorio Albuquerque Madruga Mesquita

Universidade Federal do Maranhão (UFMA)

BACKGROUND: Semiology, by tradition, consists of the agglutination of principles and bases for medical practice that guide the professional or student in the management of anamneses, in the development of clinical reasoning and in the conduction of physical exams. The objective of this work is to report the experience of early insertion of the medical student in the community to semiological practice. METHODS: Descriptive study of the experience report, based on interviews with students from the first semester of the Semiology course of the Federal University of Maranhão, Campus Pinheiro. RESULTS: The interviews showed that the students, who started with a theoretical moment in the classroom and later inserted with knowledge to begin their experiences through home visits, anamnesis and physical exams, are able to sharpen their abilities listening, emotional control and communication, which are the basis for building a good doctorpatient relationship favoring the collection of a good anamnesis and the accomplishment of the first clinical examinations. It was also reported the construction of a space of bond in which the patient can feel welcomed recognizing their role in the student's learning process. The students also reported that health care professionals provide the necessary support for academic performance, which suggests their understanding of interventions as an extension of health promotion, as well as a reinforcement of commitment to general well-being. CONCLUSION: The inclusion of Semiology in the first period of Medicine challenges the potential of the student to enter the academic dimension, since it contributes to the formation of clinical knowledge and biopsychosocial skills. This approach generates a critical posture to the students and enables theoretical and practical support in terms of maturation and comprehensive experience throughout the training.

Keywords: Semiology, Community, Experience 
103. EPIDEMIOLOGICAL PROFILE OF WHOOPING COUGH IN THE NORTHEAST OF BRAZIL IN THE PERIOD 2007 TO 2017

Luana Lara Farias de Jesus Neves; Milena Dara Farias de Jesus Neves; Monique Santos do Carmo

Centro Universitario do Maranhão (UNICEUMA), Universidade Federal do Maranhão (UFMA)

BACKGROUND: Whooping cough is an infectious disease that affects the respiratory tract, affecting mainly the trachea and the bronchi. It has as its etiological agent the microorganism Bordetella pertussis, being transmitted mainly in the catarrhal phase and places with large agglomerations of people. Thus, the objective of the study was to draw a retrospective analysis of the quantitative approach to the epidemiological profile of whooping cough in the Brazilian Northeastern population from 2007 to 2017. METHODS: The methodology used involved the evaluation of the data obtained in the Aging Notification System (SINAN) of the Ministry of Health. RESULTS: Over 11 years, 7313 cases were reported. The highest recorded index was in the year 2014 , with 2939 notifications $(40.18 \%)$. The states with the highest number of cases were Pernambuco and Bahia, with 2850 and 1552 records of the disease, which corresponds to $38.98 \%$ and $21.22 \%$ of the total respectively. With regard to sex, a proportional relationship was observed in all States. The race with the highest prevalence was the ethnic group with 3993 cases, representing $54.60 \%$. It was also observed that in the last decade, whooping cough was prevalent in the urban area with a total of 6091 cases $(83.30 \%)$. Regarding the clinical evolution, there were 315 cases of cure $(4.3 \%)$ and 1 death. CONCLUSION: Despite the evolution of public health policies in the prevention and treatment of infectious diseases, it has been observed that the Brazilian Northeast still has a prominent position in the number of cases of pertussis, evidenced by a three-fold increase in notifications in the last five years. This may be a reflection of the discontinuation of the vaccination schedule. Additionally, the subnotifications concealed the actual outcome of the clinical evolution of the patients, making it difficult to monitor the epidemiological surveillance of the disease. Therefore, the adoption of control measures capable of preventing the spread of the disease are necessary

Keywords: Whooping cough, Epidemiology, Northeast

104. MENINGOCOCCAL PNEUMONIA

Andre Rossanno Mendes Almeida; Thaise Moura Silva; Gerson Coelho Viana; Alynne Miranda Fontes De Almeida; Alexandre Guilherme Ribeiro De Carvalho; Ana Victoria Pinho De Carvalho Pascal

Hospital UDI

BACKGROUND: Meningococcal disease ranges from transient fever to fulminant disease. It can be invasive and manifest as meningococcemia, with meningitis being the main manifestation, occurring in $70 \%$ of the cases and fulminating disease in $4 \%$. Fifteen meningococcal serogroups cause most cases. They are: A, B, C, W and Y. In Brazil, in 2014, considering all age groups, meningococcus $C$ was responsible for $70 \%$ of the cases of the disease; or serogroup B, by about 20\%; and the remaining $10 \%$ were caused by $W$ and $Y$ serogroups. Meningitis is caused by groups $A, B$ and $C$ in most cases, with $W$ and $Y$ serotypes causing pneumonia. Certain conditions increase the risk for meningococcal disease, such as the absence of spleen (or malfunctioning of the organ) and certain immunity deficiencies, including those caused by immunosuppressive treatments. Invasive disease can be complicated by pneumonia (8-15\%), arthritis, myocarditis, pericarditis. CASE DESCRIPTION: The present case is ILF, 80 years old diabetic, hypertensive, breast neoplasm, admitted to the emergency room with fever 2 days ago, productive cough and torpor. Chest tomography showed consolidation with air bronchograms of permeation and centrilobular opacities, resulting in an inflammatory / infectious process. CSF puncture was performed, and the result was normal. It had $19,500 \mathrm{~mm}$ 2 leukocytosis, no deviation, sodium hyponatremia of $127 \mathrm{meq} / \mathrm{l}$, cretinine $2.5 \mathrm{mg} / \mathrm{dl}$; C reactive protein of $17.24 \mathrm{mg} / \mathrm{dl}$. Collected blood cultures, whose growth showed in the three samples Neisseria meningitidis and w135. Patient made use of cefrtriaxone $4 \mathrm{~g}$ day. Received high with all his normal examinations on June 22. Patient returned on July 4 with good general condition and exams without changes. CONCLUSION: The present case has its importance to alert the medical community to the need to be aware of the various possibilities of meningococcal infectious processes.

Keywords: pneumonia, meningococcus, sepsis
105.

REGIONS

Artur Costa Cruz; Igor Augusto Faria de Oliveira Veloso; Caylton Carneiro Aguiar; Gabriel Costa dos Reis; Ádila Ludmila Raulino Leitão; Bruna Lara Alves Felix; Carlos Danilo da Penha Souza Universidade Federal do Ceará (UFC)

BACKGROUND: Among the diseases that affect the population of the country, cancer is one of the most worrying, since, besides presenting high mortality rates, it is limited to those affected, it requires a great deal of effort in its prevention and early detection. Thus, this study aims at comparing the types of cancer that cause the most deaths among the Brazilian regions, in a way that helps to better target health resources in order to combat this disease. METHODS: This is a descriptive ecological study with data collected in the Health Information System (TABNET) from the tab "vital statistics" in the section "general mortality". In the "line" option, neoplasms were selected in ICD-BR-10 and in the "column" region. The period chosen was from 2007 to 2016. RESULTS: The total number of deaths due to neoplasia in the country was $1,880,293$, which corresponds to $16.03 \%$ of all deaths. Of these, $12.39 \%$ of the respiratory tract (NTR), $7.66 \%$ of the colon (ANC), $7.24 \%$ of the stomach (NET) and breast (NM), $7.04 \% 11 \%$ in the esophagus (NEF) and $2.79 \%$ in the cervix (NCU). In the Central West Region (OC), 116,631 deaths were recorded, $15.45 \%$ of total deaths in the region (TO), $12.78 \%$ NTR, $7.67 \%$ NCA, $6.63 \%$ NET, $7.11 \%$ NM and $7.81 \%$ NP. In the South (S) 365,312 deaths, $19.92 \%$ of TO, being $15.75 \%$ NTR, $8.63 \%$ NCA, $6.48 \%$ NET, $6.65 \%$ NM, $6.29 \% \mathrm{NP}$ and $5.34 \% \mathrm{NEF}$. In the Southeast region (SD) 911,276 deaths, $16.80 \%$ of TO, being $12.18 \%$ NTR, $8.93 \%$ NCA, $7.13 \%$ NET, $7.71 \%$ NM and $6.30 \%$ NP. In the Northeast (NE) 398,830 deaths, $13.16 \%$ of TO, being $10.34 \%$ NTR, $5.06 \%$ NCA, $7.54 \%$ NET, $7.11 \% \mathrm{NM}$ and $9.11 \% \mathrm{NP}$. In the North region (N) 88,244 deaths, $12.81 \%$ of TO, being $11.09 \%$ NTR, $4.66 \%$ NCA, $11.00 \%$ NET $5.56 \%$ NM, $7.44 \%$ NP, and 7, 40\% NCU. CONCLUSION: The NCU and NET in the $\mathrm{N}$, the NP in the NE, the NTR and the NEF in the S, and the NCA in the SD present more than $1 \%$ of the national average, evidencing the need for a greater performance of the health services that the improvement of this scenario.

Keywords: Cancer; Mortality; Epidemiology

SYSTEMIC ARTERIAL HYPERTENSION: EPIDEMIOLOGICAL PROFILE IN A HEALTH CENTER OF PARÁ

Maria clara Souza Fernandes; Karine da Silva Ribeiro Ramos; Yana de Medeiros Souza Lima; Santino Carvalho Franco

Faculdade Metropolitana da Amazônia (FAMAZ)

BACKGROUND: Systemic Arterial Hypertension (SH) is a complex chronic disease, a multifactorial clinical condition characterized by elevated and sustained blood pressure (BP) levels; is the main risk factor for chronic noncommunicable diseases; have high prevalence and low control rates. Therefore, the present study aims to analyze the epidemiological profile of hypertension in individuals residing in the area corresponding to the 1st Regional Health Center of Pará. METHOD: This is a descriptive, retrospective study performed in DATASUS / Hiperdia, through the collection of information from the HiperDia database from January 2012 to January 2017. The sample refers to users with high blood pressure belonging to the 1st Regional Health Center of Pará. RESULTS: It is estimated that in Pará there are 757,634 hypertensive patients, $58.6 \%$ of whom belong to a regional health coordinator, in which a greater frequency of hypertensives is found in the city of Belém, about $41.4 \%$, and a smaller non-Municipality of Santa Bárbara of Pará, with $1.3 \%$. A higher frequency of female hypertensive individuals was identified, with a total of 906 individuals, which corresponds to $65.6 \%$ of the total studied, most prevalent in the $55-59$ age group. CONCLUSION: The frequency of SAH is greater in females, cardiovascular diseases are more prevalent in males. The highest incidence of hypertension is found in the city of Belém and the lowest in the municipality of Santa Bárbara of Pará.

Keywords: Systemic Arterial Hypertension, epidemiology, blood pressure.

107. ANXIETY SYMPTOMS EVALUATION IN PRE ENTRANCE EXAM'S STUDENTS FROM TWO BRAZILIAN CITIES

Sara Maria Gomes Bié; Marcos Teodoro Viana Brito; Leticia Goretti Moura de Jesus: Jullys Allan Guimarães Gama Universidade Federal do Maranhão (UFMA) 
BACKGROUND: Entrance exam is a selective process which enables students' admission in colleges. Although, according to some comittees, only one fifth of the students reaches that goal. Therefore, mental health may be affected by the search for approval and anxiety uses to be a possible outcome from the process. In that scenario, this study has been performed in order to quantify the anxiety symptoms in pre entrance exam's students. METHODS: A descriptive, quantitative study has been performed, applying a questionnaire based on Beck Anxiety Inventory, in an adapted and simplified way, within 127 students, selected by convenience in schools and preparatory courses from Fortaleza-CE and São Luís-MA. The obtained data was tabulated and statiscally analyzed by SPSS (version 22) software and Pearson q-square test has been used to associate variables. RESULTS: The interviewees' average age was 18,54; the prevailing gender was female (74\%). From the interviewees, $61,4 \%$ sought biological sciences, $16,5 \%$ human sciences, $13,4 \%$ law sciences and $8,7 \%$ exact sciences. The most reported anxiety symptom was nervousness (78\%), followed by fearing the worst could happen $(63 \%)$ and inability to relaxing $(44,1 \%)$. When they were asked if they feared they could disappoint their family and friends, 84,3\% said yes; $83,5 \%$ were afraid of reproving and the attending pre entrance exam's pressure was reported by $67,7 \%$ of the students. Besides, by crossing obtained data, it could be observed that fear of reproving prevails between those who seek biological and law sciences $(p \&, 05)$. When related to the symptomatology, it's possible to emphasize the different anxiety levels in students. CONCLUSION: This paper has shown that most students presented one or several anxiety symptoms related to fears and expectations towards pre entrance exam. Then, the psychological support plans' offering is clearly needed by this group of students.

Keywords: Anxiety, Students, Questionnaires

\section{HUMANIZATION OF CHILD CARE DURING VACCINATION}

Letícia Teixeira Torres; Jéssica Raiany Costa e Costa; Maria da Conceição Pereira de Carvalho; Kirlian Karolene Araujo Pereira; Jeanine Porto Brondani; Regina Maria Abreu Mota Universidade Federal do Maranhão (UFMA)

BACKGROUND: During the first years of life, children need to receive severa doses of immunobiological, which are necessary for healthy growth and development. Most doses are given through injections, and the pain can lead to fear, physical and emotional distress. The approach and embracement by the health professionals are fundamental to promote the quality of childcare and the minimization of possible traumas. Experience report of a work created during the curricular traineeship of Nursing in primary Care, in a Primary Health Unit of São Luis, MA, during April and May of 2018, that included playful interventions and embracement in order to humanization. RESULTS: The strategies adopted to humanize the care of the children consisted of caretaker embracement, emphasizing the importance of including the child in the vaccination process, dialoguing about the procedure; the vaccine calendar; clarifying doubts; and using balloons and "courage certificates" to provide support during and after the painful experience. It was observed that children who received balloon cried less or did not cry during and after vaccination. Children from 3 years old who received information about the procedure and gained a courage certificate did not present crying episodes or cried less than those who did not receive these interventions. CONCLUSION: The care of the emotional dimension of the child and family had a positive influence on vaccination and humanized the practice. The less traumatic the experience, the greater the trust in the health service and in the health professionals, which favors the assiduity in the fulfillment of the vaccination calendar. In addition, the use of play techniques that include the child in the care process values the child being as it allows the expression of feelings and opinions and explicitly states that the health service is also for child care.

Keywords: Vaccination, user embracement, Child

109. EXOGENOUS INTOXICATIONS CARE IN THE STATE OF MARANHÃO DURING THE PERIOD FROM 2012 TO 2017

Aneliza de Fátima Figuerêdo lima; Ana Luísa Oliveira da Silva; Amanda de Oliveira Campêlo; Letícia Pires Vilanova; Luara Cristina Barros Fontineles; Letícia Rodrigues Barros; Dennise Carvalho da Silva

Centro Universitário Uninovafapi; Centro Universitário do Maranhão; Centro Universitário INTA; Faculdade Diferencial Integral (Facid)
BACKGROUND: Exogenous intoxications are considered one of the main reasons for emergency services, covering all age groups in different circumstances. It is defined as a clinical manifestation of adverse effects through its interaction with exogenous substances. Each year thousands of poisoning cases are reported in Brazil, caused by ingestion of contaminated food, medicines, pesticides, household or veterinary cleaners and other chemicals. METHODS: This is an epidemiological, descriptive, cross-sectional study with a quantitative approach, based on data collected from the Department of Information Technology of the SUS, in the Information System for Notifiable Diseases (SINAN) of Maranhão, between 2012 and 2017. The variables used were: sex, age, toxic agent, circumstances, evolution, confirmation criterion and final classification. RESULTS: There were 2,867 cases with exogenous intoxication, of which $53.6 \%$ were female. The most affected age group was between 20 and 39 years $29.3 \%(n=842)$ followed by the age group of $1-4$ years $27.5 \%(n=791)$. Accidental cases were the most frequent circumstances $29.6 \%(n=851)$, followed by suicide attempts $18.8 \%(n=541)$ and therapeutic use $9.6 \%(n=278)$. Among the toxic agents, $39.1 \%(n=1121)$, followed by food and beverages $13.5 \%(n=388)$ and rodenticides $8.2 \%(n=237)$. The cases, in the majority, are classified into intoxication confirmed $58 \%(\mathrm{n}=1665)$. The most frequently used confirmatory criterion was the clinical $63 \%(n=1813)$. Regarding the evolution of the cases, the cure without sequela was more prevalent $76.3 \%$ $(n=2190)$. CONCLUSION: Exogenous poisoning is a serious public health problem, especially in the attempt to commit suicide, in addition to targeting children significantly and requiring effective interventions and preventive actions in populations of greater vulnerability.

Keywords: Toxicology, Medication, Public Health

110. TREATMENT PROFILE OF PATIENTS DIAGNOSED WITH PELVIC PAIN IN SÃO LUÍS, BRAZIL

Islanara Diógenes Urbano Sousa; João Batista Santos Garcia; Thaís Alves Albarelli Freire; Thiago Alves Rodrigues; Débora Castro Sousa; Brisa Lima de Barros Caetano; Mariana Milet de Oliveira Regis Vasconcelos

Universidade Federal do Maranhão (UFMA)

BACKGROUND: Pelvic pain is defined as localized or referred pain in the lower abdomen, pelvis or perineum and may be acute, cyclic or chronic. Among the treatment options, there are non-invasive therapies, pharmacological management and invasive therapies. In view of this, this study aims to perform a screening of the treatment of patients with pelvic pain treated at the Pain Department of the Presidente Dutra University Hospital. METHODS: This study was carried out based on the research and analysis of medical records of 4 patients with a diagnosis of pain whose main site is the pelvic region and are treated at the referred service. We analyzed intensity and characterization of pain in the first and last consultation, continuity of treatment in the service, diagnosis of the patient and proposed therapies. RESULTS: $100 \%$ of the sample is composed of women with a diagnosis age between 29 and 52 years. Of these women, 100\% reported experiencing severe pain at the start of treatment. The characterization of the pain was as lancinante in 100\% of the cases; weight and tightness in 75\%; stabbing, pinching, throbbing and burning by $25 \%$. The diagnoses were chronic pelvic visceral pain, interstitial cystitis and dysmenorrhea. Medicinal treatment was proposed in all patients, being used: pregabalin, tramadol, amitriptyline, scopolamine butylbromide, codeine, mefenamic acid, tenoxican, venlafaxine and gabapentin. In $75 \%$ of the cases non-medicated treatments were proposed, being: physiotherapy, psychotherapy, hydrotherapy, occupational therapy and hypogastric plexus block. Only $25 \%$ of them did not return for continued treatment. Among those who returned, $66 \%$ had continued treatment for more than 5 years. $100 \%$ of these report improvement, $66 \%$ still feel intense pelvic pain yet. CONCLUSION: Despite the small sample, a prevalence of female involvement and a difficult control and relevant intensity of pelvic pain in the patients was perceptible.

Keywords: Pelvic pain, pain control, multidisciplinary treatment

111. INTERFERON FREE TREATMENT FOR HEPATTTS C IN ARAGUAINA-TO, BETWEEN 2015 AND 2017

Paulo Vitor Lima Abreu; Larissa Miranda de Amorim; Jônio Arruda Luz

Centro Universitário Tocantinense Presidente Antônio Carlos (UNITPAC), Liga Araguainense de Infectologia (LAIA) 
BACKGROUND: Hepatitis is one of the causes of slowly evolving symptoms, up to $85 \%$ of chronic cases with development of cirrhosis. The pioneer treatment of interferon alpha monotherapy, however, a sustained virological response (SVR) did not exceed $20 \%$. The current system without the use of sofosbuvir (SOF), daclatasvir (DAC) and simeprevir (SMV). An RVS in this therapy reaches values above $90 \%$ for all genotypes. The study is a study on the profile of patients treated for non-interfering hepatitis $C$ between 2015 and 2018 at the Araguaína-TO Reference Hospital, with a mean age, sex, SVR and a comparative indicator between genotypes 1, 2 and 3 . METHODS: We included clinicians treating chronic hepatitis in the hospital and previously mentioned. A descriptive analysis of the study period was performed, were registered in 37 cases. RESULTS: The mean age of the patients was 57.6 years (42-76). As for sex, 56.8\% are men (21) and $43.2 \%$ are women (16). As for the genotype, $75.7 \%$ of the patients were infected by genotype 1 (28), 5.4\% by genotype $2(2)$ and $18.9 \%$ by genotype $3(7)$ Regarding SVR, of the 37 patients who received the treatment, 1 of them (no cure). RVS in the sample presented a value of $97.29 \%$. CONCLUSION: The mean age found represents the slow deity of the disease. In the research there was a predominance of the male sex infected by the virus $C$, howeve it was not important meaning, since there is no tropism by one of the sexes. The most prevalent genotype was type 1, followed by type 3 and 2. A sample of SVR converged with the national results. Although a sample is confirmed the effectiveness of the new drugs that provide greater chances of cure for patients with hepatitis is confirmed.

Keywords: Epidemiology, Hepatitis c, Therapeutics

\section{NEUROCYSTICERCOSIS IN A CITY INSIDE THE STATE OF TOCANTINS - CASE} REPORT

Mariana da Silva do Nascimento; Poliana Lima Campos; Matheus Cabral de Oliveira; Talitha Farag de Oliveira; Francisco Silva Siriano Neto; Nilson de Jesus Pereira Batalha Junior

Centro Universitário ITPAC (UNITPAC) Universidade Federal do Maranhão (UFMA)

BACKGROUND: Neurocysticercosis is the most frequent parasitic disease in the central nervous system, being the most common cause of late onset epilepsy and hydrocephalus in adults in Brazil, characteristic of regions with poor sanitary conditions. The infection of the nervous system is caused by the larva of Taenia solium, Cysticercus cellulosae. Established in nerve tissue, the cysticerci suffer degeneration, triggered by the host's immune system, and reach degrees of development. RESULTS: Patient DPLS, 42 years old, female, was hospitalized at the Regional Hospital of Araguaína (HRA) He sought medical attention for severe headache, nausea and vomiting. The patient reported that she had chronic headache, frontal, throbbing and severe intensity, daily starting two years ago, with no improvement with analgesic and worsening with stress, when waking and lowering the head. It is associated with fainting, dizziness, blurred vision, burning eyes and memory impairment. He also reported that he had an episode of syncope two years ago and had an anxiety problem in the past, treated with clinician with improvement in three months of treatment, and increased pain in the last 15 days. Patient has myopia and astigmatism 4.5 degrees in the right eye and 4 degrees in the left eye. On neurological examination he presented ocular pain when moving the orbit up and down and moving from right to left, in addition to photophobia. Computed tomography of the skull was requested in which lumps of nodular calcification were identified in the right and left parietal lobes, probably corresponding to the calcified nodular phase of neurocysticercosis. CONCLUSION: The late diagnosis can lead to the manifestation of several symptoms by the patient, worsening if not treated in time. The case reported reveals how important the early diagnosis of neurocysticercosis is for a good prognosis of the patient. Besides that it shows the existence of neurocysticercosis in the region.

Keywords: Neurocysticercosis. Parasite. Vesminosis. Public health

113. PROFILE OF NEOPLASIC CASES: STUDY BASED ON THE DEATH VERIFICATION SERVICE

Marcus Vinicius Lindoso Silva Veloso; Thamires Sales Ribeiro Emanuel Cabral Pereira; Roseline Braga de Carvalho; Monalisa Lea Matta Machado; Paulo Afonso de Oliveira Falcão Neto; Gyl Eanes Barros Silva

Universidade Federal do Maranhão (UFMA)
BACKGROUND: Cancer is an important public health problem. By 2014, 14.1 million people were expected to develop cancer annually according to WHO. The current cancer risk framework in Brazil and its trends show relevance in the field of public health and show the continuing need for research on this topic. The objective of this study was to evaluate the cases of death related to neoplasms. METHODOLOGY: This is a descriptive study, based on the retrospective data of the death certificate of the Death Verification System of São Luís, MA, Brazil, from 2011 to 2017, where epidemiological information and associated factors were collected. The analyzes were performed in STATA 14.0. There were 3754 deaths, of which $157(4.18 \%)$ were tumors. $54.60 \%$ were male. The age ranged from 1 to 104 years (mean of $66.53 \pm 17.46$ years), and a large part $(48.77 \%)$ were older than 70 years. The majority of the deaths were at home (54.90\%). Gastrointestinal tumors $(47.77 \%)$ and lung tumors $(14.01 \%)$ were the most frequent. The main comorbidity was smoking (75.76\%). Regarding the complications of the neoplasias that caused the death, the most prevalent were cachexia (39.68\%), septic shock (14.29\%) and respiratory insufficiency $(7.14 \%)$. CONCLUSION: The Death Verification Service corroborates the profile of cases involving tumors, which allows us to know the most frequent neoplasms, comorbidities and, mainly, the main complications that lead individuals with this disease to death. This information allows the implementation of a better clinical management when showing how the evolution of these cases may occur.

Keywords: Autopsy, Neoplasm, Description

114. ANALYSIS OF THE MORTALTY OF ISCHEMIC DISEASES OF THE HEART IN PINHEIRO, 2006-2016

Vinícius Santos Mendes Restier; Daniel Santos Uchôa; Antônio Luís Rodrigues Costa Júnior: Diego Paulo Barbosa Universidade Federal do Maranhão (UFMA)

BACKGROUND: Cardiovascular diseases (CVD), especially ischemic heart diseases, have a great impact on the life of the individual, due to the vasoconstrictive pathophysiological mechanism, base of the ischemic manifestations of the heart, whose outcome generates a high mortality rate, require early identification, specialized and complex care from hospital care to home care. METHODS: Descriptive, epidemiological study, carried out in 2018, covering the years 2006 to 2016, in the municipality of Pinheiro, with a population of 82,374 inhabitants. The data were collected from the Department of Informatics of the National Health System (DATASUS) of the Ministry of Health. RESULTS: According to a survey, the death outcome for ischemic heart diseases, in all, was $n=242$, which corresponds to $0.29 \%$ of the population, of which male predominates, $n=144(59.5 \%)$; present in the age group greater than or equal to 60 years, $n=170(70.2 \%)$; in pardos, $n=140(57.8 \%)$ and in none / low schooling, $n=176(72.7 \%)$. The episodes of this outcome occurred predominantly in the hospital area, $n=197$ $(81.4 \%)$; in elderly individuals over 60 years of age, $n=140(57.8 \%)$; with the highest number of cases in 2016, $n=38(15.7 \%)$. CONCLUSION: Although the occurrence of death corresponds to less than $1 \%$ of the population given the significant population of the municipality, it is inferred the existence of cases of underreporting of a disease of great prevalence in the population. The vast majority of the contingent affected, consisting of male, brown, elderly and low education subjects, concerns a population at risk and greater susceptibility to the fragility of public health preventive policies, as well as other levels of care.

Keywords: mortality, myocardial ischemia, public health

115. BILEO-PLEURAL FISTULA AFTER TRAUMA BY FIREARMS: A CASE REPORT Vitória Gonçalves Alves de Oliveira; Lais da Hora Lucena Silva; Maria Augusta Ribeiro Gaspar; Gabriel Mendes Costa; Mateus dos Santos Baroos; Thiago Sousa Dourado; Waslei Lima Santos Universidade Federal do Maranhão (UFMA)

BACKGROUND: Pleural effusion, whose composition is bile, is a rare condition, but of considerable severity. Most cases reported were results of direct bile flow into the pleural space through a fistula, or other defect in the diaphragm. The table should be considered in patients who develop a progressive effusion after gastrointestinal surgery, as well as in cases of penetrating trauma. CASE DESCRIPTION: L.C.L, 31 years old, male, victim of a firearm injury in the thoracoabdominal region, admitted to a regional hospital, coming from a transfer, where he underwent exploratory laparotomy, with gastrorrhaphy and bilateral thoracic drainage. Physical 
examination: 68\% saturation, tachycardic, dyspneic, with abdominal drain on the left flank and bilateral thoracic drains. It was stabilized with orotracheal intubation, but progressed with a new dyspneic condition. After computed tomography of the abdomen and thorax, pneumoperitoneum and suggestive of liver injury were evidenced; presence of bilateral pleural effusion, subcutaneous emphysema, right pneumothorax and bilatera atelectasis, in addition to signs of inflammatory bronchopathy. After repositioning of the thoracic drainage through radiography, repositioning was performed, with bile finding in the thoracic cavity due to biliary fistula, with drainage of about $500 \mathrm{ml}$ of secretion. The patient evolved with occlusion of the fistulous path and good prognosis. CONCLUSION: Injuries from penetrating trauma may progress with silent manifestation, with no clear evidence during exploration, raising the challenge in surgical practice. In the case in question, the patient had an evolution of 6 days to his finding, whose drainage of the liquid demonstrated a high flow rate due to poor drainage positioning. A more thorough analysis of patients at greatest risk for developing the condition is necessary for urgent resolution and treatment.

Keywords: Biliary fistula, Pleural effusion,Trauma.

116. EPIDEMIOLOGICAL ANALYSIS OF AMERICAN CUTANEOUS LEISHMANIASIS IN MARANHÃO FROM 2012 TO 2016

Raquel Alessandra Borges Silva; Cássio Henrique de Souza; Juliana da Costa Silva; Taciana Gabrielle Pinheiro de Moura Rodrigues Universidade Federal do Maranhão (UFMA)

BACKGROUND: American Tegumentary Leishmaniasis (ACL) is an infectious non-contagious disease of eminently chronic evolution that affects humans in several wild and domestic animals. In Brazil, the species Leishmania (Viannia) guyanensis, L. (Viannia) braziliensis and L. (Leishmania) amazonensis are the most common species. The manifestations of the discipline are induced by the leishmania involved, by the characteristics of the host and the response of the infected individual. METHODS: This study aims to describe the epidemiology of ACL in the state of Maranhão, between 2012 and 2016, through the Information System of Data Diseases Available from the Department of Informatics of the Brazilian National Health System - "DATASUS". RESULTS: According to the data found, there were 9.673 reports of confirmed cases of American tegumentary leishmaniasis in Maranhão during the period studied, resulting in an annual average of 1934.6 cases. The West was the most prevalent mesoregion in the state, reaching a 51\% percentage. The male sex was the most related in all analyzed years, accounting for $71.07 \%$ of the cases; in addition, the age group most affected was mainly from 20 to 40 years, with the economically active population accounting for $41.83 \%$, and the clinical form was mainly cutaneous, with more than $90 \%$ of the analyzed cases. CONCLUSION: The correct diagnosis through appropriate means and the effective notification and monitoring of the cases are functional contributions to collective health, benefiting the population and the researchers. It is necessary to develop more effective ways of filling out the compulsory notification sheets to make them more reliable to the epidemiological reality of the regions studied.

Keywords: American cutaneous leishmaniasis, Epidemiological profile Leishmania.

\section{PRESENTATION OF BILIARY LTIIASE AND CONFLICTS GENERATED BY THE} REQUEST OF SUBSIDIARY EXAMI

Mariana de Arruda Frazão; Fábia Vanuza Mendes dos Santos Assis; Alissa Costa Hirai; Carlos Brandão Feitosa Nina; Emanuella Lima Costa Chagas; Rayla Bezerra Rocha; Valeria Carvalho Ribeiro

Centro Universitário do Maranhão(CEUMA)

BACKGROUND: Biliary lithiasis corresponds to the presence of calculi in the gallbladder and biliary tract, and can progress to choledocholithiasis, cholangitis and cholecystitis. The symptomatology is well defined, and the diagnosis is made by clinical, laboratory and ultrasonographic criteria. Therefore, it is essential to have a quality anamnesis and a careful physical examination in order to avoid additional costs. CASE DESCRIPTON: C.SM, 53a admitted to the surgical clinic of a reference hospital, São Luís - MA complaint of severe pain in the epigastric region for seven days associated with nausea and vomiting, with the accentuation of the condition 3 days ago. Constipation 2 days ago.Negative cholestatic symptoms and fever Flacidity and palpation pain in the epigastric region.LEU14.850; PQT135.000; INR1,24; Ur83; Cr1,8; AST2; ALT180; FA1,64 ;; BD5,79 , B7.76, B7.56, Mg56
GGT372.ColangioRNM: $7 \mathrm{~mm}$ calculations in the middle third of hepatocolédoco, small dilatation of biliary tract and thin-walled gallbladder with thick bile.CPRE: hardening of duodenal papilla mucosa, performed biopsy, moderate dilatation of biliary tract, passage of biliary prosthesis.EDA: mild antral enantiomatous gastritis. TC of the abdomen: oval cystic formations with parietal impregnation, in the upper segment of the left lobe, suggestive of secondary implants or abscesses. Upper abdomen MRI: perfusion alteration in segment 4 of the left lobe. Gallbladder thickened in the fundic region with cystic formations. Dystrophy dilatation of the intrahepatic bile ducts in the common bile duct with suggestive calculus. A cholecystectomy was performed with biliary tract exploration. It evolved well postoperatively. CONCLUSION: The diagnosis is clinical, associated with laboratory tests and confirmation by abdominal USG. Overconfidence in complementary tests makes medical practice less personal and more technical, compromising the physician-patient relationship.

Keywords: Cholangitis; cholecystitis; physician-patient

\section{CLASSIFICATION OF SARCOPENIA AMONG PATIENTS IN HEMODIALISE, SÃO LUÍS - MA}

Suena Cristina Rodrigues de Carvalho; Elane Viana Hortegal Furtado; Lilian Fernanda Pereira Cavalcante; Carlos André Santos Leite Universidade Federal do Maranhão (UFMA)

BACKGROUND: Loss of muscle mass is a natural process, but in patients with renal disease this loss is aggravated, leading to sarcopenia. Sarcopenia is influenced by several complications associated with chronic kidney disease (CKD), which hampers the process of protein assimilation and induces the loss of muscle proteins, worsening sarcopenia. As a consequence, sarcopenia causes great damage to the quality of life of these patients, increasing the morbidity between them. Thus, the objective of this study was to classify sarcopenia among hemodialysis patients. METHODS: A crosssectional study with 149 patients over 20 years of age, in a regular hemodialysis program for at least 3 months. For the identification of the degrees of sarcopenia, cut-off points for lean mass were determined by means of the electric bioimpedance, integrity, through the manual grip strength test (FPM) and physical performance, through the walking speed. To determine the degrees of sarcopenia, the following cutoff points were considered: Sarcopenia Grade I: IMM between 5.75 and $6.75 \mathrm{~kg} / \mathrm{m}^{2}$ for women and $>8.5 \mathrm{~kg} / \mathrm{m}^{2}$ and, $10.75 \mathrm{~kg} / \mathrm{m}^{2}$ for men, and Sarcopenia Grade II: IMM , $5.75 \mathrm{~kg} / \mathrm{m}^{2}$ and , 8.5, women and men, respectively. In addition, socio-demographic variables, nutritional status and laboratory tests (creatinine and vitamin D) were verified. RESULTS: Of the total number of patients, (96\%) had reduced FPM and low muscle mass $(46.9 \%)$. The prevalence of grade 1 sarcopenia was (14\%) and grade $2(40.3 \%)$. Of the biochemical parameters evaluated, it was observed that among those diagnosed with severe sarcopenia, $37.5 \%$ had vitamin D insufficiency and $43.7 \%$ creatinine decreased, indicating loss of muscle mass. CONCLUSION: Sarcopenia is a powerful complicator for patients with CKD. Early diagnosis and treatment help reduce mortality in this group.

Keywords: Sarcopenia, renal dialysis, nutritional evaluation, nephropaty

\section{EPIDEMIOLOGICAL
2014 TO 2017}

Dante Rodrigues de Barros Vieira; Danilo José Brito de Arruda; Pedro Paulo Souza Chaves: Samuel Rodrigues de Morais Cunha Universidade Federal do Maranhão

BACKGROUND: Brazil is a country where leprosy presents an average of more than 30000 new cases per year at the present time, and until 1976 was a disease in which the patients had compulsory hospitalization, isolation in colonies and great stigmatization. Leprosy is a granulomatous and curable infection, which has the etiological agent Hansen bacillus, which has high infectivity and low pathogenicity. Contamination occurs mainly through the upper airways and depends heavily on immunity. Early diagnosis followed by treatment with polychemotherapy prevents and interrupts cutaneous involvement and its dermatological and neurological manifestations. At the conclusion of the diagnosis, the case must be notified to SINAN, since it is a notifiable disease. One of the states with the highest rate of leprosy cases is Maranhão, which justifies the relevance of this study, which aims to make an epidemiological analysis of leprosy in Maranhão from 2014 to 2017 and to emphasize the appropriate approach to disease control. METHODS: This is retrospective documentary research and a qualitative approach, with a 
survey in the SINAN database. RESULTS: Between 2014 and 2017 there were 13,781 new cases of leprosy in the state of Maranhão. The age group of 2064 years was affected in $69.96 \%$ of the cases, in the period 3646 cases with 2 to 5 lesions, paucibacillary, and 1089 with more than 5 lesions, multibacillary. Worth mentioning is the ignored number of 8955 cases without this definition. In this period the form of dimorphic leprosy surpasses all other joints, indeterminate, Tuberculoid and Virchowiana, with 7408 cases. CONCLUSION: This situation is a direct factor of lack of education, adequate nutrition, hygiene and basic sanitation, besides the population distribution in conglomerates or communities that facilitates the dissemination, factors that involve a large part of the population of Maranhão. In addition, underreporting of cases exists.

Keywords: Leprosy, epidemiology, Maranhão.

\section{ASSOCIATION OF CLINICAL AND ULTRASONOGRAPHIC PARAMETERS IN} DIFFICULT INTUBATION FORECAST

Andrey Salgado Moraes Filho; Caio Márcio Barros de Oliveira Universidade Federal do Maranhão (UFMA), Hospital São Domingos (HSD)

BACKGROUND: Difficult intubation is seen as the need for three or more intubation attempts or total process duration that exceeds 10 minutes. The importance of predicting this event is based on the possibility of predicting complications, reducing morbidity and mortality during orotracheal intubation, especially when it comes to the obese population. The use of ultrasound along with clinical indicators can identify such an eventuality by reducing the risks to the patient. In this perspective, the present study aims to determine which clinical and ultrasonographic parameter (s) correlate with the difficulty in performing orotracheal intubation. METHODS: A prospective, observational study with 75 obese patients indicated for videolaparoscopic gastroplasty who presented ASA II or III. Held during the period of July 2017 and July 2018 at the Hospital São Domingos located in the city of São Luís. Approved by the hospital's ZIP code $(2,114,516)$, for each patient, the ICF was presented. The following variables were collected: gender, weight, height, age, modified Mallampati index, thyrotonian distance, sternomental distance, cervical perimeter, buccal opening, and finally the skin-epiglottic distance by ultrasonography. The Stata 12.0 program was used for statistical analysis. RESULTS: Among the variables collected, only three were statistically significant ( $p$ ه.05), that is, they showed a difference when compared to the easy and difficult intubation groups: age $(p=0.0072)$, Mallampati index $(p=0.005)$ and mouth opening $(p=0.0212)$. CONCLUSION: Age, Mallampati index mouth opening showed good clinical parameters for prediction of difficult intubation.

\section{Keywords: DIFFICULT AIRWAY; OBESITY; ULTRASSONOGRAPHY.}

\section{CHARACTERIZATION OF MATERNAL MORTALITY IN THE STATE OF PIAUÍ} IN THE PERIOD FROM 2012 TO 2016

Marcos Santos Luz Leal; Mateus Santos Luz Leal; Thiago Paiva de Sousa; Mathews Resplandes Batista Batista

Universidade Estadual Do Maranhão (UEMA)

BACKGROUND: Maternal mortality is the death of the woman during the gestational period or within 42 days at the end of gestation, occurring independently of the duration, due to causes related or aggravated by pregnancy or measures taken in relation to it. It represents an aggravation to public health, being an important indicator of the health of women and the population, since it depends on the quality of medical care during prenatal, delivery and postpartum. METHODS: This is a retrospective quantitative epidemiological study whose data source is the Mortality Information System between 2012 to 2016, in the state of Piauí. The variables considered were: age, macro-region of health and obstetrical cause. RESULTS: 48 maternal deaths occurred in 2012, of which 25 were from direct obstetric causes and 22 from indirect obstetrical causes. In 2013, there were 44 maternal deaths, 26 of which were caused by direct causes and 16 by indirect causes. In 2014 there are 33 maternal deaths, 25 of which are caused by direct causes and 8 by indirect causes. In 2015, there were 41 maternal deaths, 30 of which were caused by direct causes and 10 by indirect causes. In 2016, 38 maternal deaths occurred, 33 of which were caused by direct causes and 4 by indirect causes. The higher prevalence of deaths due to direct obstetric causes indicates difficulties in access to quality care, a factor that is notable in the macroregions of the interior of the state, and the macro region of Floriano presented higher numbers of maternal deaths in relation to the others in the period analyzed. A higher rate of maternal death was recorded in the age group with the highest number of births, although there is a higher risk for those under 15 or over 35 years of age. CONCLUSION: Over the years, there has been a slight reduction in maternal mortality over the years. However, training of professionals, based on public policies, would enable an early diagnosis of the vulnerability of the pregnant woman.

Keywords: Mortality, Maternal, Epidemiology, Piauí

\section{APPENDIX MUCOCELE - CASE REPORT}

Thiago Sousa Dourado; Rodrigo Lira Sousa Lima; Paulo Gabriel Sacramento Silva; Vitoria Gonçalves Alves de Oliveira; Elizeu Bruno Santos Silva; Santiago Cirilo Noguera Servin

Universidade Federal do Maranhão (UFMA)

BACKGROUND: The mucocele of the appendix is a dilatation of this organ due to the accumulation of mucoid secretion. This accumulation occurs slowly and gradually, with no signs of infection. The patient is most often asymptomatic. The most common symptom is abdominal pain, and the presence of palpable mass in the right iliac fossa and weight loss may also be observed. CASE DESCRIPTION: Patient F.P.C, 58 years old, male. He was undergoing treatment for hepatic steatosis, with changes in his life habits and interruption of alcohol consumption, however, without improvement of the condition. He performed a nuclear magnetic resonance, which identified cystic appearance tubuliform formation in the topography of the cecal appendix, and may correspond to the appendicular mucocele. The patient then performed a computed tomography scan of the abdomen, which suggested the same diagnosis. The patient was admitted and admitted to a private hospital in São Luís, Maranhão, asymptomatic. Laparoscopy was performed, and during the procedure, the appendix and cecum were released until the right colon was fully detached. Once the appendix was mobilized and exposed, resection of the cecum part of the appendix was performed. The cecum was released into the cavity, reassessed after restoration of the pneumoperitoneum and surgery was terminated with the placement of a drain. In the postoperative period, the patient remained hospitalized for 4 days in the use of antibiotics and symptomatic patients. She presented good evolution and was discharged in good general condition. CONCLUSION: The diagnosis of this pathology is confirmed in the majority of cases only in the postoperative period. It is important to keep in mind the possibility of this diagnosis when there is an appendicular tumor with these characteristics. During surgical removal of the appendix, care should be taken to avoid rupturing the appendicular mucocele, because in case of malignant etiology, it may disseminate neoplastic cells int

Keywords: mucocele, appendix, abdomen

123. PREVALENCE OF ENTEROPARASITOSIS IN CHILDREN HOUSED IN A SUPPORT HOUSE IN SÃO LUÍS / MA

Mariana da Silva do Nascimento; Nilson de Jesus Pereira Batalha Junior; Jessyca Wan Lume da Silva Godinho; Camila Arguelo Biberg Centro Universitário ITPAC (UNITPAC) Universidade Federal do Maranhão (UFMA)

BACKGROUND: Intestinal parasites are one of the main public health problems and are closely related to sociodemographic and environmental factors. Among these, we can mention the precarious socioeconomic conditions, consumption of contaminated water, nutritional status of individuals, among others. Several studies of the prevalence of parasitoses have been carried out and it is observed that the infant population is the most affected by enteroparasitoses. This study aimed to evaluate the occurrence of intestinal parasites in children of a shelter in the city of. And present prophylactic measures to the study group. METHODS: A field study was conducted, stool specimens were collected from children 0 to 12 years of age living in the Casa de Passagem Shelter. Samples were analyzed for their macroscopic and microscopic characteristics. In the macroscopic analysis, the consistency, odor, presence of mucus or blood and parasites or parts of them in the feces were evaluated. The spontaneous sedimentation method was used for the microscopic evaluation of the presence of morphological forms of parasites. In order to present prophylactic measures, health education, play activities were carried out with the group of children. All individuals participating in the study signed the Informed Consent Term. RESULTS: Eleven samples (73.3\%) were found 
in the 15 analyzed samples, $92.8 \%$ for protozoa and $7.2 \%$ for helminths. The most frequent parasites were Entamoeba coli (42.8\%), Endolimax nana $(35.7 \%)$ and Guiardia lamblia (14.2\%). CONCLUSION: This study confirms the high occurrence of intestinal parasites in children, mainly due to socioeconomic conditions and precarious health education habits, demonstrating the need for actions aimed at prophylactic measures as a means of preventing the increase of the rate of parasitosis and guaranteeing an improvement quality of life.

Keywords: Enteroparasites, Children, Health Education.

124. EVOLUTION OF MORTALTY BY MYOCARDIAL INFARCTION IN STATE OF MARANHÃO FROM 1996 TO 2015

Luciano Beltrão dos Reis Viana; Caio Marcio Barros de Oliveira; Aline Maria de Lemos Araújo; Beatriz Matos Costa; João Paulo Nascimento Miranda; Larissa Moreira Atta; Valeria Meneses Sousa Universidade Federal do Maranhão (UFMA)

BACKGROUND: Ischemic heart disease is an important cause of morbidity and mortality in Brazil, and acute myocardial infarction (MI) is one of the main causes of death, especially in regions with lower socioeconomic status. In recent years, the epidemiological transition, which occurred late in the northeast region of Brazil, contributed to the increase of chronicdegenerative diseases, causing changes in the panorama of the incidence of $\mathrm{MI}$ in the State of Maranhão. Objective: To describe the evolution in the mortality of acute $\mathrm{MI}$ in Maranhão over the last two decades, identifying the highest prevalences, according to age and gender. METHODS: Epidemiological and descriptive study, with data from Department of Informatics of the Brazilian National Health System (DATASUS), analyzed by Excel 2016 software. The population of study was composed of all deaths recorded by acute MI in the state between Jan/1996 and Dec/2015. RESULTS: The total number of deaths increase substantially. In 1996, 432 were reported; and in 2015 a total of 3159. The prevalence between the genders remained approximately constant: $37.6 \% \pm 2.1 \%$ (Mean \pm SD) in female, and $62.2 \% \pm 1.9 \%$ in male. There was significant difference $(p \quad 8.05)$ in the number of deaths by sex. The most affected age group was 70-79 years, concentrating $24.16 \%$ of the total deaths of the period. As of 2013 , mortality in the age group of over 80 years exceeded that of $70-79$ years. CONCLUSION: The data presented demonstrate the relevance of acute $\mathrm{MI}$ as a serious public health problem in the State. The increase in the mortality rate can be explained by the incomplete and late epidemiological transition of the region, leading to an increase in life expectancy and, together, an increase in its complications without adequate health care for the demand generated. Thus, we can see the Brazilian epidemiological transition not in a unified form but with specific socioeconomic, environmental, demographic and cultural specificities.

Keywords: Acute Myocardial Infarction, Epidemiological Transition, State of Maranhão

125. TECHNIQUE OF HYBRID REVASCULARIZATION IN A PATIENT WITH PERIPHERAL OBSTRUCTIVE BLOOD DISEASE

Danilo José Brito de Arruda; Ana Beatriz Santos Cantanhede; Erico Murilo Monteiro Cutrim; Katherynne Bezerra Marques; Michelly Sampaio Bonates Durans; Sebastião Barreto de Brito Filho; Vanisse Portela Ramos

Universidade Federal do Maranhão (UFMA)

BACKGROUND: Critical ischemia of the lower limbs consists of an advanced stage of peripheral arterial obstructive disease (PAOD) in which there is pain at rest or presence of trophic lesions. There is a risk of limb loss. To approach this condition, hybrid surgery has been used. Hybrid vascular surgery consists of the use of the two main approaches to periphera obstructive arterial disease - surgical bypass and endovascular angioplasty. It aims to combine the advantages of each method - such as the long-term patency of the grafts, associated with the greater speed and the lower morbimortality of the endovascular procedures. This paper aims to report the case of a patient with PAD undergoing the hybrid revascularization technique. RESULTS: R.R.A, male, 72 years old, SAH and DM, with lower right leg pain (MID) for 3 years, associated with paraesthesia increased for 3 weeks. At the examination: necrotic lesion in the calcaneus, third and fourth toes. Hyperpigmentation and hyperemia in the distal region of the limb, with unfixed cyanosis in the second pododactyl. Arteriography: right deep femoral artery with multiple stenoses; superficial femoral occluida after the origin, refilling in the channel of Hunter; with occlusion in the joint line. Arteries anterior tibial, posterior tibial and fibular occluded, without formation of the plantar arch. Ankle-brachial index (ABI) can not be assessed. Performed suprapatellar femoropopliteal by-pass with ITB: 0.41 Due to the persistence of pain, a new Arteriography ( 7 days after) was performed with evidence of previous graft and submitted to angioplasty with fibular artery ballooning. Patient evolves without pain, with wound healing and new ITB 0.8. CONCLUSION: The procedure demonstrates numerous advantages, evidenced by its increasing use in surgical practice. In the case, the surgery by hybrid technique brought satisfactory results, demonstrating clinical and functional improvement of the affected limb.

Keywords: Hybrid Revascularization, Peripheral Obstructive Artery Disease, Bypass, Angioplasty.

\section{OCULAR JUVENILE HERPES ZOSTER, A CASE REPORT}

Rafhael Richardson Gomes Silva; Laura Barros de Brito; Thaíse Maria de Morais Carvalho; Isadora Léda Braga; Juliana Pereira Rosa; Maria Gabriela Martins Silva; Adriana Leite Xavier Bertrand Centro Universitário do Maranhão (CEUMA)

BACKGROUND: Herpes zoster ( $\mathrm{hz}$ ) is a disease caused by the reactivation of varicela-zóster virus, which presents painful skin and bubbles, especially in thorax and abdome. Occurring in any age group, entretanto is more common in patients greater than 40 years old with varicela history or in immunodeprimidos. The objective of this is to report a case of eye hz eye, of inadequate initial management, generating compromise of the cornea and visual acuity, despite of correct therapy therapy. CASE DESCRIPTION: mnf, 12 years, parda, natural of rosary, seek medical attendance in the municipal hospital djalma marques with complaint of pain in the right eye there is 8 days. Refer also that there is 8 days presented pain in straight hemiface, followed by bubbles that burst and evolve for wounds in this region. Pallotage bleed and patient lost vision from this side. Three days after the beginning of the frame, looking for upa from his city, where had received medication for pain, antibiotic for domiciliary use (do not know what) for a week and the orientation of cleaning the wound with water and soap and passing nebacetin in skin injuries. Without better, he stopped medication after 5 days and decided to come to são luís. Ectoscopy infectious, coalescent ulcered injuries, in right face, important bipalpebral edema, impossibilitating the view of the right eye. To the biomicroscopic exam: corner ulcer, involving any extension of this. Visual acuity of vultures. Prescription aciclovir $5 \%$ oftalmic ointment, systane ul $3 / 3$ hour column and aciclovir oral $200 \mathrm{mg}$ of $6 / 6$ hours. The patient evolved with $20 / 200$ visual acuity correction in this eye and was enrolled in the row of the cornea transplant. CONCLUSION: HZ has become more frequently, accompanying an important number of children, which requires a minuting ophthalmological evaluation to prevent and treat serious injury and to avoid greater damages, like the irreversible loss of vision.

Keywords: herpes zoster, cornea, virus.

127. ANALYSIS OF DEATH CERTIFICATE IN MARANHÃO BY ACUTE MYOCARDIAL INFARCTION AND CEREBRAL VASCULAR ACCIDENT IN THE PERIOD FROM 2007 TO 2016

Lucas Henrique Ferreira de Sousa; Ítalo Henrique Pereira Lima; Dayna Maria Caldas Diniz; Beatriz Ferreira Feitosa; Sueli de Souza Costa

Universidade Federal do Maranhão(UFMA)

BACKGROUND: Noncommunicable Chronic Diseases represent an important part of the number of deaths in the world population, especially Cardiovascular Diseases. Cerebral Vascular Accident (CVA) and acute myocardial infarction (AMI) are within this group. Some of the risk factors for these diseases consist of being male and of a more advanced age. METHODS: A quantitative epidemiological study of a descriptive approach with data collection of death certificates digitally available in DATASUS, with a basic cause, ICD I64 and I219, in the State of Maranhão (MA) in the 20072016 period. Descriptive statistics were used using the Tabwin 4.1.3 and Microsoft Excel 2010 programs. RESULTS: In the study period, $15.5 \%$ of the deaths in the State of Maranhão were caused by unspecified stroke or nonspecified AMI, the former corresponding to $7.4 \%$ of deaths in this period and the second to $8.1 \%$. Between 2007 and 2011 , stroke mortality was higher than that for AMI, however, as of 2012, this situation reversed leading to a higher number of AMI deaths. During the period, there was a 
decrease in the percentage value of mortality due to stroke, while mortality from AMI increased both percentage and absolute numbers. In relation to sex, both men predominate. Regarding the age group, in both CIDs the mortality is higher in the 60-79 years, followed by the age group of 80 to 99 years in stroke; already in the IAM it was observed alternation of the age groups of 40 to 59 and of 80 to 99 years, being this predominance in the last years. CONCLUSION: The mortality from cardiovascular diseases is high, with stroke and AMI accounting for almost 1/6 of the deaths, as a whole, during the period studied. It was observed that there is predominance in males, as predicted in the literature. In this way, it suggests that more campaigns aimed at the prevention of these diseases are practiced.

Keywords: Mortality; Myocardial Infarction; Stroke

\section{BOCHDALEK HERNIA IN ELDERLY: CASE REPORT}

Jessika Freitas de Sousa; Evandro Oliveira Rodrigues de Sousa; Jane Augusto Guimarães Gonçalves UNITPAC

BACKGROUND: Bochdalek hernia is caused by the inadequate embryologica development of the diaphragm, usually left, with postero-lateral location manifesting in the first months of life, with systemic impairment. In adults a rare occurrence with slightly more than 100 cases described, these are generally asymptomatic and may present gastrointestinal symptoms and rarely, non-specific respiratory symptoms. The aim of this study is to report a case of Bochdalek hernia in an elderly patient diagnosed as incidental radiological findings. CASE DESCRIPTION: Patient, male, 97 years old admitted to the Regional Hospital of Araguaína with right hemiplegia dysarthria and deviation of right labial commissure, associated with agitation and disorientation. After the initial examinations, it is evidenced in anteroposterior chest radiograph, diaphragmatic dome elevation on the right and an image suggestive of an intestinal loop in the chest. Requested computed tomography of the chest without contrast that evidenced in axial section at the thorax intrathoracic intestinal loops. It was decided not to surgically approach the patient, since the abdominal apparatus was unchanged and because of the benefit-risk considering the patient's age and maintaining the clinical conduct of the presented neurological picture. CONCLUSION: The patient in question did not present complaints or compromise the physical examination of these devices, being the Bochdalek hernia, in this case, to the right and a radiological finding and withou systemic alterations. Unlike the others that present with respiratory and abdominal manifestations with life-threatening to the patient, whose immediate surgical intervention is impartial conduct.

Keywords: Hernia, Bochdaleck, radiological finding

129. A CASE OF ANTIDEPRESSANT DISCHARGE SYNDROME: DULOXETINE Mayara Sousa da Silva Serejo; Viviani Gonçalves Versiani; Karollanny Alves Costa Lima; Helena Fontoura Santiago; Larissa Borges Carvalho; Joao Florencio Monteiro Neto; Rebeca Machado Ferreira De Castro

Centro Universitário do Maranhão (CEUMA)

BACKGROUND: Antidepressant discontinuation syndrome is a set of symptoms that may occur after a sudden cessation (or marked reduction in dose) of an antidepressant medication taken continuously for at least one month. Duloxetine is a drug with a high potential for the development of the discontinuation syndrome, as it is an antidepressant for the reuptake of serotonin and noradrenaline with a half-life of only 12 hours, considered to be very short compared to other drugs. CASE DESCRIPTION: A 30-year-old female patient arrives at a neurology clinic with complaint of severe headache. The doctor prescribed Duloxetine $60 \mathrm{mg}$. After 45 days of use, the patient discontinued treatment. On the third day after the interruption, episodes of hypertension with peaks of $170 \times 100 \mathrm{mmHg}$, excessive weariness and perspiration, sensation of face fractures, delusions, nightmares, vivid dreams, insomnia, dizziness, acute anxiety, irritation, euphoria, nervousness, difficulty expressing themselves through speech and mood swings. All these symptoms remained for a period of 08 days until on her own the patient returned to use the medication. The day after his return, all these symptoms had already ceased. The patient started the weaning process. At the end of this, withdrawal symptoms resurfaced. Thus, the patient sought care with a psychiatrist, who prescribed Agomelatine, anti-depressant melatoninergic agonist and serotonergic antagonist. After 15 days of initiation of treatment, the patient stopped presenting symptoms of the syndrome caused by the discontinuation of Duloxetine. CONCLUSION: The prescription of antidepressant drugs deserves special attention by physicians, and one of the reasons for this is the risk of developing Discontinuation Syndrome, which can cause great harm to the patient's quality of life.

Keywords: Duloxetine, Abstinence, Syndrome, Discontinuation, Antidepressants.

HEALTH EDUCATION: PREVENTION OF PENIS CANCER IN THE MUNICIPALTTY OF PINHEIRO -MA

Jéssica Ferreira Bertoldo; Taynah Calixto Martins: Amanda Cristina dos Santos; Lucas Henrique Ferreira de Sousa; Ítalo Henrique Pereira Lima; Ana Paula Gameiro Capelli; Sueli Souza Costa

Universidade Federal do Maranhão (UFMA)

BACKGROUND: Penile carcinoma or penile cancer (PC) is a malignant neoplasm characterized by persistent wounds or ulcers on the glans, with discoloration. The main risk factors associated are poor hygiene, phimosis, human papillomavirus (HPV), low socioeconomic levels, smoking, and uncircumcised individuals. In Brazil, it accounts for $2 \%$ of all cases of male urogenital cancers. In Maranhão, 22.7\% of the cases were counted, with 15 deaths in 2015. The main objectives of the study were to analyze the knowledge of the population about the $\mathrm{CP}$, and to raise awareness and enable the target public to carry out prevention and early detection. METHODS: This is a descriptive study based on a pre-elaborated questionnaire distributed to participants in a circuit. Each participant answered the questionnaire before and after the circuits and these were analyzed and tabulated through Microsoft Excel 2010. RESULTS: With regard to $\mathrm{CP}$ prevention through lavage, the results obtained previously inferred that $82.4 \%$ of respondents answered correctly, to $97.8 \%$ after the completion of the circuit, and the remaining $2.2 \%$ said they did not know. Regarding the appearance of a wound as a precipitating factor, it was recorded that $73.6 \%$ responded correctly, passing to $92.3 \%$ at the end of the course, with $3.3 \%$ who answered wrong and $4.4 \%$ did not know. Regarding the treatment the initial results showed that $36.2 \%$ of the participants responded correctly, and at the end of the lectures it rose to $60.4 \%$. CONCLUSION: It can be noticed that the circuit about the $\mathrm{CP}$ obtained positive results in relation to the information provided, since we obtained increase of the correct assertions in the post-circuit questionnaires. With this, it is observed that it is necessary to carry out more work aimed at informing the population about this type of cancer and even other subjects with few debated ones, with the purpose of disease prevention.

Keywords: Penile Neoplasms; Health education; Men's Health

131. CLINICAL PROFILE OF LEPROSY IN THE MUNICIPALITY OF PINHEIRO: REIROSPECTIVE ANALYSIS

Rafael Lima Soares: Daniel Santos Uchoa; Luís Carlos Machado e Silva; Erika Cristina Moura da Silva Negreiros Universidade Federal do Maranhão (UFMA)

BACKGROUND: Leprosy is a chronic, granulomatous, slow - onset disease caused by Mycobacterium leprae and considered a public health problem due to peripheral neural involvement and its incapacitating potential. In Brazil, 151,764 new cases were registered, from 2012 to 2016, of these 25,218 cases only in 2016, representing a detection rate of 12.2 / 100 thousand inhabitants. Deficiencies in the active search of the patients, delayed diagnosis, the precariousness of the public system and lack of information about the damages caused by the disease, make the situation of this infection in the country alarming, despite being considered easy diagnosis and treatment. Thus, this paper attempts to trace the clinical profile of patients with the disease in Pinheiro - MA. METHODS: A descriptive, epidemiological study, carried out in 2018, for the year 2016, in the municipality of Pinheiro, in the state of Baixada Maranhense, with a population of 82,374 population. Data were collected from the Department of the Unified Health System (DATASUS), the Ministry of Health. RESULTS: A total of 55 reports were identified in the year 2016, of which 3 were 0 to 14 years old and 52 were aged 15 years or older. Of all these cases, three were of the indeterminate form, 13 of the turberpoid form, 20 of the dimorphous form, 16 of the Virchowian form, one unclassified case and two cases ignored. DISCUSSION: The notification of 3 cases in children under 15 indicates that there is still a high rate of transmissibility in the region. Among the clinical-operational classification, there is a greater number of 
cases with multibacillary leprosy (36), which proves the need for immediate therapeutic intervention, combined with early diagnosis, leading to interruption of the transmission chain. It is noteworthy that more than $5 \%$ of the cases were not classified or ignored, which shows failure to follow the patients.

Keywords: Leprosy, Mycobacterium leprae, Public health.

132. EVALUATION OF THE RISK OF DEVELOPMENT OF TYPE 2 DIABETES IN USERS OF A SHOPPING MALI

Vítor Gabriel Soares da Silva; Amanda Barcelos Simili; Bruna Cunha Aires; Debora Priscyla Gigante De Sousa; Fernanda Oliveira Queiroz; Leticia Carollyne Prado Do Nascimento; Mariana Caixeta Sat'Ana Universidade Federal do Maranhão (UFMA)

BACKGROUND: Type 2 diabetes mellitus (DM2) is a metabolic disease characterized by high levels of blood glucose, a situation that chronically leads to cardiovascular, renal, ocular and other complications. Because of their morbidity and mortality, prevention and screening are key to avoiding comorbidities. In this scenario, the Finnish Diabetes Risk Score (FindRisc) questionnaire is an instrument that assesses the risk for the development of DM2 in the next 10 years, with sensitivity of $81 \%$ and specificity of $76 \%$; thus, the objective was to evaluate the risk of part of the population that goes to a mall in Imperatriz - MA - and to identify the predisposing factors most involved. METHODS: The approach chosen was the transversal approach with non - probabilistic sampling by traffic in a mall in a city of Maranhão during one day. Anthropometric data were measured, such as height, weight and abdominal circumference, followed by application of the questionnaire with FindRisc and socioeconomic data. A total of 120 individuals participated. The data were tabulated in Excel $\circledast$ and the statistical analyzes performed in BioEstat $5.0 \AA$. RESULTS: It was observed that $16.6 \%$ of the interviewees had a high or very high risk, implying that such individuals may up to a $50 \%$ chance of being affected by DM2. Of these, 16 individuals (80\%) were female. There were general findings: $40 \%$ had a first-degree relative with DM: $31.7 \%$ had the abdominal circumference above the recommended one; $36.7 \%$ in overweight and $20.9 \%$ in obesity. Statistically, the variables that showed the greatest significance were female gender, schooling below the ninth year, age above 45 years, family history for DM2, use of hypertension and obesity. CONCLUSION: The use of FindRisc should be encouraged because it is a reliable, fast, low-cost and noninvasive instrument that allows the identification of predisposing factors. In addition, it can be used as a basis for health education in public places.

Keywords: Preventive Medicine; Type 2 Diabetes Mellitus; Predisposing Factors; Health education

\section{SCREENING AND EARLY DIAGNOSIS}

Werbene Caroline de Queiroz Gomes; Gideon Batista Viana Júnior: Kaiza Vilarinho da Luz; Fernando Cleydson Lima Paiva Filho; Raynnara Carvalho Silva; Mayara Pessoa Feitosa; Orientadora: Eliana Campelo Lago

Universidade Estadual do Maranhão (UEMA); Universidade Estadual do Piauí (UESPI).

BACKGROUND: Breast cancer is the most common neoplasm among women worldwide. It is considered a cancer of relative good prognosis, when diagnosed and treated early. Age is the major risk factor for female breast cancer. The objective of this study was to present the Brazilian epidemiological survey comparing the different regions of the country regarding the prevalence of breast cancer in the period from 2010 to 2017. METHODS: This is an exploratory-descriptive study with a quantitative approach. Data collection was performed through the collection of data from the Hospital Information System of SUS (SIH / SUS), provided by DATASUS RESULTS: Between January 2010 and December 2017, 433,204 cases of breast cancer hospitalizations were reported in Brazil, the majority of which were female patients, with 427,705 cases $(98.73 \%)$, and the highest number of cases was 2017, with 64.931 (14.99\%) cases of hospitalizations. In this interval, the Southeast Region had the highest number of cases, with $223,145(51.51 \%)$, mainly 50-59 years old, representing 62,877 $(28.18 \%$ cases, mostly white, totaling $115,071(51,57 \%)$ cases with $19,877(8.90 \%)$ deaths. The Northeastern Region was followed by 90,094 (20.80\%) cases, mostly 50-59 years old, with 23750 (26.36) cases, and brown, making up $55,057(61.11 \%)$ of the cases. cases, of these $7.032(7.90 \%)$ evolved to death. In Brazil, the number of deaths was 36,309 (8.38\%). CONCLUSION: Based on the data presented, it can be observed that the prevalence and mortality due to neoplasia present differently among the regions of the country. It is worth emphasizing the need to know better the different social strata with the objective of establishing effective strategies for better screening and early diagnosis, essential for a better therapeutic result and prognosis of the cases.

\section{Keywords: BREAST CANCER, PREVALENCE, EARLY DIAGNOSIS}

\section{PHOTOPROTECTION BEHAVIOR AND SELF-EXAMINATION IN SÃO LUÍS- MA (BRAZIL)}

Luciano Beltrão dos Reis Viana; Carolina Nívea Moreira Guimarães; Beatriz Matos Costa; Claudio Henrique de Melo Pereira Filho; Jamille Silva Almeida; Lidmar Costa Lima Júnior; Ricardo Tadeu Villa

Universidade Federal do Maranhão

BACKGROUND: Photoprotection is a set of habits that helps minimize the damage caused by sun exposure. With the increase of numbers of cutaneous neoplasms in the Brazilian population, these protection mechanisms have become, together with self-examination, an important tool in health promotion. The objective of the study was to carry out a situational diagnosis of the behavior of photoprotection and skin selfexamination in users of basic care in São Luís-MA. METHODS: Observational and transversal quantitative study. A questionnaire validated by the Brazilian Society of Dermatology containing 27 objective questions about the characteristics of the participants, behaviors in photoprotection and selfexamination of the skin was used. RESULTS: Our sample had the following characteristics: $68 \%$ of the female sex $(n=77)$, with higher education $(31 \%$, $n=31)$, phototype III $(41 \%, n=44)$. The majority of respondents stated that they never get sun exposure with the intention of sunbathing $(47 \%, n=54)$, never had sunburn (55\%, $n=64)$, photoexposure $30 \mathrm{~min}$ from $11-15 \mathrm{~h}(66 \%$, $n=77)$, did not wear long clothing $(60 \%, n=65)$ or headgear $(47 \%, n=55)$, always protected in shade $(49 \%, n=57)$, and $(36 \%, n=42)$. As for selfexamination, most consider it important $(58 \%, n=65)$, source of anxiety $(33 \%, n=37)$, and do it regularly $(42 \%, n=47)(36 \%, n=41)$, and in that case, they would seek the doctor $(46 \%, n=52)$, who would be able to make the diagnosis $(41 \%, n=46)$. CONCLUSION: It is observed that, even in the face of a low daily exposure to the sun's rays, the population studied does not cultivate the habit of using mechanisms with a sun protection factor, so it is still necessary to consolidate their need in view of the risk development of skin cancer.

Keywords: self-examination, cutaneous neoplasms, self-care

\section{PREVALENCE OF METABOLIC SYNDROME IN PATIENTS WITH POLYCYSTIC} OVARIAN SYNDROME

Emilly de Jesus Garcia Ataide; Luciane Maria Oliveira Brito; Haissa Oliveira Brito; Aline Maria de Lemos Araujo

Universidade Federal do Maranhão

BACKGROUND: Metabolic Syndrome (MS) can be defined as a complex disorder characterized by central obesity, dyslipidemia, hyperglycemia and systemic arterial hypertension, representing a great challenge to public health. According to Ehrmann et al, in women with Ovarian Syndrome, the prevalence of MS is about 33.4\%. METHODS: Cross-sectional study in patients attended at a Gynecology Outpatient Clinic of the University Hospital of the Federal University of Maranhão. For the determination of MS, the criteria of National Cholesterol Education Program's Adult Treatment Panel III (NCEP ATP III) were applied. We evaluated 100 patients, 59 in the test group and 41 in the control group. The prevalence of MS and its components HDL, Waist Circumference, triglycerides, blood pressure and fasting blood glucose were evaluated. RESULTS: The MS was present in $35,6 \%$ of women with PCOS and in 7,3\% women without diagnostic of PCOS. In the group of PCOS, among the components of MS, it was obtained a prevalence of $76,2 \%$ of women with $\mathrm{HDL}$ values lower than $50 \mathrm{mg} / \mathrm{dL}, 54.2 \%$ of women with Waist Circumference values higher than $88 \mathrm{~cm}, 47.4 \%$ of women with triglyceride values higher or equal to $150 \mathrm{mg} / \mathrm{dL}, 27.1 \%$ of women with blood pressure values higher or equal to 130 by $85 \mathrm{mmHg}$ and $6.7 \%$ of women with glycemic values higher or equal to $110 \mathrm{mg} / \mathrm{dL}$. While in the control group it was obtained a prevalence of $60,9 \%$ with $\mathrm{HDL}$ of less than $50 \mathrm{mg} / \mathrm{dL}, 21.9 \%$ with Waist Circumference higher than $88 \mathrm{~cm}, 7.3 \%$ with triglycerides higher than or equal to $150 \mathrm{mg} / \mathrm{dL}$, $4.9 \%$ with blood pressure values higher or equal to 130 by $85 \mathrm{mmHg}$ and there was not register of patients with fasting glycemia higher or equal to $110 \mathrm{mg} / \mathrm{dL}$. CONCLUSION: It is observed the high prevalence 
of Metabolic Syndrome in patients with PCOS. In order to prevent future complications, treating early manifestations and insulin resistance is crucial in the management of these patients.

Keywords: Polycystic Ovarian Syndrome, Hyperinsulinemia, Metabolic Syndrome

\section{PROFILE OF THE USE OF VASOACTIVE DRUGS IN PATIENTS DIAGNOSED} WITH SEPSIS OR SEPTIC SHOCK

Lais Maria Gaspar Coelho; Francisca Luzia Soares Macieira de Araújo; Thayná Catarino Leite; Abel da Silva Araújo; Laura Sales de Carvalho Lima; Gleydson Cavalcante Nogueira; Luiz Nycollas Carneiro de Oliveira

Universidade Federal do Maranhão (UFMA)

BACKGROUND: In the intensive care units, vasoactive drugs are among the most widely used drugs, since they aid in the treatment of patients with the aim of correcting hemodynamic instability. Thus, the present study aims to describe the profile of the use of vasoactive drugs in patients with sepsis or septic shock in an Intensive Care Unit (ICU) of a public hospital in São Luís, Maranhão. METHODS: This was a retrospective study, based on the analysis of hospital records of 55 patients admitted to the ICU of a public hospital in São Luís, Maranhão, Brazil, with a diagnosis of sepsis or septic shock during hospitalization from January 2017 to December 2017 Patients less than 18 years of age and those with a hospitalization time of less than 24 hours were excluded from the study. RESULTS: Of the 55 patients included in the study, the mean age found was 64 years, with $54.5 \%$ men. $41.8 \%$ of patients diagnosed with sepsis or septic shock were not medicated with vasoactive drugs. As for those who underwent this class of medication $90.6 \%$ were medicated with noradrenaline and $9.3 \%$ received noradrenaline and dobutamine concurrently. The mean time of use of vasoactive drugs was 4.5 days. CONCLUSION: Observed data reveal a high prevalence of vasoactive drugs in patients with sepsis or septic shock. Norepinephrine, on the other hand, is widely used in this class of drugs.

Keywords: intensive therapy, vasoactive drugs, shock, sepsis, septic shock, hemodynamic instability

\section{POST-TRAUMATIC STRESS IN PREGNANCY TOXEMIA TRACING IN} PRIMARY HEALTH CARE

Juliana Lins da Paz Portela; Letícia Rezende da Silva Sobral; Márcia Rodrigues Veras Batista; Adriana Sousa Rêgo; Ricardo da Rocha Porto; Edna Coutinho da Silva; Flor de Maria Araújo Mendonça silva Centro Universitário do Maranhão (CEUMA), Fundação de Amparo à Pesquisa e Desenvolvimento Científico do Maranhã̃o (FAPEMA)

BACKGROUND: Pregnancy toxemia is multisystemic disease, occurs late in pregnancy with clinical manifestations associated with hypertension and proteinuria; with risk of developing post-traumatic stress disorder, which is a disorder due to traumatic situations related to childbirth that are major risk factors. OBJECTIVES: To evaluate the presence of symptoms of posttraumatic stress in pregnancy toxemia in women attending Primary Health Care. METHODS: Cross-sectional study, data collection by filling out a sociodemographic questionnaire and posttraumatic stress evaluation in 72 Attention women Primary School in São Luís (MA), from February / 2016 to February / 2018. Data analyzed in STATA 14.0 software; qualitative variables by absolute and percentage frequencies; Qualitative and nominal categorical variables by Chi-square test with significance level of 0.05 . Poisson regression and Test Parm for non-binary variables. RESULTS: Prevalence of first pregnancy age range 18-21 years $46(63.89 \%)$; between $1-3$ pregnancy 56 (77.78\%); elementary school $67(93.06 \%)$; brown color $46(63.89 \%)$; marital status with partner $52(72.22 \%)$; Catholic religion $45(61.36 \%)$; without renumbered activity 43 (59.72\%); use of alcohol before pregnancy 64 (91.67\%); denies smoking in pregnancy 68 (94.44\%); smoking during pregnancy $42(95.45 \%)$; denies hypertension $54(75.00 \%)$; denies diabetes $67(94.06 \%)$. Association of variables with the Perceived Stress Scale, there was statistical significance for the age range of first pregnancy 18-24 with $(p=0.05)$; schooling $(p=0.03)$; race $p, 0.01$; religion $(p=0.03)$; use of alcoholic beverage $p .0 .01$; smoker $p=0.05$; hypertension $p=0.05$. CONCLUSION: High prevalence of this disorder in women who had pregnancy toxemia, reiterates the need for perinatal follow-up in order to provide treatment, ensuring psychological well-being, preventing chronicity and improving quality of life.
Keywords: Pregnancy, Toxemia, Posttraumatic Stress Disorder

138. OVERLAP SYNDROME: DERMATOMYOSITIS AND SCLERODERMA ASSOCIATED WITH ACUTE BILIARY PANCREATITIS

Andreia Coimbra Sousa; Raquel Moraes da Rocha Nogueira; Lynara Pinheiro Moraes; Thais Silva de Jesus; Thamires Sales Riberio; Rafael Machado Gonçalves; Beatriz Ximenes Mendes

Centro Universitário do Maranhão (CEUMA)

BACKGROUND: Inflammatory myopathies are systemic diseases of connective tissue with clinical effects of chronic muscular inflammation. The most common forms are polymyositis and dermatomyositis. More prevalent in women, in the proportion 2: 1. They rarely manifest as overlap syndrome when there are 2 or more autoimmune connective tissue diseases. CASE DESCRIPTION: Patient, female, 37 years old, Caucasian, with dermatomyositis diagnosed 7 years ago, on regular use of prednisone $20 \mathrm{mg} /$ day. She sought emergency treatment with acute upper abdominal pain and uncontrollable vomiting. Concomitantly, there was a decrease in muscle strength in the upper and lower limbs. At examination, presence of scleroderma facies, sclerodactyly, thickening of the skin proximal to the metacarpophalangeal joints, Raynaud's phenomenon and Gottron's papule scars. Laboratory: Amylase 3,438; Lipase 1.591; AST 635; ALT 514; Total bilirubin of 3.05; direct bilirubin 2.84; FA 352; GGT 777; CPK 4.184; LDH 1,131; Aldolase 57.5. The positive FAN (1/340), of fine dot pattern. Anti-Scl, anti-RNP and anticentromere negative. Tomography of the corresponding abdomen with Balthazar C pancreatitis of biliary origin. The histopathological examination of the skin confirmed scleroderma. Initiated therapeutic support for acute pancreatitis with zero and symptomatic diet, in addition to prednisone $1 \mathrm{mg}$ / kg / day, followed by pulse therapy with methylprednisolone $1 \mathrm{~g} /$ day for 5 consecutive days. After clinical and laboratory stabilization, she underwent endoscopic retrograde cholangiopancreatography and videolaparoscopic cholecystectomy, and was discharged for outpatient follow-up. CONCLUSION: Inflammatory myopathies should be treated according to their evolution and, the case reported, aims to call attention to pancreatitis as a triggering factor of the disease activity and to describe its therapeutic management. In addition, it contributed to the diagnosis of overlap syndrome, being an unusual case of overlap of der

Keywords: overlap, dermatomyositis, scleroderma, pancreatitis

\section{UTERINE COLUMN NEOPLASIA - A CASE REPORT}

Ticiana Guimarães do Nascimento; Eny Ribeiro de Lemos; Daniel Gonzaga Saldanha

Universidade de Fortaleza (UNIFOR)

BACKGROUND: Cervical cancer presents an estimated 16,370 new cases for the year 2018. Even with the existence of several programs carried out in Primary Care that aim at the prevention of this type of cancer, cervical neoplasia still presents high mortality. In this context, it is still known the difficulty that exists for the understanding and acceptance of the disease by the patient, which characterizes a communication challenge for health professionals. Thus, the objective of this report was to present the risk factors presented by the patient, as well as to know the mechanisms that the patient used to cope with the disease when performing the treatment. CASE DESCRIPTION: A.Z.L.S., 42 years old, female, living in the interior of Ceará; initiated with an increase in menstrual volume, abnormal vaginal bleeding associated with continuous pain in hypogastric and right iliac fossa, adynamia, episodes of dizziness, fever, hyporexia. When she noticed abnormal vaginal bleeding, she sought the Basic Health Unit, where she underwent transvaginal ultrasonography and was diagnosed with cervical cancer. She was referred to treatment at the Ceará Cancer Institute, where she underwent chemotherapy and radiation therapy. As for the pathological antecedents, G7P4A3, performed curettes after the abortions. It has systemic arterial hypertension (SAH) and family history of neoplasia. She receives family support from her children and siblings. He also said that spirituality was an essential factor to reinvigorate and help her in coping with the disease. CONCLUSION: Therefore, despite the constant efforts of the programs offered by basic care, it is verified that the cases of cancer continue to persist. This reveals that there are barriers to care as well as access barriers that hamper both prevention and early screening. It is worth emphasizing the importance of offering psychological assistance as an essential support for coping with the disease.

Keywords: Cervical Neoplasms; Primary Health Care; Diagnosis 
140. BURNOUT SYNDROME IN HEALTH PROFESSIONALS: A CASE REPORT Thayrine Larissa Melonio Almeida; Erica Fernanda Silva Lima; Maycon Jhones Batista Mota

Centro Universitário do Maranhão (CEUMA)

BACKGROUND: Burnout syndrome, recognized in the 1970s as determined by a triology of proportions (Depersonalization, Emotional Stress and Attenuation of Personal Achievement), is a requirement for work organization, and has been targeted in hospital settings. CASE DESCRIPTION: After the diagnosis, the health professional was removed from his position, presented in a depressive state, present in the burnout being temporary and associated with a specific condition of his personal life, in the case the work. Report of the case of Health Professional A.S.L, 52 years old, married, Nurse of an Intensive Care Unit (ICU), employee of the current Institution for 20 years. His problems began in 2012 with successive administrative changes. She was transferred 3 times in the Public Health Unit, and assumed a management position (General Coordinator of the Nursing Sector) in the last unit, thus increasing her duties, while restricting the number of people. Among its functions, it granted the resignation of employees. She began to feel very tired physically, tense and anxious, deep sadness, weight loss, among other signs and symptoms that prevented her activities within the hospital environment. In addition to physical exhaustion, he felt emotionally limited. Initial treatment with guidance from psychologists and psychiatrists, and antidepressant ingestion. CONCLUSION: It is evident how important is the beginning of a treatment soon after the diagnosis, in addition to developing and implementing effective strategies in search of quality of work of these health professionals in front of the hospital environment.

Keywords: Burnout Syndrome, Diagnosis, Health Professionals.

141. THE GROWTH OF PREMATURE NEWBORNS IN THE NEONATAL INTENSIVE CARE UNIT

Taynara Figueiredo Costa; Carolina Campos de Carvalho; Andressa Bastos e Bastos

Universidade Federal do Maranhão (UFMA), Hospital Universitário Unidade Materno Infantil (HUUFMA)

BACKGROUND: The study addresses the growth rhythm of preterm infants hospitalized in a Neonatal Intensive Care Unit (NICU). The NICU is the ideal therapeutic environment for the treatment of newborns at risk, since they present greater vulnerability to infections and complications, moreover, in the NICU they receive accentuated care that contribute to survival and decrease mortality. Preterm infants have their uterine development interrupted and are born before the period of greatest somatic growth. The measurement of growth during hospitalization in the NICU is a simple way to analyze the evolution of the newborn in the first days of life. OBJECTIVE: To analyze the growth of preterm infants, according to sex and gestational age during the period of hospitalization in a NICU. METHODS: Data from 90 preterm newborns from the NICU database of a University Hospital of São Paulo Luís MA in the year 2017. RESULTS: Data from 90 premature children, whose hospitalization time ranges from 16 to 144 days, of gestational age ranges from 24 to 37 weeks; being 49 girls and 41 boys. Boys with a gestational age of 24 to 28 weeks had on average a growth of $6.2 \mathrm{~cm}$, from 29 to 31 weeks had on average a growth of 5.5 and from 32 to 33 had on average $2.9 \mathrm{~cm}$ and from 34 to 37 weeks had on average a growth of 3.1. In relation to girls with gestational age from 26 to 29 weeks had on average a growth of $7.4 \mathrm{~cm}$, from 29 to 31 weeks had on average a growth of 5.7 and from 32 to 34 had on average $3.2 \mathrm{~cm}$. CONCLUSION: Although preterm infants represent a risk group, they have the potential to regain their growth, if accompanied by adequate nutrition in the NICU. Thus, they present rapid neonatal growth, recovering the interrupted growth in gestation. Growth in $\mathrm{cm}$ and weight gain demonstrate suitability to the new medium.

Keywords: growth rate, preterm infants, NICU

142. CO-INFECTION BETWEEN VISCERAL LEISHMANIASIS AND HIV IN THE STATE OF MARANHÃO: GENERAL ASPECTS

Imayra Zuilla Cardoso Silva; Conceição de Maria Pedrozo e Silva de Azevedo; Laize Nogueira de Caldas; Uiara Regina Silva de Lima; Djanira Carvalho de Abreu; Claudilene Setúbal Araújo; Neisa Betânia da Silva Lima

Universidade Federal do Maranhão (UFMA), Hospital Estadual Presidente Vargas
BACKGROUND: Visceral leishmaniasis (LV), a pathology transmitted by sandfly mosquitoes, has been receiving increasing attention from the scientific community. With the establishment of the epidemic of HIV infection, cases of co-infection began to appear between the two pathologies, which led to the need to study these cases. The objective of this study is to describe the epidemiological, clinical and laboratory profile of LV cases co-infected with HIV. METHODS: A prospective and retrospective study of the cases of VL, co-infected with HIV, regardless of whether they developed AIDS, was conducted with individuals attended at a referral hospital for HIV / AIDS patients in the state of Maranhão. Data collection was done through a protocol record developed for the study; demographic, epidemiological, clinical, laboratorial and evolutionary characteristics were considered. RESULTS: The sample consisted of 35 individuals in the prospective study and 52 in the retrospective study. In the prospective study, 34 patients were male and 1 female, all cases are autochthonous from the state of Maranhão. Among the clinical manifestations, fever, hepatomegaly, splenomegaly and anorexia were the most frequent ones. HIV treatment among co-infected patients ranged from 8 groups of antiretroviral combinations. Regarding $\mathrm{VL}$, the treatment performed in the entire prospective sample was with Liposomal Amphotericin B. CONCLUSION: With this study, it can be concluded that the clinical manifestations of $\mathrm{VL}$ in co-infected patients are more evident, frequent, and sometimes severe compared to patients with VL monoinfected, but it is confusing with other opportunistic diseases, which sometimes overlaps with LV. The rate of relapse is greater, which sometimes makes it difficult to manage. In addition, the risks inherent in HIV infection are added. Thus, such patients should be subject to close and constant follow-up.

Keywords: Leishmaniasis, HIV, Co-infection.

\section{HOMICIDES OCCURRED IN MARANHÃO IN 2013: A DATA ANALYSIS}

Natália Marques Vieira Rosa; Anderson Felipe de Sousa Reis; André Júnior Francelino de Moura; Betânia Oliveira Garcez; Jullyanna Maria Rodrigues Almeida

Universidade Federal do Maranhão (UFMA)

BACKGROUND: Homicide is the elimination of extrauterine life from one person to another. This parameter has a great impact on public health indicators, and the Northeast is the Brazilian region with the highest number of homicides since 2009, justifying in-depth studies about its occurrences, to analyze and intervene on the issue. Maranhão is not among the states with the highest number of homicides, although these proportions may occur through underreporting of data. The present study aims to analyze the predominant profile of the victims and the place of occurrence of homicides occurred in Maranhão during the year 2013. METHODS: A crosssectional epidemiological descriptive study was carried out, data provided by the Department of Information Technology of the Unified Health System , referring to homicides that occurred in the state of Maranhão in the year 2013. A quantitative-qualitative analysis of these 1420 deaths was performed, considering age, sex, color, schooling and marital status of the victims, as well as the place of occurrence. RESULTS: The profile found follows the national pattern, with non-white adult males being highly affected by the reality of urban violence. Individuals with student training lasting 4-8 years are the most victimized, totaling $38.7 \%$ of the total. Singles are $67.76 \%$ of the victims, suggesting a possible relationship between family ties and reduced exposure to violence. The public road was the site of approximately $45 \%$ of the deaths in question. CONCLUSION: The black man mortality pattern is an important facet of the marginalization of this group and an information tool about the black family's family context. As far as the predominant place of occurrence is the public highway, there is a demonstration of possible failures in public security in favor of immediate victim assistance. These findings contribute to the defense of new strategies, focused on public education and security, aiming at citizenship exercised with ethics and respect for the other

Keywords: Epidemiology, Homicide, Maranhão, Violence

144. IDIOPATHIC THROMBOCYTOPENIC PURPURA REFRACTORY TO SPLENECTOMY: A CASE REPORT

Cícero Emerson de Araújo Sena; Augusto Ramires Costa Coronheiro; Fernanda Santos Magalhães; Luiz Venicius Resplandes Gomes; Cecilma Miranda de Sousa Teixeira; Nadja Nadynne Beserra dos Santos; Pedro Antônio Borges Melo Universidade Federal do Maranhão (UFMA) 
BACKGROUND: Idiopathic thrombocytopenic purpura (ITP) is a frequent hematological disease, characterized by the production of autoantibodies directed against platelet membrane proteins, which leads to the sensitization of platelets that are phagocytosed by macrophages, mainly of the spleen. Treatment of ITP, in general, includes the use of corticoid and splenectomy, and the use of intravenous immunoglobulin in high doses The purpose of this case report is to emphasize the behavior of an infrequent clinical situation of refractoriness and splenectomy in the treatment of ITP. CASE DESCRIPTION: Patient, 38 years old, female, without comorbidities, with previous diagnosis of ITP for seven years, treated with glucocorticoid Prednisone at a dose of $50 \mathrm{mg}$ orally for 4 weeks. Without improvement, it evolved with recurrent hemodynamic instability and was then submitted to splenectomy, after vaccination for anti-pneumococcus, Haemophilus type $\mathrm{b}$ and meningococcus, evolving with progressive improvement in the number of platelets until their stabilization. After one year of the procedure, he presented important thrombocytopenia and hemorrhagic signs. Serologies for secondary causes such as HIV, Lupus and Viral Hepatitis were obtained, obtaining all the negative results, besides the bone marrow aspirate, which was compatible with ITP. With other causes ruled out, the association of Prednisone and Rituximab was prescribed for four weeks, which resulted in a significant improvement in the clinical picture and in the platelet count, maintaining the stable condition, and the patient is currently under clinical follow-up. CONCLUSION: It is understood therefore, that in cases of ITP refractory to initial corticosteroid therapy, Rituximab alone, or after splenectomy, the association of Prednisone with Rituximab may be an effective management in the clinical stability of these patients.

Keywords: Purpura, thrombocytopenia, splenectomy, refractoriness.

145. AMERICAN TEGUMENTARY LEISHMANIOSIS PREVALENCE IN BRAZIL FROM 2007 TO 2016

Larissa Chaves de Carvalho; Lorena Natali Cardoso Fernandes Caldas; Louise Paola Nichilatti; Consuelo Penha Castro Marques Universidade Federal do Maranhão (UFMA)

BACKGROUND: American cutaneous leishmaniasis (ACL) is transmitted by females of sandfly mosquitoes. The skin disease has a painless ulcer preceded by a papule. Its diagnosis is clinical and by direct research or IDRM (intradermal test), the treatment is with Glucantime. It is a public health problem, with 0.7 to 1.3 million new cases / year in the world; $A C L$ is among the 6 most important infectious diseases. Brazil added 6 countries are responsible for $90 \%$ of the cases. METHODS: This is a cross-sectional study, with secondary data from the 05 Brazilian regions from 2007 to 2016 , from the SINAN (National Institute of Public Health Information System). The Kruskal Wallis and Pearson Correlation tests were used for statistical analysis $(\alpha=5 \%)$. RESULTS: ACL cases are more prevalent in the north region (NO) - $42 \%$ of the total cases, followed by the northeast region (NE) - 31\%. There was a tendency for cases of this disease to reduce - all regions - from 2007 to 2016. There is a statistically significant difference in the cases among the Brazilian regions $p \$ .0001$. Analyzing one region with another, we found statistically significant differences between the north and southeast, south, and center-west regions, all with $p \notin .05$, as well as differences between the northeast and southeast and south with $p \varnothing .05$ and between the south and center-west with $p \Varangle .05$. CONCLUSIONS: NO and NE respond for more than $70 \%$ of national cases, emphasizing the importance of health actions specific to these places. The statistical difference observed in the comparison between the regions shows that the spatial distribution of the disease in Brazilian territory is a result of different ecological/ geographical conditions, poor government planning for control and prevention.

Keywords: Leishmaniasis, Epidemiology, Public Health

146. HIRSCHSPRUNG'S DISEASE: A CASE REPORT

Lucas Torres Pacheco; Paulo Henrique Dias Moraes; Pedro Ernesto Alves Mangueira Júnior

Centro Universitário Instituto Tocantinense Presidente Antonio Carlos - UNITPAC

BACKGROUND: Hirschsprung's disease, also known as congenital intestinal aganglionosis, is characterized by the absence of the intramural neurons of the parasympathetic nerve plexuses, affecting the large intestine, usually in its more distal segments, such as the rectum and the sigmoid colon. alters the relaxation by keeping the affected segment contracted, preventing the progression of the fecal content. It is a relatively common anomaly in children, accounting for one-third of neonatal bowel obstruction, ranging from $1 / 2000$ to $1 / 5000$ live births. About fifty percent of committed and untreated children die in the first years of life and the vast majority do not reach adulthood. This report aims to present a case of a patient, diagnosed with Hirschsprung's Disease, presenting chronic constipation and recurrent fecaloma, being submitted to surgical treatment. CASE DESCRIPTION: Patient E.A.S., female, 15 years, admitted to the Regional Hospital of Araguaína, with chronic intestinal constipation since childhood and recurrent fecaloma. On physical examination, abdominal apparatus presenting palpable mass in the left iliac fossa. A diagnosis was made through anorectal manometry, which evidenced a negative retinal inhibitory reflex. For definitive treatment, sigmoid colon and rectum colon resection was performed with reconstruction of the intestinal transit using the Duhamel technique. CONCLUSION: Reconstruction of intestinal transit by Duhamel surgery is the technique of choice for the treatment of Hirschsprung's disease due to the low rate of complications and a higher rate of reestablishment of anal sphincter function.

Keywords: Aganglianosis, HIRSCHSPRUNG, Duhamel

\section{EPIDEMIOLOGICAL PROFILE OF VISCERAL LEISHMANIOSIS FROM 2013 TO} 2017 IN MARANHÃO

Aline Barros Silva; Alana Jessica Pinheiro Oliveira; Alianna Christine Assunção Pinto; Samyra Marjoyreanne Alvares da Silva Universidade Federal do Maranhão (UFMA)

BACKGROUND: Visceral leishmaniasis (VL) is a chronic and systemic disease that, when left untreated, can progress to death in more than $90 \%$ of cases. The etiologic agent is protozoan trypanosomatids of the genus Leishmania. Transmission occurs through the bite of the infected vectors. The disease is more common in children younger than 10 years. The reason for the greate susceptibility of the children is explained by the state of relative cellular immunological immaturity aggravated by malnutrition, so common in the endemic areas, besides a greater exposure to the vector in the peridomicile. The objective of the study was to describe the LV data between 2013 to 2017 in the state of Maranhão (MA). METHODS: This is a descriptive, retrospective study, carried out in January 2018, with analysis of secondary data, obtained in the Information System for Notifiable Diseases (SINAN). All the information obtained gave rise to a database, which was stored and analyzed in Microsoft Excel 2013. RESULTS: There were 3439 confirmed cases of LV in MA. In 2017, it was the year with the highest number of notifications with 831 cases and 2014 was the year with the lowest number with 571 cases. Between 2013 to 2017, 359 cases with incomplete 1st to 4th grade schooling and 5 cases with complete higher education, 1740 cases did not apply. 1081 confirmed cases in the age group of 1 to 4 years, 2351 residents in urban areas and 951 in the rural area, 2623 of confirmed cases are brown 2232 are male and 1207 are female. In relation to the evolution, 1911 cases were cured and 236 died from VL. CONCLUSION: The study made it possible to know the epidemiological profile of the disease, besides confirming that $\mathrm{LV}$ is a problem of public health in the MA, demonstrated by the number of cases reported. Because it is a notifiable disease and with clinical characteristics of severe evolution, the diagnosis must be made as accurately and as early as possible.

Keywords: Visceral Leishmaniasis, Public Health, Compulsory notification.

148. ANALYSIS OF HANSEN'S DISEASE CASES AT A REFERENCE HOSPITAL OF SÃO LUÍS IN 2017

Moisés Farias Santos

Universidade Federal do Maranhão (UFMA), Hospital Aquiles Lisboa (HAL)

BACKGROUND: Hansen's disease is a chronic, infectious granulomatous disease caused by the Mycobacterium leprae bacillus, required investigation and compulsory notification throughout the national territory. Data from 2015 show a reduction in Hansen's disease cases in Brazil and Maranhão. In view of the significance of this disease and its direct impact on health, it was aimed to identify the aspects of its treatment offered by the Aquiles Lisboa Hospital, a reference in the diagnosis and treatment status of this disease, and, therefore, it was also aimed to trace the epidemiological profile of patients and highlight the prevalent forms of the disease, as well as evaluate the quality of medical records. METHODS: The epidemiological profile of the patients, reasons for discharge, the form of the disease and 
the treatment adopted were analyzed and 128 medical records were analyzed in 2017 and closed until May 2018, with complete and legible data, 75 of the total 203, due to inadequate filling. RESULTS: According to the results obtained, $41.41 \%$ of the patients had the sensitivity preserved, whereas $35.16 \%$ had loss of sensitivity grade 1 ; In addition, $14.84 \%$ presented visible deficiency and $4.69 \%$ were not evaluated for this issue. $59.38 \%$ presented the second most severe form of dimorphism, and there was a slight predominance of the most severe forms in men. $80.47 \%$ were treated with polychemotherapy for a multibacillary form, with the majority of patients remaining in the hospital for up to 30 days. The main reason for leaving was the transfer discharge. CONCLUSION: The findings reveal some inefficiency in avoiding the progression of the disease, as well as late diagnosis and evolution of some patients to the infecting forms. Thus, it is necessary to invest in information systems as a form of epidemiological surveillance. It is also necessary to seek to reduce the epidemiological indicators of the disease by educating people about the demands of treatment.

Keywords: Hansen`s disease, Epidemiology, Treatment, Maranhão

149. MAIN SEPSIS FOCUS IN A INTENSIVE CARE UNIT IN SÃO LUÍS

Larissa Rolim de Oliveira Sales; Francisca Luzia Soares Macieira de Araújo; Beatriz Morais Costa; Yanca Lacerda Albuquerque; Maira Letícia Souza de Carvalho; Wellington Alves Serra; Raphael Jesus Lara Chacon

Universidade Federal do Maranhão (UFMA)

BACKGROUND: Sepsis can be defined as a potentially fatal organic dysfunction caused by a dysregulated host response to infection, and is the leading cause of death worldwide in noncardiologic intensive care units. It is known that a more detailed study of the septic foci can optimize the diagnosis and treatment of this disease. Thus, the present study has the objective of analyzing the main infectious foci causing sepsis in an Intensive Care Unit (ICU) of a public hospital in São Luís, Maranhão. METHODS: This was a retrospective study, based on the analysis of hospital records of 55 patients admitted to the ICU of a public hospital in São Luís, Maranhão, Brazil, with a diagnosis of sepsis or septic shock during hospitalization from January 2017 to December 2017 Patients less than 18 years of age and those with a hospitalization time of less than 24 hours were excluded from the study. RESULTS: Of the 55 patients analyzed, the mean age found was 64 years, being $45.4 \%$ female and $54.5 \%$ male. The main foci of sepsis were the respiratory system (58.1\%) and the urinary tract (20\%). In $12.7 \%$ of cases it was not possible to determine the focus of the infection and in $5.4 \%$ of the cases the infection affected more than one system. The mean duration of hospitalization of patients included in the study was 9.4 days. In the respiratory infectious foci, the mean duration of hospitalization was 9 days, while in those with urinary tract infection it was 7.3 days. CONCLUSION: Data show a higher prevalence of outbreaks of respiratory and urinary infections. The hospitalization time was higher in patients with respiratory tract infection.

Keywords: sepsis, infection, intensive therapy, infectious focus

\section{REPRESENTATION OF PARKINSON'S DISEASE IN BRAZIL DURING THE LAST} DECADE

Matheus de Souza do Vale; Kaíza Vilarinho da Luz; Gideon Batista Viana Júnior; Fernando Cleydson Lima Paiva Filho; Rebecca Lemos da Silva Lages; Mayara Pessoa Feitosa; Eliana Campelo Lago Universidade Estadual do Maranhão (UEMA); Universidade Estadual do Piauí (UESPI); Centro Universitário UNINOVAFAPI (NOVAFAPI)

BACKGROUND: Parkinson's disease (PD) is the second most frequent neurodegenerative disorder of movement disorders, affecting the central nervous system with reduced nigrostriatal and cortical dopaminergic influence. Its prevalence is 550 cases per 100,000 inhabitants at 70 years of age. The instability of the disease and the fact that it is incurable constitute a difficult reality to be faced for the rest of life, accompanying individuals in their relationships and in their daily lives. The objective of this study was to conduct an epidemiological survey of hospital admissions of patients with PD in Brazil in the last 10 years. METHODS: This is an exploratorydescriptive study with a quantitative approach. Data collection was performed through the collection of data from the Hospital Information System of SUS (SIH / SUS), made available by the Department of Information Technology of the Unified Health System (DATASUS). RESULTS: As to the number of hospitalizations, there was a prevalence of males with 5071 $(55.85 \%)$ and the age group from 70 to 79 years of age, with $2551(28.10 \%)$ cases. Of the five Brazilian regions analyzed, the Southeast Region is the region with the highest absolute number of hospitalizations with 3936 $(43.35 \%)$ hospitalizations in the period compared to the other regions. When color / race, white was predominant with $4331(47.70)$ cases. The number of deaths related to hospitalizations was 470 (5.18\%). CONCLUSION: In the country, the predominance of PD was predominantly in the Southeast region, in males, whose mean age of admissions was 70 years. From this perspective, it is worth emphasizing that the disease has a high impact on the quality of life of the individuals affected. In addition, it is necessary to increase the specific public health policies for individuals affected by PD, with a view to reducing the stigma of chronic disease and improving care with these clients.

Keywords: Parkinson's disease; Chronic diseases; Hospital admissions.

\section{JUVENILE MYASTHENIA GRAVIS IN CHILDREN OF A HOSPITAL UNIT IN} SÃO LUÍS - MA

Luiz Gonzaga Marques Dos Reis Júnior; Decarthon Vitor Dantas Targino; Raissa Alves Bringel; Ana Karolina Carneiro Cutrim; Caroline Silva Ramos; Thaís Dias Araújo; Romana Angelica Matos de Macedo Hospital Infantil Juvêncio Matos (HIJM)

BACKGROUND: Myasthenia gravis (MG) is an autoimmune disease of the postsynaptic portion of the neuromuscular junction, characterized by oscillating muscle weakness, which improves with rest. It may be limited to specific or generalized muscle groups. It is a rare disorder in childhood and its main etiology is the destruction of neuronal acetylcholine receptors There is a slight predominance of the disease in women. When diagnosed before 18 years of age, it is called Juvenile Myasthenia Gravis. CASE DESCRIPTION: A 13-year-old female patient started progressive rhinolalia, palpebral ptosis, and reduced strength in cervical, facial, upper and lower limbs. He also presented dysphagia and gastroesophageal reflux. There were multiple medical consultations in public and private units due to exacerbations of the condition and diagnostic difficulty. He sought medical attention again at an emergency unit in São Luís, due to severe dyspnea secondary to bronchospastic pneumonia. He needed hospitalization and invasive ventilatory support in an intensive care unit. She performed electromyography with a response indicative of MG. Anti - acetylcholine receptor: positive. Muscle - specific anti - thyrokinase (MusK) antibody: negative. Magnetic resonance imaging of the mediastinum: normal. Further investigation revealed no other conditions. The patient was treated with pyridostigmine and prednisone. It evolved with progressive and total remission of symptoms. She was discharged from hospital and was referred for outpatient follow-up. CONCLUSION: MG is an infrequent disorder in childhood, a reason that makes recognition and its early treatment difficult. These would reduce morbidity, mortality, hospitalization time and treatment costs for the patient and public health services. It is hoped that this study may draw attention to the importance of MG and rare diseases as a whole.

Keywords: Myasthenia, Gravis, Acetylcholine, neuromuscular

\section{EVALUATION OF COGNITIVE PERFORMANCE IN ELDERLY PARTICIPANTS} OF THE 2018 GLOBAL ACTION IN SÃO LUÍS

Regislene Bomfim de Almeida Brandão; João Florencio Monteiro Neto; Lorenna Batista Braga de Sousa; Vivian Aragão Carvalho; Maria Zali Borges Sousa San Lucas; Lídia Maria Lopes da Silva; Jessica Kerly Garcês Campos Centro Universitário do Maranhão

BACKGROUND: With age there is a significant decline in functions, such as attention, memory and executive functions, even in the elderly who are not affected by diseases. Because of this, it is important to make use of geriatric assessment instruments that include the evaluation of the elderly from the cognitive point of view. One of the instruments of evaluation of cognitive function, widely used in hospitals and clinics, is the Mini Mental State Examination (MMSE). Thus, the objective of this research was to evaluate cognitive performance in elderly participants of a global action in the city of São Luís MA. METHODS: This is a cross-sectional descriptive study, conducted in May 2018 during the global action in the city of São Luís / MA. The instrument used was the Mini Mental State Examination (MMSE), which evaluates the cognition of the elderly. We evaluated 27 elderly people of both sexes, being included in this research only people with minimum age 
of 60 years, being excluded 2 participants because they were not within the age group, having a final sample of 25 elderly. Statistical analysis was performed through the Excel 2017 program, with results expressed as mean, minimum and maximum, and absolute and relative frequency. RESULTS: The sample consisted of the majority of females representing $56 \%$ of the total. The mean age of participants was 67.88 years, with the minimum age being 60 years and the maximum being 88 years. The highest prevalence was of literate elderly (72\%), representing a minority of illiterates (28\%). The results of the Mini Mental State Examination (MMSE) were 20.71 for illiterates ranging from 14 to 28 and 25.89 for literates ranging from 18 to 35 . A score equal to or above 19 was used for illiterates and the same or above 24 for those with schooling. CONCLUSION: The study showed that the literate people present a higher cognitive performance, revealing that schooling reduces the cognitive decline present in aging.

Keywords: cognition, elderly, mini mental state examination

153. EVALUATION OF INFERTILE WOMEN WHO WAS SUBMITTED TO MINILAPAROTOMY FOR MYOMECTOMY

Karen Johana Ortiz Morea; João Nogueira Neto

Clinica Afeto, Hospital São Domingos

BACKGROUND: Uterine leiomyomas are benign tumors most common in women of reproductive age. They appear in the myometrium with different volume and location characteristics. The highest prevalence occurs in black women aged less than 45 years. They are associated with infertility in 2 to $3 \%$ of cases, directly influencing the quality of life of women and couples who wish to become pregnant. We evaluated infertile women with uterine leiomyomas with a desire to become pregnant who underwent minilaparotomy for myomectomy at a private clinic in. METHODS: a quantitative (descriptive and analytical of a retrospective) and qualitative study, a convenience sample of 68 women aged between 20 and 45 years who underwent minilaparotomy for infertility treatment at a private hospital in. from 2014 to 2016; after one year of the surgical procedure, the patients were followed up and evaluated on the following items: desire to become pregnant prior to surgery, pregnancy after surgery, complementary clinical treatment with gosserelin acetate and treatment satisfaction. RESULTS $20.6 \%$ achieved a pregnancy, $14.2 \%$ had abortion in the first trimester and ectopic pregnancy, mean age was 30.1 years, minimum age 32 years and maximum age 36 years. The average age of women who did not get pregnant was 38.8 years and those who are trying to get pregnant was 34.72 years. The action of gosserelin acetate was evaluated by the time of menstrual delay, $58.8 \%$ used, $30 \%$ with three doses of $3.6 \mathrm{mg}$ and $70 \%$ with a dose of $10.8 \mathrm{mg}$; the highest time of amenorrhea was 13 months, and the shortest time was one month. $97 \%$ reported satisfaction with the surgical procedure CONCLUSION: Minilaparotomy for myomectomy combined with gosserelin acetate has proven to be a viable treatment for infertile women with leiomyomas who wish to become pregnant.

Keywords: Leiomyoma, Infertility, Myomectomy, Gosserelin acetate.

\section{DERMATOFRIBROSARCOMA PROTUBERANS - CASE REPORT}

Brenna Carolina Sousa Braga; Walerson Lacerda de Almeida; Monalisa Leal Matta Machado; Gabriel Abreu Bacellar de Souza Martins; Taciana Gabrielle Pinheiro de Moura Rodrigues Universidade Federal do Maranhão (UFMA)

BACKGROUND: Cutaneous tumors of mesenchymal origin are rare neoplasms, with protruding Dermatofibrosarcoma (DFSP) being one of the most frequent tumors in this unique group of neoplasms. DFSP can occur at any age, but prevails among adults $20-50$ years. Located preferentially in the trunk, it has slow and sluggish growth and may sometimes be associated with previous traumas. Clinically it presents as agglomerated nodules in hardened plate, protuberantes, being able to have surface and eventually ulcerate. This fibro-histiocytic tumor has intermediate malignancy, rarely occurring metastases. Usually, it presents as a tumorlike tumor lesion, but there is a pisgmentate variant that is called the Tumo of Bednar. In histopathology, we have spindle cells in storiform pattern with areas "swirling", invading deep dermis and hypodermis Immunohistochemistry reveals characteristic positivity for CD34. The treatment is surgical with variable relapse rate, depending on the method employed. RESULTS: A.C.P., a 52-year-old black female worker, sought out the HUUPD Dermatology Service because of the spontaneous appearance of a keloid-like tumor lesion in the right clavicle region at 1 year of evolution.
He vehemently denied previous traumas. He was submitted to skin biopsy and sent material for histopathological analysis and culture for fungi. There was no growth of microorganisms in the culture and histopathology was observed atypical fusiform cells in a fibrotic stroma, in the dermis and involving the subcutaneous, organized in irregular, intertwined fascicles, mitotic activity is light and nuclear pleomorphism is minimal, confirming the diagnosis of DFSP. CONCLUSION: The present report emphasizes the importance of clinical examination as a fundamental tool in Dermatology for the differential diagnosis of nonspecific cutaneous tumors, which will only have the diagnosis of certainty after histopathological analysis.

Keywords: Dermatofibrosarcoma, cutaneous neoplasms, differential diagnosis

155. EPIDEMIOLOGY OF ACCIDENTS CAUSED BY SPIDERS IN MARANHÃO FROM 2013 TO 2016

Helen Mendes Teixeira

Universidade Estadual do Maranhão (UEMA)

BACKGROUND: An average of 5,000 cases of accidents caused by spiders are notified per year in Brazil. According to the Ministery of Health, there are three medically important genus of spiders in the country: Phoneutria (armed spiders), Loxosceles (brown spiders) e Latrodectus (black widow spiders). Accidents caused by other genus like Lycosa and Mygalomorphae are less important in regard of clinical severity. In this context, the purpose of the present study is to analize the epidemiological scenery of the araneism in Maranhão. METHOD: It is an exploratory-descriptive and documental study, with a quantitative approach. The data were collected from the notifications available in the database System Diseases Information and Notification (SINAN), referent to the period of 2013 to 2016. The aspects evaluated were: number of cases per year, type of spider, evolution of the case and affected micro-regions. RESULTS: It was found out that, in the analyzed period, 339 cases of accidents caused by spiders were notified. From this perspective, the lowest number of notifications was found in 2014, with 68 cases, while the hightest number was evidenced in 2016, with its 104 registers, among the occurrences, four deaths were registered exclusively due to the accident. Among the cases which the specie of the spider was indentified, the Loxosceles genus has the highest number of notifications (72 cases). With respect to the micro-regions, the greatest number of notifications was found in Pidaré (47 cases), followed by Imperatriz ( 33 cases) and Baixada maranhense ( 32 casos). CONCLUSION: Besides the rising of the cases since 2014, another worrying factor is the prevalence of accidents caused by the Loxosceles genus. Since this genus corresponds to the more serious form of araneism in Brazil and, although been typical from the south region, this study ratifies the consulted literature which confirms the presence of the Loxosceles amazonica specie in the northeast of Brazil.

Keywords: Accidents caused by spiders, public health, epidemiology.

\section{DEATHS BY RENAL COMPLICATIONS IN INSULIN-DEPENDENT PACIENTS} IN MARANHÃO AND PIAUÍ 2007-2016

Daizy Carlota Coelho Aguiar; Lucas Henrique Ferreira de Sousa; Jéssica Ferreira Bertoldo; Dayna Maria Caldas Diniz; Ítalo Henrique Pereira Lima; Jailson do Nascimento Salazar; Sueli de Souza Costa Universidade Federal do Maranhão (UFMA), Faculdade de Imperatriz (FACIMP)

BACKGROUND: Diabetes Mellitus (DM) is a chronic disease, resulting from the absence of insulin and / or the latter's inability to exercise its actions It is accompanied by several complications such as retinopathy, nephropathy and diabetic neuropathy. The Brazilian Society of Nephrology reports that $25 \%$ of people with type I DM and $5 \%$ to $10 \%$ of type II patients develop renal insufficiency, being a process of invisible and irreversible damage that can progress to the terminal chronic kidney form. The present work makes a comparative analysis about the deaths occurred in the states of Maranhão (MA) and Piauí (PI) due to insulin-dependent DM with renal complications (ICD-10: E102). METHODS: Quantitative epidemiological study of a descriptive approach with data collection of death certificates digitally available in DATASUS, with basic cause, CID E102, in Maranhão and Piauí in the 2007-2016 period. Descriptive statistics were used using the Tabwin 4.1.3 and Microsoft Excel 2010 programs. RESULTS: Proportional mortality as cause CID E102 was higher in the MA during the whole period, being 92 deaths, in which both sexes had 46 cases. In the IP, there were 15 cases, 10 males 
and 5 females. Between the years 2010-2012, the MA increased by $140 \%$ (from 5 cases to 12 ), and in the IP this number remained unchanged. Between 2015-2016, the IP had a large increase in mortality (400\%), from 1 case to 5 . In the same period, the MA had a 23.6\% drop in cases, from 17 to 13. CONCLUSION: When comparing the number of cases of deaths in which the underlying cause is CID E102, the MA presents 77 cases more than the state of the $\mathrm{Pl}$ in a period of 10 years. In relation to the involvement by sex the MA state presents an equivalent proportion, whereas in the PI the highest incidence occurs in the male sex. Finally, it can be seen that, in the last two years analyzed, Piauí presented an important increase of cases whereas in Maranhão there was a moderate decline.

Keywords: Diabetes Mellitus; Nephropathies; Mortality

\section{KLIPPEL-FEIL SYNDROME CASE REPORT}

Ingrid de Macêdo Araújo; Matheus Rizzo de Oliveira; Lukas Pedrosa Duarte

Centro Universitário do Maranhão (CEUMA)

BACKGROUND: Klippel-Feil Syndrome (SKF) is a complex congenital anomaly that commonly affects the cervical vertebrae. Characterized by defective segmentation or fusion of 2 or more cervical, thoracic or lumbar vertebrae, occurring between 3 to 8 weeks of gestation. It is a rare disease that affects 1 in 42,000 individuals and presents a triad described by fusion of vertebrae, limitation of the movements of the neck and low implantation of the scalp in the posterior part. In addition, clinical manifestations such as scoliosis, hemivertra and respiratory disorders may also be present. This paper aims to report the case of a patient diagnosed with the syndrome. CASE DESCRIPTION: The patient I.G.S.C., 15 years old, male, presented for 3 months an increasing loss of motor force with presence of headache and oscillating gait. In the last crisis he presented cyanosis and evolved with respiratory insufficiency, being taken by the SAMU to the Municipal Hospital Dialma Marques after a cardiorespiratory arrest (PCR) of approximately 10 minutes. Scanning tomography showed extensive pleural effusion, tetraventricular hydrocephalus, hemi-vertebrae in $\mathrm{L} 3$ with fusion, determining lumbar scoliosis. In addition, he presented the classic SKF triad. Thoracic drainage, external ventricular shunt (PVD), cystostomy (due to urethral injury) and peritoneal ventricular shunt (DVT) were performed. The patient evolved with pneumonia and peritonitis evidenced by purulent secretion. He continued with worsening of the overall picture and acute respiratory distress syndrome (ARDS), evolving to death after 7 days of hospitalization. CONCLUSION: SKP is a rare pathology with severe neurological, cognitive, musculoskeletal and functional repercussions. The knowledge of its etiopathogenesis and its management has great value for the adequacy of the care provided and the reduction of morbid and fatal outcomes related to the population affected by it.

Keywords: Klippel-Feil syndrome, fusion of vertebrae, congenital anomaly

\section{BRAZILIAN CONTEXT OF ENDOMETRIOSIS IN THE LAST 5 YEARS}

Helen Mendes Teixeira; Gideon Batista Viana Júnior; Kaiza Vilarinho da Luz; Raynnara Carvalho Silva; José de Ribamar Rodrigues dos Santos Júnior; Lorena Lis Nolêto Sá Corrêa

Universidade Estadual do Maranhão (UEMA), Universidade Estadual do Piauí (UESPI), Universidade Federal do Maranhão (UFMA)

BACKGROUND: endometriosis is defined as the presence of endometrial glands and stroma in extrauterinos locations, usually in the pelvis. Is with great morbidity and disease is considered to be the main risk factor for ectopic pregnancy. Endometriosis presents itself almost exclusively in women of reproductive age, average between 25 and 29 years, being rare not only in pre-pubescent and climacteric, but also before the menarche and tending to decrease after menopause. The objective of this work was to carry out an epidemiological survey on the cases of endometriosis in the last 5 years. Methods: this is a descriptive exploratory study with quantitative approach. Data collection was carried out through collection of data from the hospital information system of SUS (SIH/SUS), provided by the Department of Informatics of the unified health system (DATASUS). RESULTS: were recorded 56059 hospitalizations for endometriosis in hospital services linked to the SUS of Brazil in the period between 2014 and 2018, and the year 2014 was the highest number of hospitalizations, with $14947(26.66 \%)$ cases. With regard to socio-demographic characteristics, the majority of patients were aged 40 to 49 years, with 23367 (41.68\%), white color, with $21575(38.49 \%)$, with large resident participation in the Southeast, totaling
23391 (41.73\%) hospitalizations. CONCLUSION: in the country, the occurrence of endometriosis predominated in the Southeast region, in women in the age group of 20 to 49 years, corroborating with literature. In this context, although endometriosis is a benign disease, malignant transformation can occur, making the diagnosis and the early crucial in tracking women's approach in their different social contexts.

Keywords: Endometriosis, Hospitalizations, Women's health.

EPIDEMIOLOGICAL PROFILE OF ACCIDENTAL TETANUS IN MARANHÃO IN THE PERIOD FROM 2013 TO 2017

Pedro Paulo Souza Chaves: Dante Rodrigues de Barros Vieira; Danilo José Brito de Arruda; Samuel Rodrigues de Morais Cunha Universidade Federal do Maranhão (UFMA)

BACKGROUND: tetanus is a non-contagious bacterial infection, caused by the Bacillus Clostridium tetani, able to reach the Central Nervous System after entering the bloodstream through a mild or severe injury. In Brazil, most of the cases is linked to individuals not immunized that enter accidentally contact the Etiologic Agent. Figuring the Maranhão among the Northeastern States with the largest number of confirmed cases of the disease. Given this, the goal is to draw an epidemiological profile of accidental tetanus in the State of Maranhão, in the period from 2013 to 2017. METHODS: this is a retrospective study of information present on epidemiological investigation of confirmed cases of accidental tetanus Bank of SINAN (Information System of reportable diseases) in the period from 2013 to 2017. RESULTS: the data analyzed for the period from 2013 to 2017, totaling 62 confirmed cases of accidental tetanus in Maranhão. Most occurred in people male $(90.3 \%)$ and race with the highest number of cases is the Brown breed (70\%), followed by the black race $(23.3 \%)$. The age group with the highest incidence was people aged $40-59$ years $(38.7 \%)$, followed by people aged $20-39$ years $(27.4 \%)$ and the greater coefficient of incidence occurred in the urban area $(59.3 \%)$. The lethality of the disease in the studied period was $64.4 \%$. CONCLUSION: the population most affected by accidental tetanus in Maranhão in the period from 2013 to 2017 comprises individuals from Grizzly male, aged 40-59 years, residents of urban areas. It can be concluded that, even imunoprevenivel, tetanus is an important public health problem in the State of Maranhão, given that the lethality of the disease in the State (64.4\%) follows quite high.

Keywords: accidental Tetanus, epidemiology, Maranhão

160. PROFILE OF PATIENTS WITH BREAST CANCER AT THE ALDENORA BELLO HOSPITAL BETWEEN 2009 AND 2014

Juliana Lins da Paz Portela; Juliana Lima Araújo; Natália Cristina Silva Oliveira; Nathália Lustosa Souza Domiciano; Ĺcia Barcelos Hortegal; Andrey Pinto da Silva; Rodrigo Lopes da Silva

CEUMA, Hospital do Câncer Aldenora Bello

BACKGROUND: breast cancer ranks first in cancer mortality in women in the world and is responsible for $28 \%$ of the cases of the disease in Brazil. It is a rare pathology, i.e. $90 \%$ shows no association with hereditary factor. The main risk factors are related to exposure to ovarian and exogenous estrogens, diet, high levels of stress and sedentary lifestyle. In Brazil your incidence varies with the region, as it is a heterogeneous country in racial, cultural and socioeconomic aspects, the study of the role of these variables in pathology becomes important. Objective: to Analyze the profile of cases treated in the Hospital of cancer between 2009 and 2014 Nupur Bello, highlighting the age of risk, clinical staging, diagnosis and treatments. METHODS: Medical records raised for the years 2009 to 2014 of the cases of malignant neoplasm (analytical), with information available registered in standardized plug. For the staging of tumors, TNM Classification was used, the International Union against cancer (UICC-6th Edition). The data were analyzed and cataloged in the SISRHC program (Hospital cancer registry system), version 3.2, provided by the National Cancer Institute. RESULTS: the study showed 2229 cases, with predominance (99.3\%) in women, $26.7 \%$ between $40-49$ years, $21 \%$ in stage $2 \mathrm{~A}$ at the moment of diagnosis, $36.5 \%$ presented a family history of cancer. In $95 \%$ of cases the diagnosis was made by primary tumor histology, $57.3 \%$ were treated with surgery and $40.5 \%$ of patients had complete remission at the end of the first treatment $11.3 \%$ of patients came to death. CONCLUSION: the research demonstrated high incidence in women, with a peak in the fourth decade of life and demonstrated the importance of histology in the diagnosis and surgery in 
the treatment. The large number of diagnoses in advanced stages underscores the need for a more effective screening.

Keywords: breast cancer, Maranhão, Aldenora Bello Hospital

\section{BOTULISM SCENARIO IN BRAZIL}

Harrison Baldez Reis; Gideon Batista Viana Júnior; Kaiza Vilarinho da Luz; Fernando Cleydson Lima Paiva Filho; Vanessa Thaylla Coelho Silva Pinto; Pedro Emanoel Rodrigues da Silva; Lorena Lis Nolêto Sá Corrêa

Universidade Estadual do Maranhão (UEMA); Universidade Estadual do Piauí (UESPI); Universidade Federal do Maranhão (UFMA).

BACKGROUND: Botulism is a notifiable disease, resulting from the action of a potent toxin that has high lethality and should be considered a medical emergency and public health. The disease is a rare illness, however, it is of worldwide distribution and attacks on family outbreaks or in isolated cases, bringing misfortune to public health due to its high lethality and severity. The objective of this work was to demonstrate the Brazilian epidemiological survey of cases of botulism in the period from 2010 to 2015. METHODS: This is an exploratory-descriptive study with a quantitative approach. Data were collected through data collection of the information system of notifiable diseases-Sinan, made available by the Informatics Department of the Unified Health System (DATASUS). RESULTS: Between 2010 and 2015, 30 cases and 6 deaths diagnosed as botulism were recorded in Brazil, with an incidence of 5.0 cases/year and 1 death/year, and the South region was the most affected, with 13 (43.33) cases. Of the 30 cases, 28 (93.33\%) were due to food. The age group with the highest number of cases was from 20 to 39 years of age, with $17(56.67 \%)$. Regarding the sex of the diagnosed population, there was no difference, since $15(50 \%)$ cases were men and 15 $(50 \%)$ cases were women. CONCLUSION: Regarding the characterization of the cases, there was a predominance in the South region, affecting men and women equally, in the age range from 20 to 39 years. In view of this, it is necessary to pay attention to food safety, quality control and sanitary conditions. These measures should be monitored by governmental agencies, avoiding occurrences of food-borne diseases. Therefore, it is necessary to create specific nutritional policies that aim to change the Brazilian parameters.

Keywords: botulism, clostridium botulinum, sanitary surveillance.

162. LAPAROSCOPIC MULTIVISCERAL SURGERY FOR REMOVAL OF TWO SYNCHRONOUS MALIGNANT TUMORS

Daniela Lima Campos; Poliana Lima Campos; Murilo Lima Campos; Sérgio Ryschannk Dias Belfort; wilson José de Sena Pedro

Universidade Federal do Maranhão (UFMA), Centro Universitário Tocantinense Presidente Antônio Carlos (UNITPAC), Centro Universitário do Maranhão (CEUMA)

BACKGROUND: Multiple primary neoplasms are coexistent tumors that have different histology and site. Its possible causes are the increased survival of cancer patients, hereditary and risk factors to which they were exposed. The aim of this study is to report the case of a patient presenting syncronic primary tumors, where the laparoscopic surgical technique was successfully employed. CASE DESCRIPTION: S.N.T., 63 years old, male, admitted with abdominal pain type colic in hypogastrium and pelvis associated with Hematochezia for 7 days. Physical examination showed a painful abdomen with diffuse deep palpation, without further alterations. Abdominal ultrasonography showed a solid-cystic mass in the left kidney, which was seen in computed tomography as an expansive lesion of the neoplastic aspect. Colonoscopy already identified a pedicled polyp in sigmoid. Polypectomy and Histopathologic study were performed, which showed well-differentiated adenocarcinoma with invasion of the lamina propria and compromised surgical margins (TisNOMO). A laparoscopic approach was performed (left radical nephrectomy + rectosigmoidectomy). The renal pathology defined adenocarcinoma of clear cells (pT2a, PNX), and the sigmoid colon, the absence of residual neoplasia. There was no indication for adjuvant therapy and the clinical evolution occurred without complications. CONCLUSION: Laparoscopic access for the treatment of primary neoplasms has been defined as a safe and respectful technique to the Oncologic principles (precepts of radicality) comparable to conventional surgery. The advantages of laparoscopy are emphasized: less need for postoperative analgesia, reduced length of hospital stay, faster return to habitual activities and superior aesthetic effect. In a literature review, few reports were found in which the technique was extended to the Multivisceral concept, justiing access to more than one organ by maintaining the benefits of the laparoscopic approach.

Keywords: Surgery, Laparoscopy, Multiple neoplasms

\section{EPIDEMIOLOGICAL PROFILE OF CASES OF STROKE IN PINHEIRO-MA OF} 2010-2015

Luis Carlos Machado e Silva; Júlia Reis de Sousa; Myrian Alves Linhares; Mirella Fontenele De Castro; Cristianne Talitha Lopes Sampaio; Consuelo Penha Castro Marques; Aeriberto Carlos Lindoso de Sousa

Universidade Federal do Maranhão - UFMA

BACKGROUND: cerebral vascular accident (CVA), ischemic or hemorrhagic, is a neurological disorder, with duration of more than 24 hours and rapid development of symptoms. In Brazil, it's the disease that kills more and have high rate of sequels, with impediment of return to work at $70 \%$. The main risk factors are: age, sex, race and smoking. This study traces the epidemiological profile of the patients suffering from STROKE, in PinheiroMA. METHODS: descriptive study of STROKE in Pine-epidemiological/MA between 2010 and 2015, collected in the Department of Informatics of the unified health system (DATASUS). RESULTS: we analyzed 803 cases of hospitalization for STROKE, of these: 721 cases-(89.7\%)-50 years, $82>(10.3 \%)$ of 50 years-< The age group most affected: 70 to 79 years-222 cases, 40 to 49 years-only with more women than men ( $24 \mathrm{~m}: 29 \mathrm{~F})$. Breed: $549(68.36 \%)$ Browns, $9(1.12 \%)$, blacks (1.24\%) white 10 and $208(25.9 \%)$ reported. There were 198 death patients (106M: 92F)-death rate in 24.66 (reason deaths and hospitalizations $x$ 100). CONCLUSION: the largest number of cases in men (426M: 377F). Between 40 and 49 years rate of $20 \%$ more cases of women versus men. Very high death rate of $24.66 \%$, showing high lethality, failure in prevention and management of the disease. The higher incidence in Browns blacks contradicts the world epidemiological profile. The confirmed cases in the basic attention corroborate the hypothesis of lack of identification and prevention to early signs of stroke.

Keywords: stroke; Epidemiology; Collective Health

\section{NURSING DIAGNOSES OF A PEDIATRIC PATIENT WITH} MUCOPOLYSACCHARIDOSIS

Marina Santiago Frias; Reivax Silva do Carmo; Larissa Bianca Vales Cunha

Hospital Universitário da Universidade Federal do Maranhão (HUUFMA)

BACKGROUND: Mucopolysaccharidosis (MPS) is a hereditary metabolic disease severe, chronic, multisystem in which there is a Lysosomal Storage occurring accumulation of mucopolysaccharides non-degraded in cells and tissues, caused by deficiencies specific enzyme. This accumulation results in impairment of cell function and organic, leading to numerous progressive clinical manifestations affecting multiple organs. The objective of this report fits in apply systematization of nursing care (SAE) to a pediatric patient, gradual serious genetic disease: Mucopolysaccharidosis. This is a case report carried out in a University Hospital of Saint Louis in the medical clinic, with nursing diagnoses proposition based on taxonomy II of NANDA-I. RESULTS: the main nursing diagnosis (of) identified were: delay in growth and development as a result of disability-related, evidenced by growth changes (pathological change); situational low self-esteem related to change in body image, evidenced by verbalized autonegativas; impaired physical mobility related to the stiffness of joints evidenced by limited amplitude movements; impaired verbal communication related to physiological conditions evidenced by speaks with difficulty; impaired dentition related to genetic predisposition, evidenced by misalignment of teeth; risk of vascular trauma related to difficulty to see the vein. CONCLUSION: the identified are of paramount importance in patient care and management, serving as facilitator subsidizing an individualized care plan based on the needs of each patient, stressed the importance of the commitment of multidisciplinary team in the care of this patient, which provided improvement in response patterns and the involvement of the patient in your self-care.

Keywords: nursing Diagnoses; Mucopolysaccharidosis; NANDA 
165. PREVALENCE OF OVERWEIGHT IN HYPERTENSIVE PATIENTS REGISTERED IN THE HIPERDIA IN MARANHÃO

Lindalva Yehudy Gomes de Araújo; Luciano Beltrão dos Reis Viana

Universidade Federal do Maranhão (UFMA)

BACKGROUND: Hypertension (HAS) is a medical condition defined by the persistence of blood pressure $>140$ and/or $90 \mathrm{mmHg}$, and one of the risk factors for cardio and cerebrovascular diseases. Multifactorial causes, is associated with the functional alterations and metabolic diseases: diabetes mellitus, overweight and sedentary. [1] 2016 data indicate that more than $50 \%$ of the brazilian population and $44 \%$ of the Northeast are overweight [2], and, in Brazil, $32.5 \%$ is hypertensive. [3] objective: to describe the prevalence of overweight in hypertensive patients enrolled in the HIPERDIA program in the State of Maranhão in the period Jan/2002 to Apr/2013. METHODS: Descriptive epidemiological study, which used data from the DATASUS, analyzed by 2016 Excel software. The study population was composed of all patients enrolled in the HIPERDIA program with HAS, in Maranhão, in the period referred to, evaluated by sex and age group. RESULTS: The patients presented the characteristics: $65.3 \%$ women $(n=$ 169,905 ), of which $31.0 \%$ overweight. The male portion, $20.7 \%$ sobrepesados. The prevalence of overweight has grown with age, reaching a peak between $55-64$ years $(n=19,290)$, and displaying decrease thereafter. CONCLUSION: The overweight was not as prevalent risk factor for HAS in the State. This can be elucidated to low socioeconomic conditions, corroborating with malnutrition endemic to the region. The higher prevalence of overweight in the age group 55-64 years, can be explained by factors associated with the metabolic transition common to this population, such as decreased physical activity, basal metabolic rate and body stature. [4] the lowest prevalence after 64 years is given by the direct relationship between weight loss and longevity, because of the limitations of senility and nutritional consumptivas syndromes. Furthermore, the reduction in life expectancy generated by overweight confirms to the lower prevalence of this comorbidity in the far superior old.

Keywords: Hypertension, Overweight, Maranhão, Prevalence, HIPERDIA

166

PATIENT WITH OSTEOGENESIS IMPERFECTA UNDER PALIATIVE CARE: A CASE REPORT

Leticia Arrais Rocha; João Batista Santos Garcia; Thiago Alves Rodrigues; Vanise Barros Rodrigues Motta; Alexandre Lima Machado; Renato Albuquerque Heluy; Enéas Dantas de Queiroga Júnior

Universidade Federal do Maranhão (UFMA)

BACKGROUND: Osteogenesis imperfecta (OI) is a rare genetic condition that leads to bone fragility due to the formation of collagen. The Sillence classification was created due to the various clinical manifestations, ranging from predisposition to fractures to high perinatal lethality. The team approach to palliative care is required in these cases, in order to adopt measures of comfort for better quality of life of the patient and family. The study reports a case of a patient of 11 months with HI grade II. CASE DESCRIPTION: W.L.P. C, male, 11 months, born in São Luís. He was born at Hospital Universitário Presidente Dutra, cesarean birth, showing hip dislocation, malformation and bone structure, in need of neonatal resuscitation and permanence in CPAP. Maternal obstetric ultrasound image with suspicion of H. First x-ray showed rib fractures, spine, femur, humerus, RADIUS, tibia, bones of the hand and feet, most already consolidated, as well as deformity in the bone framework and bluish sclerae. Such findings contribute to the diagnosis, being confirmed grade II in the classification of disease Sillence, most severe form of $\mathrm{HI}$, with high prevalence of intrauterine or perinatal death. At 6 months after acute respiratory infection, called the palliative care team, which found Dyspnea and pain presumed (crying) left untreated. After two meetings with the family, the team adopted measures of comfort for the patient, introducing morphine 0,1 $\mathrm{mg} / \mathrm{kg}$ of 6/6:00, initially denied by the mother and nursing staff. With more meetings with the family, the conduct was accepted, controlling pain and reducing cry, enabling extubation. Awaits transfer to home monitoring. CONCLUSION: the relevance of this report is given on the severity of the disease and low prevalence of $\mathrm{HI}$, being estimated 12,000 cases in Brazil. It highlights the importance of palliative care for the improvement of the functionality and quality of life for the patient and your family.

Keywords: Osteogenesis Imperfecta, Palliative care, Genetics, Pain
167. ANXIETY IN ASTHMATICS: PREVALENCE AND ASSESSMENT OF IMPACTS IN THE CONTROL OF ASTHMA

Laize Nogueira de Caldas; José Alvaro Nascimento Paixão; Josiel Guedes da Silva; Amanda Pereira Carvalho; Solano Kaluangila Andrelino Santiago; Vitor Paixão Cruz; Maria do Rosário da Silva Ramos Costa

Universidade Federal Do Maranhão (UFMA), Hospital Universitário Presidente Dutra (HUPD).

BACKGROUND: Living with a chronic disease is a potential source of anguish and concern. Bronchial asthma is a chronic disease affecting about $10 \%$ of Brazilians. In Brazil, according to the WHO, the prevalence of anxiety disorder affects $9.3 \%$ of the population. There is evidence that asthma is associated with increased psychiatric symptoms and mental disorders. Thus, in view of the impacts of a mental disorder in a patient with chronic disease, it was sought to verify the prevalence of anxiety in asthmatic patients and to evaluate its relationship with asthma control. METHODS: Cross-sectional analytical study carried out at the university Hospital of the Universidade Federal do Maranhão with patients diagnosed with moderate or severe asthma by the criterion of the Global Initiative for Asthma (GINA) 2017, aged . 18 years and in Outpatient follow-up for more than 06 months. We used the Asthma control Test (ACT) to evaluate asthma control and the Hospital Anxiety and Depression Scale for the score or diagnosis of anxiety. The chi-square test was used to analyze the proportions, considering statistical significance values of $p \quad \$ .05$. RESULTS: Of the 48 patients evaluated, 20.8\% (10) presented components for probable anxiety and $16.7 \%$ (8) for possible anxiety. Correlation between asthma control and anxiety score revealed a statistically significant difference $(p \otimes .05)$. Thus, it was observed that of the $33.3 \%$ (16) who had uncontrolled asthma, $43.75 \%$ (7) scored for probable anxiety and $18.7 \%$ (3) for possible anxiety. CONCLUSION: This study showed that, in moderate and severe asthma patients, the prevalence of anxiety was higher than that found in the general population. In addition, it was observed that patients in this group more frequently, had uncontrolled asthma. Therefore, a better understanding of this correlation is necessary for a more adequate approach in the treatment of asthmatics.

Keywords: Asthma, Anxiety, Mental Disorder.

\section{ANALYSIS OF CAROTID ENDARTERECTOMIES IN A UNIVERSITY HOSPITAL} OF SÃO LUÍS-MA

Carlos Eduardo Coimbra Melonio; João Victor Pimentel de Oliveira; Ciro Bezerra Vieira; Bruno Leonardo Pereira da Silva; Vanisse Portela Ramos Universidade Federal do Maranhão (UFMA)

BACKGROUND: carotid endarterectomy (ACE) is the surgery that aims to remove the wall plate arterial atherosclerosis or atheroma of carotid artery. Is a prophylactic procedure on brain ischemic injury prevention. METHODS: a cross-sectional study and retrospective analysis of medical records of 17 patients with carotid stenosis submitted to ECA, between 2012 and 2017 in vascular surgery service at the University Hospital of the Federal University of Maranhão. Epidemiological, clinical and surgical aspects inherent to the technique have been assessed. RESULTS: among the 17 patients studied, $58.8 \%$ were men and $41.2 \%$ were women, with age ranging from 59 to 84 years, and the average age of 70 years and 10 months. One of the comorbidities, $94.1 \%$ were hypertensive, $47.1 \%$ dislipidêmicos $41.2 \%, 58.8 \%$ smokers and diabetics. The right carotid artery was the most affected $(52.9 \%)$. The patch was used in $82.4 \%$, with prevalence of Polytetrafluoroethylene. The Shunt was used only in two patients. Three patients did not use drain suctor. In relation to surgical complications, two patients had cervical bruise immediately after the procedure, a pneumothorax during central venous puncture performed by the team of Anesthesiology, and another developed carotid thrombosis common at the operated side. In relation to the clinical outcome, there was clinical complication in $70.6 \%$ of cases, $41.17 \%$ for hypertension and 35.39 percent for cerebrovascular accident (AVE) in the postoperative period. Of all patients, only one evolved into death, caused by BIRD. CONCLUSION: Carotid disease is prevalent in men and people over 60 . The main risk factors are Hypertension (SAH), smoking, Dyslipidemia, and diabetes. The use of patch and drain kept the trend of other studies. In relation to postoperative complications, HAS been the most prevalent and the BIRD in the most serious, being the immediate cause of death only. 
Keywords: carotid stenosis, carotid endarterectomy, cerebrovascular accident

169.

CHECK SERVICE

Raphael Oliveira Lima Silva; Laís da Hora Lucena Silva: Marcos Adriano Garcia Campos; Andrey Salgado de Moraes Filho; Rebeca Aranha Barbosa Sousa; Leonardo Oliveira Alves Borborema Júnior; Raissa Lorena Brito Amorim

Universidade Federal do Maranhão (UFMA)

BACKGROUND: Liver cirrhosis is a chronic disease, with several etiologies and that leads to high rate of hospitalization due to complications from liver failure and hypertension door, high morbidity and mortality. OBJECTIVES: To Analyse the main causes of death and associated factors in patients whose diagnosis was defined as liver cirrhosis in verification Service of deaths (SVO). METHODS: this cross-sectional study performed in the city of São Luís SVO-Maranhão, from may 2014 and may 2017. Socio-demographic characteristics were identified, causes of death and etiology of cirrhosis The analyses were made with the SPSS program 23.0. RESULTS: During the period, 3,009 cases were analyzed, of which $57(1.8 \%)$ had cirrhosis of the liver. Among these, $84.2 \%(48 / 57)$ were men. Most had skin colo black/brown, 95\% (54/57). The schooling measure in years of study showed that $72.4 \%$ had more than 8 years. The average age was $51.8 \pm 16$ years (3.5\% had less than 20 years, $43.85 \%$ had between 20 and 49 years, $35.1 \%$ had between 50 and 69 years and $17.55 \%$ had more than 70 years). The main causes of death were upper gastrointestinal bleeding (HDA) (45.6\% $26 / 57)$, infection $(31.6 \%, 18 / 57)$, acute liver failure $(15.8 \%, 9 / 57)$, acute oedema of lung $(5.2 \%, 3 / 57)$ and cerebral edema $(1.8 \%, 1 / 57)$. The causes of cirrhosis were reported in $70 \%$ of cases (40/57): alcoholic etiology in $87.5 \%(35 / 40)$, viral hepatitis in $10 \%(4 / 40)$ and autoimmune hepatitis in $2.5 \%(1 / 40)$. CONCLUSIONS: among individuals undergoing autopsy in São Luís (MA), liver cirrhosis was infrequent. Among the immediate causes of death the HDA, infection and exacerbation of liver failure were the most described. Alcohol intake was the most frequently described as a cause of liver cirrhosis.

Keywords: Liver Cirrhosis, SVO, Deaths

\section{DERMATOPOLYMOSITE WITH DERMATOLOGICAL INJURY}

Monalisa Leal Matta Machado; Gabriel Abreu Bacellar Souza Martins; Karen Lopes de Sousa Ferreira; Walerson Lacerda de Almeida; Thállisso Martins da Silva Rodrigues; Taciana Gabrielle de Moura Rodrigues

Universidade Federal do Maranhão (UFMA)

BACKGROUND: Dermatopolymyositis is a connective tissue disease of idiopathic, inflammatory and chronic origin that affects skin, muscles and organs. Its etiology may be associated with autoimmunity, histocompatibility antigens, viruses and drugs. The female gender is most affected, and the median age of diagnosis is 40 years. Cutaneous manifestations, muscle weakness, respiratory changes and dysphagia are among the most frequent repercussions. The main diagnostic criteria are proximal muscle weakness, increased muscle enzymes, myopathic changes in electroneuromyography and the presence of characteristic cutaneous lesions. The importance of the knowledge about the immunological factors, clinical characteristics and systemic manifestations incapacitating of the disease is emphasized. CASE DESCRIPTION: We report the case of a 47-yearold diabetic, hypertensive, smoker, diagnosed in 2016 with Dermatopolymyositis, using weekly methotrexate and folic acid, in addition to daily prednisone. He presented symptomatology of muscular weakness, besides several dermatological manifestations as fotossensibilide, caja paste, heliotrope, Gottron's papules, periungual capillaritis, erythema on extensor surfaces of elbows. In addition, several painful nodules appeared on the arms and thighs compatible with septal and lobular panniculitis which was confirmed by biopsy in 2018. Laboratory tests showed increased Aldolase, CPK, ASL, ALT. CONCLUSION: Dermatopolymyositis is rheumatologic disease, but which presents many dermatological manifestations. In this case, the exuberance of the cutaneous symptoms is emphasized, besides the presence of panniculitis that is not common. The more assertive and early the diagnosis and the implementation of the treatment, the better the prognosis and the lower the chances of a serious evolution of the disease that, although it has no cure, can be well controlled.
Keywords: Dermatopolymyositis; Autoimmune Diseases; Cutaneous manifestations

\section{SOCIO DEMOGRAPHIC PROFILE IN SCREENING OF CERVICAL CANCER AN}

\section{EXTENSION PROJECT}

Karen Lopes de Sousa Ferreira; Ioão Victor de Sousa Garcia; Saphyra

Medeiros Salem; Gelson Farias Arcos Júnior; Ana Josephy da Silva Costa Oliveira; Helaine Dias Guimarães; Graça Maria de Castro Viana Universidade Federal do Maranhão (UFMA)

BACKGROUND: Maranhão has cervical cancer as the most prevalent in the female population, accounting for a gross incidence rate of 30.55 / 100,000 inhabitants in the state and 41.78 / 100.000 in the capital city of São Luís. has the objective of characterizing the sociodemographic profile of women submitted to the Pap smear attended in the University Extension Program linked to the Pathology Department of the Federal University of Maranhão in the city of. METHODS: A cross-sectional, analytical-descriptive and quantitative study with 97 women attended by university extension programs linked to the Pathology Department of the Federal University of Maranhão (UFMA), Bacanga campus. The data was compiled into a Microsoft Excel $2010 \AA$ spreadsheet for both exploratory and descriptive analysis Quantitative, descriptive study, with application of a questionnaire related to the sociodemographic profile performed in the women attended in the University Extension Program submitted to the Papanicolau screening exam. RESULTS: 95 women were included, with the predominant age group being 40 to 49 years $(29.47 \%)$. In relation to schooling, women with more than 8 years of schooling predominated (54.74\%). As for the marital status, $54.74 \%$ married or in a stable union. In relation to race, the majority of the women declare themselves brown (49,97\%). Regarding family income, $71.58 \%$ reported between one and three minimum wages. CONCLUSIONS: The prevalence was found in women of childbearing age, brown, married or in stable union. It suggests that more and more young women are among those affected by the disease and the importance of screening for early detection and diagnosis.

Keywords: Uterine cervix neoplasms; Screening; Sociodemographic profile

\section{AUTOIMMUNE HEPATTTIS: CASE REPORT}

Ana Luisa Oliveira da Silva; Amanda de Oliveira Campêlo; Letícia Pires Vilanova; Indira Maria de Almeida Barros; Caroline de Fátima Moura Albuquerque; Cláudia de Oliveira Silva; Ana Valéria Santos Pereira de Almeida

Centro Universitário Uninovafapi

BACKGROUND: Autoimmune hepatitis (AIH) is caused by a disorder of the immune system, leading to progressive destruction of the liver and fibrosis. In Brazil it is responsible for 5-19\% of liver diseases. The clinical picture has insidious onset, lethargy and asthenia associated with laboratory abnormalities and findings of physical examination suggestive of chronic liver disease. In younger patients, it presents acutely, mimicking viral or drug-toxic hepatitis, and half of them refer to previous or current jaundice episode. The conventional treatment consists of prednisone (PD) monotherapy at the dose of $60 \mathrm{mg} / \mathrm{d}$, or at the dose of $30 \mathrm{mg} / \mathrm{d}$ associated with azathioprine (AZA) $1-2 \mathrm{mg} / \mathrm{kg} / \mathrm{d}$, both with similar response rates. CASE DESCRIPTION: A 19-year-old female patient reports that for 5 years she presented with asthenia, adynamia and jaundice, was hospitalized with suspected diagnosis of hepatitis $A$, with exclusion of this hypothesis, negative serologies for viral hepatitis, and began the investigation for HAl She complained of edema in the face and limbs, polyarthralgia and alopecia. The hypothesis of systemic lupus erythematosus (SLE) was raised. Laboratory tests: Protein electrophoresis: hypergammaglobulinemia, TGO: 105, TGP: 88; FAN: homogenous nuclear standard positive and FAN-hep2 reagent, USG with heterogenous liver and discrete splenomegaly. Biopsy showed altered architecture at the expense of fibrosis and intense predominantly mononuclear inflammatory infiltrate. Conduct: AZA $100 \mathrm{mg}$ and PD 20mg, later suspended. CONCLUSION: HAl associated with othe autoimmune diseases may delay its diagnosis. Despite having suggestive FAN, the patient does not have all the criteria necessary for the diagnosis of SLE according to Systemic Lupus International Collaborating Clinics. He evolved without complaints, followed up with Rheumatology, using methotrexate, with persistently normal biochemistry and with ambulatory follow-up every 2 months.

Keywords: Autoimmune hepatitis, Lupus, Autoimmunity. 
173. SCHOOLING AS A FACTOR FOR PROTECTION OF CARDIOVASCULAR DISEASES IN ADULTS OF SÃO LUÍS, MA

Caio Márcio Barros de Oliveira; Luciano Beltrão dos Reis Viana; Aline Maria de Lemos Araujo; Beatriz Matos Costa; João Paulo Nascimento Miranda; Larissa Moreira Atta; Valéria Meneses Sousa Universidade Federal do Maranhão (UFMA)

BACKGROUND: Schooling is widely studied in global epidemiology due to the importance of life habits in the prevalence of many diseases. In Brazil, due to the epidemiological transition, there is an increase in the incidence and prevalence of Noncommunicable Chronic Diseases (NCD), such as Diabetes Mellitus (DM) and Arterial Hypertension (AH), which have the main Risk Factor (RF) associated with overweight. Thus, it is important to describe the prevalence of HA and other cardiovascular RFs in a sample an adult population in São Luís - MA. METHODS: A sample of 201 patients, aged 21 years and older attended at an event (World Heart Day 2016) in São LuísMA. Two groups were divided, according to self-reported schooling: A) Without Higher Education ( $n=102$ ) e B) With Complete or Incomplete Higher Education $(n=89)$. The following variables were analyzed: age, sex, Body Mass Index (BMI), Abdominal Circumference (AC), and Systolic Blood Pressure (SBP) and Diastolic Blood Pressure (DBP). For the statistica analysis, the software Microsoft Excel 2016 and Student's T test were used. RESULTS: $43,57 \pm 13,72$ years of average age; $59,2 \%$ women $(n=113)$; BMI avarage $\left(\mathrm{Kg} / \mathrm{m}^{2}\right)$ of $27,92 \pm 5,14 ; A C$ avarage $(\mathrm{cm})$ of $89,63 \pm 10,96$ for $A$ and of $86,17 \pm 12,12$ for $B(p 8,05)$. Group A presented higher values of SBP and DBP respectively $(124,36 \pm 16,29$ and $81,03 \pm 12,44 \mathrm{mmHg})$ than group $B$ $(119,79 \pm 14,35$ and $80,76 \pm 9,79 \mathrm{mmHg})$; however, this difference was statistically significant only for SBP. CONCLUSION: One of the factors related to the high prevalence of NCD and increase in $A C$ is the limited education of the population. Longer access to education has been associated with lower incidence of smoking and BMI, a favorable lipid profile and a reduced prevalence of DM and sedentary lifestyle. These findings raise the need for greater investments in access to education for the Brazilian population.

Keywords: Schooling, Cardiovascular Diseases, Blood Pressure

\section{ANTHROPOMETRIC INDICATORS AS A RISK FACTOR FOR} CARDIOVASCULAR IN ADULTS OF SÃO LUÍS - MA

João Paulo Nascimento Miranda; Dr. Caio Marcio Barros de Oliveira; Aline Maria de Lemos Araújo; Beatriz Matos Costa; Larissa Moreira Atta: Luciano Beltrão dos Reis Viana; Valeria Meneses Sousa Universidade Federal Do Maranhão - UFMA

BACKGROUND: Cardiovascular diseases (CVD) are important in clinical management in Brazil, since they are the leading cause of death in the world. The proven relationship between the incidence of these diseases and the risk factors, such as dyslipidemia and obesity, requires tools such as screening, prevention and control of CVD. Among these, anthropometric indicators are a simple and effective measure of abdominal adiposity - one of the best predictors of CVD1, 2, 3. Thus, it is sought to evaluate with such tools the cardiovascular risk in a sample of the adult population of São Luís. METHODS: The sample included 193 patients over 21 years attending an event allusive to World Heart Day 2016, in a public place of São Luís-MA Group A: 21 to 40 years ( $n=85)$, Group B: 41 to 60 years $(n=86)$, and Group $C: 61$ to 80 years $(n=22)$. The following variables were analyzed: Age, Sex Body Mass Index (BMI) and Abdominal Circumference (CA). For the statistical analysis, the software Microsoft Excel 2016, and the Student's T test were used. RESULTS: Patients had: $43.16+13.14$ years of age; $62.7 \%$ women $(\mathrm{n}=121)$; Mean BMI $\left(\mathrm{kg} / \mathrm{m}^{2}\right)$ of $27.99 \pm 5.11 \mathrm{~kg} / \mathrm{m}^{2}$; Mean CA $(\mathrm{cm})$ of Group A of $85.60 \pm 12.57$, Group B of $89.49 \pm 10.71$ and Group C of $92.73 \pm$ 8.48. There was a statistically significant difference $(p \quad 8.05)$ in the comparison between Group A and Groups B and C. CONCLUSION: According to Haun et al. The anthropometric indicators IMC and CA are capable of indicating a high coronary risk. 4 It was because of the lack of healthy habits of life, which, together with the natural conditions of aging, affect the population. Thus, it is necessary to seek to raise awareness of the issue, through campaigns of the Ministry of Health, acting in a more effective way in order to increase the expectation and quality of life for Brazilians.

Keywords: Cardiovascular diseases, Anthropometric indexes, Abdominal circumference, Abdominal adiposity

\section{5. \\ TREATMENT OF PATIENTS WITH POST-LEPROSY NEUROPATHY AT SÃO} LUIS, BRAZIL

Islanara Diógenes Urbano Sousa; João Batista Santos Garcia; Luciana Alencar Fialho Bringel; Luiz Nycollas Carneiro Oliveira; Thiago Alves Rodrigues; Gabriel Santana Machado

Universidade Federal do Maranhão (UFMA)

BACKGROUND: Maranhão is one of the states where leprosy is hyperendemic in Brazil. In 2009, the detection rate in the country is 67.26 per 100,000 inhabitants and the sequels rate is 5.82 in the state. In this context, the objective of this study is to delineate the treatment profile of patients treated at the Pain Service of the University Hospital of the Federal University of Maranhão. METHODS: This study was realized based on the medical records of nine patients diagnosed with post-leprosy pain treated at the referred service. In the first and last consultations, the intensity and characteristic of the pain, the proposed therapy and the continuity of the treatment were investigated. RESULTS: During the diagnosis, $78 \%$ of the patients reported severe pain and $22 \%$ moderate pain. After treatment, $45 \%$ presented mild pain, 33\% moderate pain and $22 \%$ severe pain. The most prevalent symptoms include paraesthesia, present in all patients, changes in muscle strength, hypoesthesia on the touch, edema, changes in movement and allodynia. Regarding the therapeutic proposal, the following medications were prescribed during the follow-up of these patients: amitriptyline, gabapentin, pregabalin, methadone, tramadol and codeine Regarding non-pharmacological therapy, physiotherapy was indicated in $44 \%$ of the cases; hydrotherapy and psychotherapy in $33 \%$ of cases; and acupuncture, $22 \%$ of the time. The rate of adherence to the proposed treatment was $56 \%$, with the main reasons related to non adherence: lack of financial conditions and side effects of medications. CONCLUSIONS: Therapy presented a good response for the treatment of pain in patients with post-leprosy neuropathy, indicating that the use of tricyclic antidepressants, anticonvulsants and opioids act satisfactorily in the control of this type of pain. In addition, the use of non-pharmacological measures was also important in the management of these patients.

Keywords: Neuropathy, Leprosy, Pain Control.

176. UTERINE ARTERY EMBOLIZATION FOR SYMPTOMATIC UTERINE MYOMA IN TRANSRADIAL ACCESS

Pedro Paulo Souza Chaves; Cláudio Henrique de Melo Pereira Filho; Beatriz Matos Costa; Lais Cristina Aguiar de Castro; Ronaldo Ewerton Viana Neto; Vanisse Portela Ramos; Sebastião Barreto de Brito Filho Universidade Federal do Maranhão (UFMA)

BACKGROUND: The Uterine artery embolization (UAE) has been used in the treatment of symptomatic uterine fibroids since 1995 and is seen as an alternative treatment to hysterectomy in many studies. The UAE has traditionally been held by accessing transfemoral (ATF), however, evidence shows remarkable benefits in transradial access (ATR). The goal is to show the Uterine artery embolization using the ATR as a treatment of symptomatic uterine myoma through data collected during realization of the procedure at University Hospital of the Federal University of Maranhão. RESULTS Patient, 39 years, G.M.M. began complaining of metrorrhagia, pelvic pain and Dyspareunia. Performed ultrasound that showed suggestive of intramural myoma of $3 \mathrm{~cm}$, the resonance of the pelvis showed intramural myoma in body wall right sidebar if hinting on endometrial cavity (submucosal component), measuring $4 \mathrm{~cm}$. Checked to perform the fibroid embolization. Initially, accomplished access radial artery retrograde left for angiographic study of the arteries hipogástricas. This demonstrated hypertrophy of uterine arteries (to the right), nurturing multiple masses hipervasculares located in pelvic fossa, compatible with uterine myoma. Then microcateterismo took selective Uterine artery where it was injected (PVA) to 500 micro-700mc, leading to a subsequent distal occlusion of these vases, promoting satisfactory devitalization. In the first postoperative day (DPO) clinically stable patient evolved with pain in abdominal colic and two episodes of vomiting, with improvement after medication. Discharged in the 2opod without complaint, in good general condition, flabby abdomen and painless. Radial puncture site without changes. CONCLUSION: the Uterine artery embolization technique by ATR for symptomatic fibroids treatment proved to be an efficient, safe and method that provides rapid recovery to the patient.

Keywords: Uterine artery Embolization, Leiomyoma, Fibroids Treatment 
177. EPIDEMIOLOGICAL PROFILE OF PATIENTS FROM THE REGIONAL INTENSIVE CARE UNIT OF THE BAIXADA MARANHENSE OF PINHEIRO (BRAZIL)

Ana Victoria Pinho de Carvalho Pascal; Hilda Mariana Costa Clementino; Samira Soledade Silva; Dayse Eveline Santos Sousa; Yago Galvão Viana; Simone Soares do Lago; Ana Claudia Pinho de Carvalho

Hospital Regional da Baixada Maranhense Dr. Jackson Lago

BACKGROUND: Knowing the epidemiology of health units help to define strategies to improve patient care, optimizing care, in view of the growing number of critical patients admitted to this sector and the high cost of the service, with High-tech equipment and qualified multidisciplinary team. OBJECTIVE: To outline the epidemiological profile of hospitalized patients from the hospital macrorregional de Pinheiro-MA. METHODS: A retrospective study using secondary data from patients admitted to the ICU of the Macrorregional hospital in the period from January to March 2018, with the following variables: Age, sex, month, days of hospitalization, provenance and diagnosis, and a database was created in the EPI Info statistical program. RESULTS: In the studied period, $54 \%$ of the hospitalized patients corresponded to males and $46 \%$ to females. As for the age group more than half had more than 60 years. Regarding the affected system, about $40 \%$ were due to neurological causes, with cerebrovascular accident (CVA) and Cranioencephalic Trauma (TBI) as main diagnoses, followed by $16.6 \%$ of orthopedic causes. The municipalities that most regulated patients were turilândia, Santa Helena and São Bento. The average occupancy rate per bed was 4 patients. CONCLUSION: Evaluating the data, it can be inferred that hospitalizations were more frequent in elderly patients, being the main causes of neurological, such as stroke and TBI, results that guide the strategy of optimization of resources directed to this profile of Patients.

Keywords: macroregional; epidemiological profile; Icu

\section{CONGESTIVE HEART FAILURE: CASE REPORT}

Mayllane Lays Barbosa; Andréa de Jesus Sá Costa Rocha Universidade Federal do Maranhão (UFMA)

BACKGROUND: Congestive heart failure is a clinical syndrome characterized by a structural or functional alteration of the heart, which generates an inability to eject and/or blood accommodation within physiological pressure values. The diagnosis is based on the patient's clinical history, symptomatology and physical examination, complemented with laboratory and imaging exams are complementary. Treatment should be focused on three important objectives: tissue oxygenation, hemodynamic stabilization and congestion relief. CASE DESCRIPTION: All stages of the nursing process were performed and the main nursing diagnoses listed were: decreased cardiac output characterized by bradycardia related to altered heart rhythm Impaired spontaneous ventilation characterized by dyspnea related to accessory muscle fatigue; Excessive fluid Volume characterized by edema related to impaired regulator mechanism; Impaired tissue integrity characterized by injured tissues related to invasive devices; Acute pain characterized by facial expression of pain related to invasive device-thoracic drain. From the identified diagnoses, expected results and nursing interventions were established, which included monitoring of vital signs, control of water balance, evaluation of edema and peripheral perfusion, skin supervision, Preventive measures against infection, qualitative evaluation of pain and analgesic care for the patient as prescribed. CONCLUSION: Congestive heart failure has several clinical manifestations that impact on the quality of life of its carriers. Knowing the clinical profile of the patient is fundamental for the identification of nursing diagnoses and the implementation of nursing interventions in search of the expected results through the systematization of nursing care.

Keywords: heart failure, nursing, health care.

\section{MESOTHELIOMA AS A DIFFERENTIAL DIAGNOSIS OF ACUTE RESPIRATORY} DISORDER SYNDROME

Mirelly de Souza Rosa; Fabrício Silva Souza; Raphael Coelho Figueredo

Universidade Federal do Maranhão (UFMA)

BACKGROUND: Typically, the factors most associated with the development of Acute Respiratory Distress Syndrome are those that promote direct or indirect lung injury, such as pneumonia, aspiration of gastric contents, sepsis and severe trauma with shock. However, some unusual pathologies may mimic acute respiratory distress and make accurate diagnosis difficult, such as Mesothelioma: a tumor arising from the mesothelial and submesothelial cells of the pleura, which can cause dyspnea, dry cough and chest pain. The present study reports the case of a female patient, 41 years old, caucasian, who sought the first aid presenting symptoms of fever, chest pain on the basis of the right hemithorax, cough and dyspnea after 45 days of hysterectomy for myoma removal. It denies a history of other previous diseases or occupational exposure to asbestos. RESULTS: Hemogram showed a very high C Reactive Protein $(169,9 \mathrm{mg} / \mathrm{L}$, with reference value $6.0 \mathrm{mg}$ $(\mathrm{L})$ and other normal results. Postero-anterior Thorax X-ray showed erasure of the right diaphragmatic hemicule. Ultrasonography revealed a net collection in the right lung base. Relief and diagnosis thoracentesis was performed, whose histopathological examination showed negative results for bacterial cultures, positivity for expression of cytokeratin, calretinin, WTI protein and presence of necrosis areas, being compatible with the diagnosis of mesothelioma. CONCLUSION: Mesothelioma's ability to mimic diseases such as Acute Respiratory Distress Syndrome, added to its rarity without asbestos involvement, make it a difficult differential diagnosis. In this way, diagnostic research based on clinical, radiological and cytological aspects is essential to properly identify a mesothelioma, and to initiate treatment in a timely manner for patient improvement.

Keywords: Mesothelioma, Asbestos, Pleura.

\section{DIALOGUE CIRCLE WITH PREGNANT WOMEN: A STRATEGY OF HEALTH} EDUCATION

Jéssica Raiany Costa e Costa; Letícia Teixeira Torres; Kirlian Karolene Araujo Pereira; Maria da Conceição Pereira de Carvalho; Regina Maria Abreu Mota; José Gonçalves da Rocha Neto Universidade Federal do Maranhão (UFMA)

BACKGROUND: The gestational period is characterized by physical, physiological and emotional changes in a woman, and can be the cause of joys and anxiety, doubts, uncertainties and concerns about the concept in development. It is common to raise doubts about various issues involving the woman's body, her and baby's health. This is an experience report of a work promoted during the obligatory curricular nursing traineeship in primary health care, which occurred during April and May of 2018. The training field made possible to have a conversation with pregnant women, which addressed issues that involved from the first trimester of pregnancy to the puerperium, such as healthy food, breastfeeding, childbirth, and myths and truths about gestation. RESULTS: The realization of the dialogue circle provided a space for listening and interaction between pregnant women health professionals, which is often not possible due to the great demand of the unit. In addition, the dynamic / interactive approach adopted allowed the appreciation of pregnant women's knowledge about the period experienced. It was possible to clarify doubts and strengthen the bond of the pregnant women with the primary care service. CONCLUSION: The dialogue circle was an experiment that reached the proposed objectives, increasing the interrelation and bonding of pregnant women with professionals and demonstrating the importance of including or expanding educational work with this group, taking into account the value of prevention and health promotion to always get quality service.

Keywords: Health education; pregnant woman, Primary health care

\section{MIASTENIA GRAVIS AND IMMUNOSUPPRESSOR TREATMENT: A CASE} REPORT

Flávia da Conceição Silva Reis; Itallo Alves dos Reis; Vilena Marjana Bezerra Pereira; Felipe Serafim Teixeira; Diego de Sousa Silva; Marjorie Tarsila Lima Dantas; Luecya Alves de Carvalho Silva Universidade Federal do Maranhão (UFMA)

BACKGROUND: Myasthenia gravis (MG) is a chronic autoimmune neurological disease that affects post-synaptic structures of the neuromuscular junction of the skeletal striated muscles, characterized by localized or generalized muscle fatigue. The study aims to report the evolution of the treatment of the disease. RESULTS: A 32-year-old female patient, Caucasian, with no relevant pathological history, with MG. Symptoms manifested from the age of eight, with muscle weakness of the lower limbs, causing constant falls. Sickle cell anemia was the initial hypothesis. Faced with the erroneous treatment, signs and symptoms were aggravated and revealed by diplopia, dysphagia, nasal voice and facial paraesthesia. Therefore, the patient was 
referred to the neurologist and, after clinical analysis, eyelid ptosis was observed, at which time complementary tests were requested, such as thymus computed tomography, electromyography and blood test to identify anti-acetylcholine receptor antibodies. The patient was then diagnosed with myasthenia gravis associated with follicular thymic hyperplasia. Initially, pyridostigmine and prednisone were given. Subsequently, she underwent thymectomy, which is why the symptoms remained controlled. However, at the age of 14, with the hormonal changes of puberty, new myasthenic crises occurred, accentuating, mainly, dysphagia. The patient was then given increased prednisone and pyridostigmine dosages and initiated pulse therapy with immunosuppressants. After successive therapeutic adjustments, clinical status has evolved significantly and is currently stable, performing plasmapheresis. CONCLUSION: The report shows the complex treatment of the disease, due to its aggravation with age and the need for surgery, plasmapheresis and immunosuppressive use for symptom stability. It is therefore seen the indispensability of differential and early diagnosis of the disease.

Keywords: Neuropathology, Myasthenia gravis, Immunosuppressants

182. THE INFLUENCE OF THE INTERNET IN THE MEDICAL-PATIENT RELATIONSHIP IN THE BASIC UNITS OF IMPERATRIZ MA

Letícia Carollyne Prado do Nascimento; Amanda Costa Marra; Eryka Escórcio Brito Rêgo; Ana Karine Lopes Vilanova; Rossana Vanessa Dantas Almeida-Marques

Universidade Federal do Maranhão (UFMA)

BACKGROUND: The situation in which patients enter medical offices with "diagnoses" based on information from Cybermedicine is common, reflecting impacts on the physician-patient relationship. In view of this current scenario, this study aims to analyze the interference of the Internet in the physician-patient relationship in primary health care. METHODS: A cross-sectional, exploratory, descriptive and quantitative approach study. The sample consisted of 120 users of the Nova Imperatriz and Milton Lopes (Imperatriz - Maranhão) basic health units. The participants were between 18 and 59 years of age, of both sexes. A self-administered questionnaire of 20 questions was given to them, together with the Informed consent form (ICF). RESULTS: Of the volunteers $69.2 \%$ were female and $30.8 \%$ male, with an average of about 31 years. Of these $80.8 \%$ employ the Internet for auto diagnostics. Pharmacy Sites and Biochemical laboratories were the main research vehicles, with $36.7 \%$. $50 \%$ of the participants reported the diagnostic research to the physician, and $12.5 \%$ of them affirmed the discouragement of the act by the professional. $65.8 \%$ complement or total office failure guidelines with the Internet. Moreover, $80.8 \%$ feel more comfortable in going to the medical consultation after carrying information obtained in the virtual environment. And, $47.5 \%$ use the Internet for Analysis of laboratory exams. CONCLUSION: The autonomy of the patient is amplified with the use of the Internet, especially for self-diagnosis, since those who use it, do it independently or not of consultations with physicians. Moreover, the patient's confidence towards the physician does not change significantly, and adherence to treatment is therefore not impaired. It was notorious that, due to failure in the doctor-patient communication, it is common for patients to use the network to clarify diagnoses and medications

Keywords: doctor-patient relationship, cybermedicine, primary care

183. USE OF THE INCP TAXONOMY FOR PATIENT WITH EMBOLISM AND THROMBOSIS OF THE LOWER LIMBS ARTERIES

Maria Paula Macedo Brito; Mayrla Karen Rodriques Mesquita; Priscilla Ingrid Gomes Miranda; Agostinho Antônio Cruz Araujo Palloma Neves Cavalcant; Cleane gomes dos santos; Ana Maria Ribeiro dos Santos

Universidade Federal do Piauí (UFPI)

BACKGROUND: This is a case report held on May 07 and 14, 2018, developed in a teaching hospital, a reference in high complexity for the northern region of Brazil. Female patient, 43 years old, Brown, single, rural worker, from Campo Maior. It presents extensive lesion in the right lower limb, with regular borders and occlusive dressing at the lesion site. It was transferred from the referral hospital in urgent care of the municipality, with initial medical diagnosis of embolism and thrombosis of lower limb arteries. She performed inferior limb arteriography that showed chronic occlusion of the superficial femoral artery. The objective of this study was to construct statements of nursing diagnoses for patients with embolism and arteria thrombosis. The taxonomy of the International Classification for Nursing Practice-ICNP ${ }^{\circledR}$ was used to systeize nursing care, based on the theory of basic human needs. RESULTS: Thrombosis is a disease characterized by the formation of Thrombi in the cardiocirculatory system, mainly affecting patients who present risk factors such as compromised mobility, presence of infection, recent surgery and age Advanced. It is noteworthy that surgical intervention is the main treatment. The nursing diagnoses listed above were: Pain per current wound in the right leg, compromised skin integrity and compromised mobility. Among the planned interventions, it was highlighted: to assess pain in the right leg frequently; Apply dressing using aseptic technique in right leg in the morning, after bathing, supervise right leg wound continuously and monitor tissue perfusion of the patient $6 / 6$ hours. CONCLUSION: The use of ICNP ${ }^{\circledR}$ enabled the operationalization of the nursing process in order to organize a holistic and targeted assistance to achieve the following results: pain and improved skin integrity, increased mobility level.

Keywords: Nursing; Nursing processes; Nursing diagnosis.

\section{AMYAND'S HERNIA}

Larissa Balby Costa; José Nazareth Barbosa Santos Filho; Nailde Melo Santos; Rayssa Mayara Rodrigues de Souza; Maria Arlete da Silva Rodrigues; Isabella Froes Souza; Amanda Carvalho e Barbalho Centro Universitário do Maranhao (CEUMA)

BACKGROUND: Amyand hernia is a rare surgical disease of the anterolatera wall of the abdomen, with a difficult preoperative diagnosis, in which it is defined as an inguinal hernia in which the vermiform appendix, inflamed or not, lies within the herniated SAC Inquinal. The name is due to the British surgeon Claudius Amyand, who in 1935 described the first case of perforated appendicitis in the hernia sac. The exact incidence is unknown, but it is estimated that the non-inflamed appendix is about $1 \%$, while appendicitis is present in $0.3 \%$ of the inguinal hernias. The clinical presentation does not differ from the manifestations of any other inguinal hernia, such as swelling and pain in the inguinal region, especially efforts. In the presence of acute inflammatory condition, abdominal pain is more intense. Thus, the diagnosis is mostly, in an intraoperative manner. Thus, the report of the present case has the objective of alerting surgeons, especially those who work in the emergency sector, for the correct diagnosis and treatment of this rare surgical condition. CASE DESCRIPTION: In this sense, the report of the clinical case presented is a male patient, 68 years old, diagnosed with right inguinal hernia whose intraoperative finding showed Amyand's hernia, operated in the General Surgery service of the hospital Santa Casa de Misericordia, in São Luís-MA, presenting satisfactory clinical evolution postoperatively. CONCLUSION: Amyand's hernia is an uncommon pathology and is sometimes considered rare. However, it is important to orient physicians to a correct therapeutic approach in this surgical emergency, considering that there is the possibility of association between strangled inguinal hernia and acute appendicitis, avoiding, in view of this, the complications and decreasing the length of hospital stay.

Keywords: Amyand hernia, Appendix Cecal, Inguinal hernias.

185. DERMOID CYST IN THE RIGHT SUBMANDIBULAR REGION

Ana Clara Sampaio Lima Vasconcelos; Rayla Bezerra Rocha; João Víctor Pacheco Florentino; Wesley Costa Barros; Larissa Vidigal Hortegal de Oliveira; José Helder Vasconcelos Filho Centro Universitário do Maranhão (CEUMA)

BACKGROUND: The Dermoid cyst is a developmental alteration in the form of a relatively rare cystic teratoma in the head and neck region. These cysts originate from epithelial remnants retained in the midline during closure of the mandibular branchial arches and hyoid bone. They are more prevalent in young adults, with no predilection for sex. They are presented as tumefaction, soft consistency and slow growth. Early diagnosis is essential for the prophylaxis of physiological disorders. CASE DESCRIPTION: W.L.T.B., Male, 18 years old, resident and natural of São Luís-MA, referred from Otorhinolaryngology to head and neck surgery, presenting sinusitis and tonsillitis of repetition and tumefaction with discomfort in the right submandibular region there Approximately 7 months. On physical examination, the lesion was painless, and soft consistency. Tomography revealed a cystic lesion of about $8 \mathrm{~cm}$, with characteristics of congenital origin, suggesting lymphangioma due to the absence of symptomatology. 
The biopsy aspirative puncture showed cells with nuclear atypias and overlap with proteinaceous and hemorrhagic background. Magnetic resonance imaging characterized the lesion as a solid aspect, confronting the results of the tomography. We opted for the realization of enlarged resection of soft tissue tumors, with an aciform incision in the cervical fold of $6 \mathrm{~cm}$, rebeating of the flaps, exposure and preservation of the right mandibular marginal nerve and right submandibular gland. Dissection and resection of a cystic-like tumor with viscous, greeny material and yellowed points of $10 \mathrm{~cm}$ in diameter. Histologica analysis confirmed the diagnosis of dermoid cyst. CONCLUSION: The Dermoid cyst in the head and neck is relatively rare and reveals the importance of discussing this case. The treatment of choice is surgical excision due to low risk of recurrence, and an early diagnosis is important for adequate intervention and prevention of complications.

Keywords: Cervical cyst, Submandibular teratoma, Dermoid cyst, Cervical tumor

186. MALIGNANT NEOPLASM OF THE THYROID GLAND: DEATHS IN MARANHÃO AND PIAUI DURING THE PERIOD 2007-2016

Lucas Henrique Ferreira de Sousa; Daizy Carlota Coelho Aguiar; Italo Henrique Pereira Lima; Dayna Maria Caldas Diniz; Jessica Ferreira Bertoldo; Sueli de Souza Costa

Universidade Federal do Maranhão (UFMA)

BACKGROUND: Malignant neoplasm of the thyroid gland is the most common in the head and neck region. The cause is not clarified, but factors such as irradiation of the neck area and positive family history for Neoplasia are important for the clinical history. The present work presents a comparative analysis of the deaths occurring in the states of Maranhão (MA) and Piaul (PI) due to malignant neoplasm of the thyroid gland (ICD-10 C73). METHODS: Quantitative epidemiological study of a descriptive approach with data collection of the death certificates available digitally in Datasus, with basic cause the ICD-10 C73 in the MA and PI in the period 2007-2016. The analysis was made through descriptive statistics using the programs Tabwin 4.1.3 and Microsoft Excel 2010. RESULTS: The proportional mortality of people who had the ICD-10 C73 as the basic cause was equivalent in both states throughout the period, except in 2011, which was higher in the IP. During the study period, the MA presented 164 deaths and the PI 115. Regarding gender, in the MA 43 cases (26.2\%) were in males and $121(73.8 \%)$ in females and in PI 36 cases (31.3\%) were in males and $79(68.7 \%)$ in females. Between 2009 and 2011 years, PI showed an increase of $633 \%$, from 3 to 22 cases, while in the MA there was a small increase, ranging from 13 to 15 However, in the period between the years 2007 and 2013 the MA had an increase of $177.8 \%$ of the cases, which may be observed in the proportional mortality that increased in $113.2 \%$. CONCLUSION: When analyzing proportional mortality due to thyroid cancer throughout the period, it is observed that in both states there was an increase, and the PI with a slightly higher rate. Mortality from thyroid cancer, although not one of the main causes of death in both states, has significant numbers in the period analyzed, with a prevalence in females and thus indicating the need for prevention policies.

Keywords: mortality; thyroid gland neoplasms; Epidemiology

187. SCREENING OF DIABETIC FOOT IN THE BASIC CARE UNIT OF IMPERATRZMA, BRAZIL

Gabriela Alencar de Lima Mota; Livia Maia Pascoal; Paula Vitória Costa Gontijo; Maysa Alves de Sousa; Maksandra Silva Dutra; Samanta Cunha Mesquita; Aldo Lopes da Costa Júnior Universidade Federal do Maranhão (UFMA)

BACKGROUND: Diabetic Foot is one of the most frequent complications of Diabetes Mellitus (DM), and is responsible for $20 \%$ of hospitalizations of individuals with DM, which do not rarely culminate in amputation of the affected limb. This outcome can, however, be avoided through periodic screening and educative approach of people with DM. Thus, the aim of this study is to evaluate the feet of diabetic patients and investigate whether the risk screening for diabetic foot has been made in the units Basic health (UBS's) of Imperatriz - MA. METHODS: A cross-sectional descriptive study was carried out with 153 patients diagnosed with type II DM, followed at UBS's of Imperatriz. Data were obtained from February 2016 to March 2018 through interviews, with the help of a semi-structured questionnaire addressing sociodemographic data of the patient, monitoring the disease by the UBS and physical examination of the feet. RESULTS: The majority of the sample consisted of women (68.6\%) with mean age of 64 years and mean time of diagnosis of 8 years. On physical examination, sensitivity depletion was observed in $14.3 \%$ of the cases, in addition to dryness $(60 \%)$ and deformities (15\%), suggestive of neuropathy. The deep pulses of the foot were diminished or not palpable in $49.6 \%$ of the cases, indicating angiopathy. Regarding the pathological history, $15.6 \%$ had a history of ulcers, and $4.5 \%$ had ulcers at the time of evaluation. When questioned about the follow-up of the disease, $72 \%$ of the patients reported regular consultations performed by a medical professional in $81 \%$ of the cases. It was observed that $61 \%$ of the patients reported never having received guidance on how to avoid foot injuries, and $82.4 \%$ stated that they had never had their feet examined during the consultation. CONCLUSION: Although a large part of the sample presented risk factors for diabetic foot complications, screening was not performed in most cases, demonstrating a deficit in this area of primary care in Imperatriz-MA.

Keywords: Screening, Diabetic foot, Diabetes Mellitus

\section{HEALTH EDUCATION ON TYPE 2 DIABETES IN CHILDREN AND TENEAGERS} Vitor Paixão Cruz; Jacira do Nascimento Serra; Luis Cleiton Callegario; Danilo José Brito de Arruda; Ester Erćlia Borge; Igor Roberto Guilhon Costa; Daniella Pereira da Silva

Universidade Federal do Maranhão (UFMA)

BACKGROUND: In Brazil, overweight and obesity increased in all age groups, including children and adolescents. Such factors comprise a higher risk for the development of type 2 diabetes mellitus (DM2), which favors the perpetuation of the prevalence of this disease in adults. Therefore, the present work aims to report an action proposed by the integrative axis (El), which consists of a scientific branch of problem-based learning, from the Federal University of Maranhão, in the problem of DM2 in childhood and adolescence. RESULTS: An educational action was carried out at a public school in São Luís-MA, conducted by the group of the El, which has 14 undergraduate students of medicine. At first, students were questioned about DM2 in order to identify what they knew about it. It was identified that most students did not know the prevalence of the disease in their age groups; Besides the risk factors (such as obesity) and life habits that favor prevention. In a second moment, there was an explanation to the students about the concept, prevalence, risk factors, prevention and treatment. After that, a playful activity was performed with the drawing in the table of a food pyramid, in which the students were instructed to fill them as they found it to be correct. With this activity, it was observed that the majority did not know how to complete it adequately, being promptly oriented about the correct and instructed way about which foods should consume more, and which should consume less. Finally, an educational leaflet was distributed regarding DM2, its risk factors and signs and symptoms. CONCLUSION: Although initially unaware about DM 2 and everything that involves it, the students showed interest in the activity with possible understanding of what was passed on, which corroborates that educational activities such as this are fundamental to Decrease in the prevalence of this disease in children and adolescents.

Keywords: Type 2 Diabetes mellitus; Prevention Child Teenager

PERSPECTIVES OF PRENATAL ASSISTANCE IN BRAZIL AND MARANHÃO Débora Priscyla Gigante de Sousa; Larissa Holanda Assunção; Fernanda Santos Magalhaes; Luis Venicius Resplandes Gomes; Paulo Vitor de Oliveira Cardoso; Ergellis Victor Cavalcanti de Lima Universidade Federal do Maranhão (UFMA); Centro Universitário do Estado do Pará (CESUPA)

BACKGROUND: Prenatal care has undoubted relevance in the protection and prevention of adverse events in obstetric health since it allows the identification and clinical management of timely interventions on the various risk factors for maternal and neonatal health complications. Therefore, the failure to perform or inadequate prenatal care to understand the quality of this care in the care of the pregnant woman should be highlighted. METHODS: A cross-sectional descriptive study was carried out by analyzing the numbers of prenatal consultations with emphasis in Brazi and Maranhão collected in the DATASUS database (SUS Department of Informatics) from 2014 to 2016. RESULTS: At the Brazilian level, there were gradual decrease of $12.27 \%$ in the number of inadequate consultations over the years, which could characterize an increase in the coverage of the health 
system as well as greater access to information by pregnant women. The age group that performed the least prenatal visits was 15 to 24 years old, with $51.5 \%$. In relation to Maranhão, there was also a reduction in the number of inadequate consultations with $12.96 \%$, but despite the decrease proportional to the national level, the State is the second with the worst rates in the northeast region. The age group that performed the least prenatal visits was also 15 to 24 years old, with $57.37 \%$. CONCLUSION: This research makes possible the understanding of the assistance to the pregnant woman in a region of low prenatal care in the country and can contribute to the evaluation of health system coverage in the State of Maranhão and Brazil, expose trends and promote a better understanding of the quality of the access to the least served age groups and the minimum number of consultations recommended by the Ministry of Health for the creation of public actions, especially in regions where there is no efficient coverage.

Keywords: Assistence, Prenatal, Pregnancy

\section{INFLUENCE OF BREASTFEEDING ON THE HEAD CIRCUMFERENCE OF} BRAZILIAN CHILDREN

Ana Paula Costa Castro dos Santos; Carolina Abreu de Carvalho; Sarah Aparecida Vieira Ribeiro; Isabela Leal Calado; Maria Tereza Borges Araujo Frota; Sylvia do Carmo Castro Franceschini; Poliana Cristina de Almeida Fonseca

Universidade Federal de Viçosa (UFV), Universidade Federal do Maranhão (UFMA)

BACKGROUND: The first infant feeding is breast milk, which is necessary for the nutrition of every child. Difficulties in maintaining the supply of human milk contribute to the background of other types of milk. However, there are studies that prove that the type of milk offered to the baby influences their brain development. This study aims to evaluate the influence of breastfeeding types and other variables on head circumference growth in the first six months of life. METHODS: Cohort study with follow-up of children in the 1st, 2nd, 4th and 6th month of life of the municipality of Viçosa-MG The cephalic perimeter evaluated through calculation of mean, standard deviation and percentiles 5, 50 and 95. Student's t-test or ANOVA (post-hoc test: Bonferroni) were used. The level of significance was $5 \%$. All the statistical analyzes were conducted in the Stata statistical program, version 13.0. The results in percentiles were compared to the WHO / 2006 standard. RESULTS: Children with exclusive and predominant breastfeeding had higher head circumference measurements than those who introduced formulas ( $p$ $=0.024)$. Children who had difficulties in breastfeeding in the first month $(p=0.002)$ and who used pacifiers in the sixth month $(p=0.036)$ had lowe cephalic perimeter means. The head circumference in both sexes followed the 50th percentile of the WHO / 2006 standard in the first semester. CONCLUSION: The results show that children who were followed up grew according to WHO / 2006 curves and suggest that head circumference measures are influenced by the type of breastfeeding, breastfeeding difficulties and pacifier use.

Keywords: Breastfeeding, Infant formula, Cephalometry

191. ACUTE HEART FAILURE CAUSED BY VIRAL MYOCARDITIS: A CASE REPORT Pedro Antonio Borges Melo; Bárbara Lays Bedin; Rubens Henrique da Silva Barreto; Ilfran Magalhães Silva II; Jorge Soares Lyra Universidade Federal do Maranhão (UFMA)

BACKGROUND: Dilated cardiomyopathy is a dysfunction that occurs dilation of the ventricles and systolic dysfunction. Its etiology is multifactorial, but the infectious cases are due to previous infection, followed by the phases: latency, diffuse cardiomyocyte necrosis and chronic fibrosis. The symptomatology varies from imperceptible to arrhythmias, intense fatigue and precordial pains. CASE DESCRIPTION: A 32 - year - old female patient from São Luís - MA, admitted to the hospital on June 18, 2018, complaining of progressive fatigue and dyspnea for 7 days, progressing with chest pain. He reports that a few weeks ago presented intense pharyngitis and selfmedicated with anti-inflammatories. It presents afebrile, denies chronic, hereditary diseases and cardiopathies. Laboratory abnormalities were: erythrocyte sedimentation rate (ESR) of $25 \mathrm{~mm} / \mathrm{h}$, C-reactive protein (CRP) of $4.78 \mathrm{mh} / \mathrm{dL}$ and positive serology for cytomegalovirus. Thus, the patient was referred to the cardiologist, who underwent electrocardiogram (ECG) which indicated alteration in lateral and inferior wall ventricular repolarization, 3-channel holter ( 1 ventricular tachycardia, 10 beats of 230 bpm), and echocardiogram ejection $=45 \%$, enlargement of the left atrium and ventricle, and diffuse hypokinesia). Thus, the sum of the findings at the patient's clinic and the positive inflammatory markers confirmed an acute myocarditis. CONCLUSIONS: Infectious myocarditis should be considered as a cause of heart failure when presenting with recent infections, non-specific ECG changes, sinus tachycardia disproportionate to fever, cardiac arrhythmias or acute conduction disorders, a third right or left ventricular outflow, radiography and precordial discomfort. The drug treatment prescribed for the patient was carvedilol, naprix, pantoprazole, ibuprofen and azithromycin, in addition to preventive measures for heart failure.

Keywords: myocarditis, infection, echocardiogram

192. RELATIONSHIP BETWEEN MORBIMORTALITY AND HOSPITAL COST OF CARDIOVASCULAR DISEASES, 2012-2017

Vinícius Santos Mendes Restier; Consuelo Penha Castro; Aeriberto Carlos Lindoso de Souza; Daniel Santos Uchôa; Luís Carlos Machado e Silva; Alejandro Elias Mouchrek Jaldin Universidade Federal do Maranhão (UFMA)

BACKGROUND: Cardiovascular diseases (CVD) stand out due to their high incidence and mortality in all regions of the country and in both sexes. Such involvement is so significant that when it does not lead to death, it causes sequelae, hospitalizations and costs, filling hospital and public hospital beds and burdening the public health service. The present study analyzes the relationship between admissions, deaths and value of hospital services by Brazilian region in the period from 2012 to 2017. METHODS: Crosssectional study with secondary data from the Department of Informatics of the Unified Health System from 2012 to 2017. Descriptive statistics, Kruskal Wallis analysis of variance and Pearson's correlation test were performed. RESULTS: During the period analyzed, a high rate of hospitalizations for CAD was found among regions (with similar indexes) - a slight predominance of the Southeast region - as well as the increasing tendency of hospitalizations and high expenditures for services dispatched, respectively, with ( $p \notin 0001$ ) and the value of hospital services provided $(p \& .0002)$. Death rates did not follow the pattern of hospitalizations in the period and did not follow the variation in service values. There was no correlation between deaths, number of hospitalizations and value of services provided in the Brazilian regions ( $p \oplus .05)$. CONCLUSION: Deaths due to CAD are not associated with hospitalizations, however the value of hospital services provided is closely related to the occurrence of deaths in almost all regions of the country. The cost associated with unfavorable prognoses is costly since much is spent on hospital services in order to recover the individual without having the satisfactory evolution. The prevention of complications of these diseases should be a priority in Brazilian public health, in order to avoid such costly and fatal outcomes.

Keywords: mortality, hospitalization, cardiovascular system

\section{LAMEШAR ICHTHYOSIS: A CASE REPORT}

Andreza Maues Dias Nascimento; Valéria de Castro Fagundes; Caroline Braga Barroso

Universidade Federal do Maranhão (UFMA)

BACKGROUND: Lamellar Ichthyosis is an autosomal recessive genodermatosis, classified as non-syndromic congenital ichthyosis and affects the metabolism of keratin and cell transit in the epidermal layers. The clinical picture of this type of ichthyosis is marked by the presence of a skin in "armor" appearance due to thick corneal plaques, that is, lamellar scaling over the entire body, formed by adherent and dark scales. The prognosis of lamellar ichthyosis varies with the presence or not of associated complications due to the breakdown of the dermatological barrier, which is the gateway for secondary infections. CASE DESCRIPTION: A male patient, one year and three months old, presented desquamative lesions throughout the body and these are present from birth. At the clinical examination, hyperpigmented plaques and scales were observed throughout the skin, some areas exulcerated but without signs of infection. Laboratory tests were requested for the initiation of acitretin and, as a result, the patient presented hepatic enzyme alteration $(T G O=81 \mathrm{U} / \mathrm{L}$ and $\mathrm{TGP}=32 \mathrm{U} / \mathrm{L}$ ), therefore it was not possible to start treatment, and hydration was prescribed and new examinations to evaluate them CONCLUSION: Ichthyoses are rare pathologies whose management is challenging, due to the potential risk of death of the patient. The treatment 
aims to eliminate scales and reduce xerosis without irritating the skin. In newborns and young children, cleansing and moisturizing are the first therapeutic choice, to improve the barrier function of the skin and facilitate flaking. Caution in the management of acitretin is justified because it is an aromatic retinoid for oral use, which presents elevation of transaminases among the main adverse effects. Because of the recessive nature, genetic counseling is important to guide the family about the nature of the disorder, the mode of transmission and the risk of future manifestations in other members.

Keywords: Lamellar Ichthyosis, Harlenquin, Acitretin

194. URETERO-VAGINAL FISTULA AFTER HISTERECTOMY IN URETER DUPLICATE: CASE REPORT

Laís da Hora Lucena Silva; Raphael Oliveira Lima Silva; Raffael Medeiros Alvarenga; Gil Ricardo dos Santos Fonseca; José Álvaro Nascimento Paixão; Marcos Adriano Garcia Campos

Universidade Federal do Maranhão (UFMA)

BACKGROUND: Urogenital fistulas are abnormal communications between the female genital tract with bladder, urethra, or ureters. In developed countries, these are uncommon, in general, are sequelae of gynecological surgery, and in less cases as a result of obstetric injury, severe pelvic disease or radiotherapy. In developing countries, these fistulas are a common complication of labor and urinary incontinence tends to persist. RESULTS: E.C.F, female, 38 years old, in postoperative hysterectomy evolved with urinary incontinence. After URO-CT, vesicle-vaginal fistula was suspected, the bladder was slightly distended with slightly irregular walls, and failure of the floor revealed contrast to the vagina. A cystoscopy, which did not identify the presence of a fistulous orifice, after having submitted to the methylene blue test in the bladder, extravasated urine was not stained. In Uro-TC / Uretrocisto-CT, there was extravasation of venous contrast in the excretory phase into the vagina. The contrast used in the bladder revealed no escape into the vagina. Diagnostic impression of tota duplication of the pielocalicinal system and left ureter, with anomalous insertion of the left ureter, with no anatomical distal definition possible. Ureteroscopy was performed on the 3 ureters, with fistula in one of the ureters on the left, identifying it by double J placement and performing ureteral reimplantation using the Lich-Gregoir technique. CONCLUSION: There were differences between the radiological and urological findings. The hypothesis was raised that there was injury during hysterectomy of one of the duplicated ureters with subsequent fistulization to the vaginal wall. It is important to highlight the difficulty in identifying which of the two duplicated ureters fistulized, and then perform the subsequent correction.

Keywords: Uretero-vaginal fistula; Urinary incontinence; urogenital fistulas Palavras-chave: Fístula uretero-vaginal; Incontinência urinária; fístulas urogenitais

195. SCENARIO OF ALZHEIMER'S DISEASE IN THE LAST YEARS IN BRAZIL

Thais Abreu Borges; Gideon Batista Viana Júnior; Kaiza Vilarinho da Luz; Fernando Cleydson Lima Paiva Filho; Rebecca Lemos da Silva Lages; Mariel Osório Silva; Eliana Campelo Lago Universidade Federal do Maranhão (UFMA), Universidade Estadual do Maranhão (UEMA), Centro Universitário UNINOVAFAP

BACKGROUND: Alzheimer's disease (AD) is classified as the most frequent behavioral and mental disorder among dementias. It is a neurodegenerative syndrome characterized by loss of cognitive functions, progressive impairment of daily living activities and other changes that compromise the quality of life in aging. The objective of this study was to conduct an epidemiological survey on hospital admissions of patients with $A D$ in Brazil from 2012 to 2017. METHODS: This is an exploratory-descriptive study with a quantitative approach. Data collection was performed through the collection of data from the Hospital Information System of SUS (SIH / SUS), made available by the Department of Information Technology of the Unified Health System (DATASUS). RESULTS: In the period between 2012 and 2017, 7803 AD hospitalizations occurred in Brazil. There was a prevalence of females with $5029(64.45 \%)$ and the age group of 80 years and over, with $4384(56.18 \%)$ cases. Of the five Brazilian regions analyzed, the Southeast Region is the region with the highest absolute number of hospitalizations with $4666(59.80 \%)$ hospitalizations in the period compared with the other regions. When color / race, white was predominant with 3739 (47.92) cases. CONCLUSION: In the country, the hospitalizations for AD predominated in the Southeast region, in female individuals, whose average age was 80 years and over. In this sense, it is necessary to focus on the fact that the disease has high significance in the quality of life of the individuals and that, although there is no clinical intervention that can prevent the appearance of $A D$ or cure it, there are the risk factors that need to be clarified, with a view to early diagnosis of the disease. Thus, the implementation of programs of early physical activity, more effective nutritional programs and changes in the food pattern of the Brazilian population, would be effective measures that could delay the onset of dementia.

Keywords: Alzheimer's disease, Neurodegenerative syndrome, Hospital admissions

\section{TRENDS ON YOUTH SUICIDE IN THE NORTH AND NORTHEAST REGION OF} BRAZIL FROM 2006 TO 2015

Fernanda Santos Magalhaes; Luiz Venicius Resplandes Gomes; Vanessa Pinto Rodrigues; Marina Georgia Cruz Keuffer; Arima Arruda Jucá; Débora Priscyla Gigante de Sousa; Larissa Holanda Assunção Universidade Federal do Maranhão (UFMA); Centro Universitário do Estado do Pará (CESUPA)

BACKGROUND: Adolescence is characterized by a transition phase that encompasses anatomical and physiological changes that generate restlessness and expectation about the role of the adolescent in society and, consequently, behaviors marked by impulsiveness and difficulty to face problems, factors that can cause more serious situations such as death by violent forms, one of the main being suicide. METHODS: Data were collected from the Mortality Information System (SIM) of the North and Northeast Regions of Brazil in the period from 2006 to 2015 made available to the public by the Department of Informatics of the Brazilian National Health System (Datasus). RESULTS: An epidemiological study of suicide in Brazil identified a $21.8 \%$ increase in suicide in the age range of 10 to 24 years in the North region during the years of 2002 to 2012. Moreover, according to the same study, the Northeast region obtained the highest percentage increase in the suicide rate, with a $64.2 \%$ increase in the age group and in the period studied. In these regions, the tendency of such an event can be explained by the lack of opportunities, where social isolation and poor social support network persist and prevention efforts for this group are scarce. CONCLUSION: We emphasize the importance of the results obtained for the creation of intervention strategies and adolescent health management, contributing to the improvement of the quality of life of this age group.

Keywords: Mortality, Suicide, Teenagers, Northeast, North. 